Aus dem Institut Pharmakologie und Toxikologie

(Prof. Dr. med. W.-H. Zimmermann)

der Medizinischen Fakultät der Universität Göttingen

\title{
Rolle der Phosphodiesterase 2 in der menschlichen und experimentellen Herzinsuffizienz
}

\author{
INAUGURAL-DISSERTATION \\ zur Erlangung des Doktorgrades \\ der Medizinischen Fakultät der \\ Georg-August-Universität zu Göttingen
}

vorgelegt von

Julius Emons

aus

Eutin

Göttingen 2017 
Dekan:

Referent/in

Ko-Referent/in:

Drittreferent/in:
Prof. Dr. rer. nat. H. K. Kroemer

Prof. Dr. med. A. El-Armouche

Dr. Axel Kaul

Datum der mündlichen Prüfung: 17.10.2017 
Hiermit erkläre ich, die Dissertation mit dem Titel "Rolle der Phosphodiesterase 2 in der menschlichen und experimentellen Herzinsuffizienz" eigenständig angefertigt und keine anderen als die von mir angegebenen Quellen und Hilfsmittel verwendet zu haben.

Göttingen, den 04.02.2017

(Unterschrift) 


\section{Inhaltsverzeichnis}

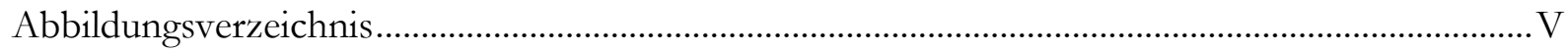

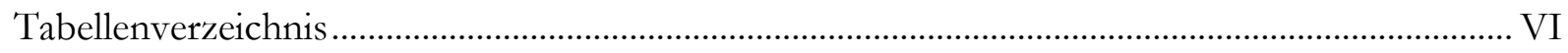

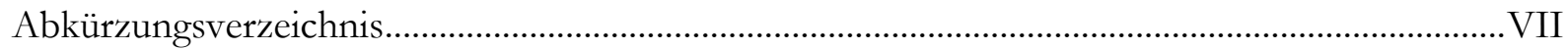

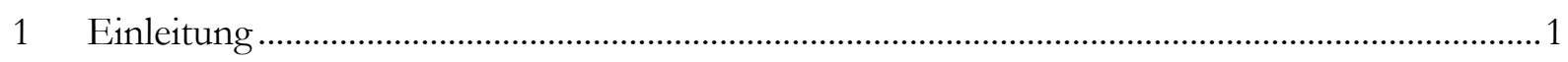

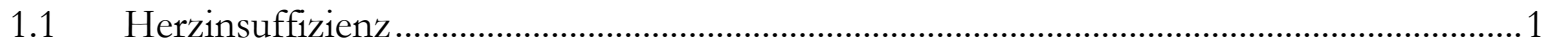

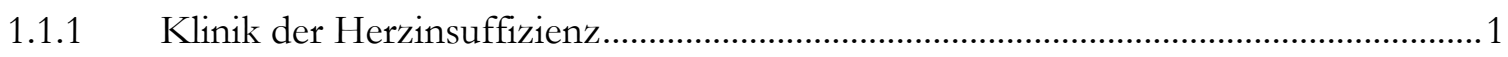

1.1.2 Die $\beta$-adrenerge Signalkaskade und ihr Einfluss auf die Herzaktivität .......................2

1.1.3 Störung der $\beta$-adrenergen Signalkaskade ....................................................................... 3

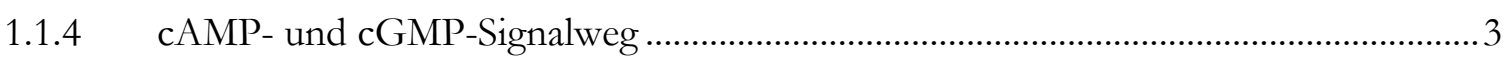

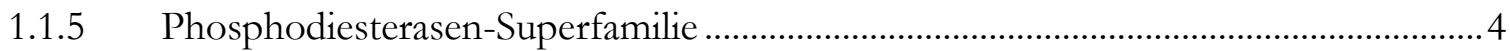

1.1.6 Phosphodiesterasen in Herzmuskelzellen...............................................................

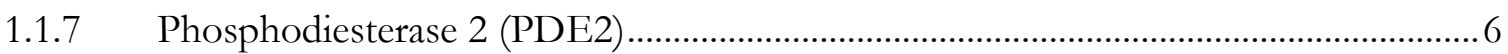

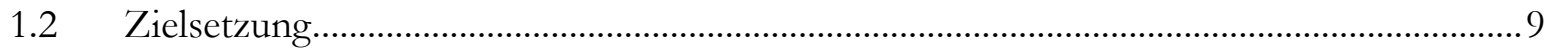

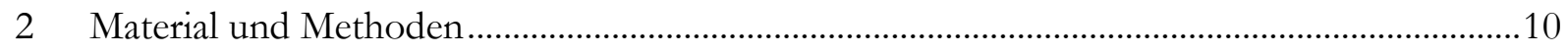

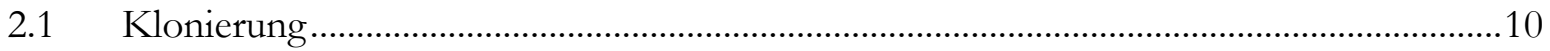

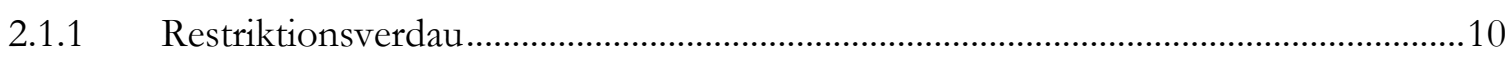

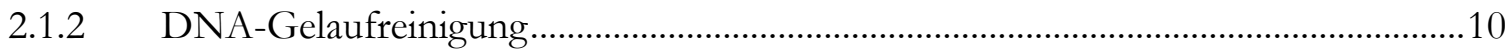

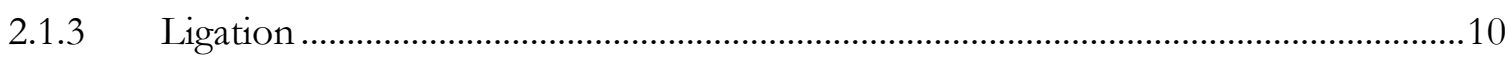

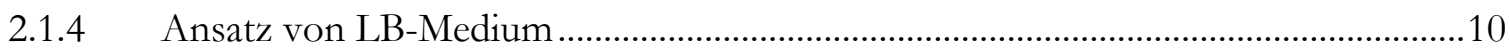

2.1.5 Transformation von PDE2A3-Plasmid-DNA in hitzekompetente Bakterien..........11

2.1.6 Transformation von PDE2- Plasmid-DNA in elektrokompetente Zellen................11

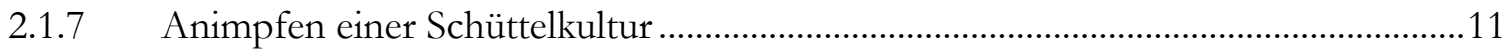

2.1.8 Mini-Plasmidpräperation aus einer Schüttelkultur ........................................................11

2.1.9 Transfektion von Plasmid-DNA in HEK293-Zellen ...............................................12

2.1.10 Isolation großer Plasmid-DNA-Mengen durch Ionenaustauscher-Säule ...................12

2.2 Adenovirale Expressionssysteme …………........................................................................ 14 
2.2.1 Klonierung des PDE2-Konstrukts in den pAD-Track CMV- Vektor.......................14

2.2.2 Linearisierung und Aufreinigung des pAd-Track-PDE2-CMV ..................................15

2.2.3 Homologe Rekombination mit dem Ad-Easy-System..............................................15

2.2.4 Herstellung Rekombinanter Adenovieren in HEK293-Zellen....................................15

2.3 Modelle der menschlichen und experimentellen Herzinsuffizienz ...................................17

2.4 Chronisches beta-adrenerges Stressmodell in der Ratte ....................................................18

2.4.1 Implantation von osmotischen Mini-Pumpen ............................................................. 18

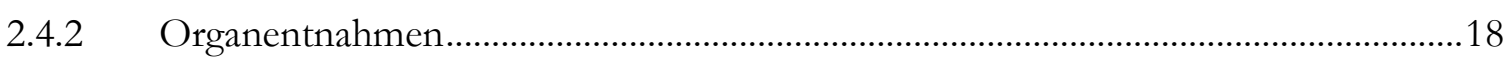

2.4.3 Großtiermodell der Herzinsuffizienz in Rapid-Paced-Hunden ...................................18

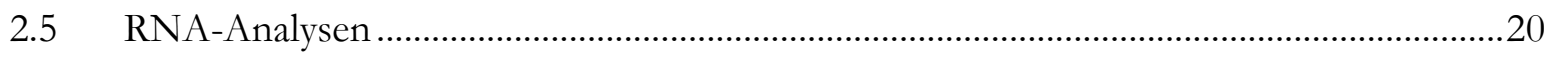

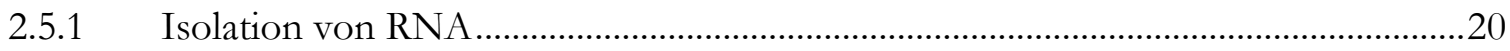

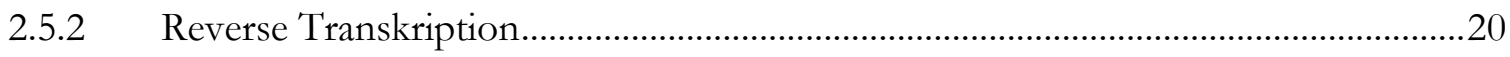

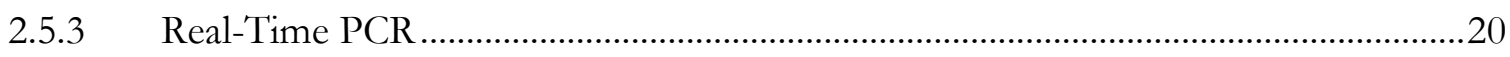

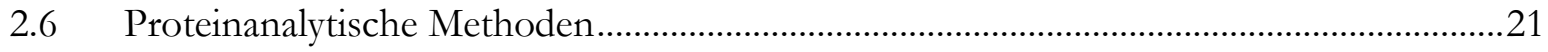

2.6.1 Proteingewinnung aus Gewebe für Immunoblot-Analysen......................................21

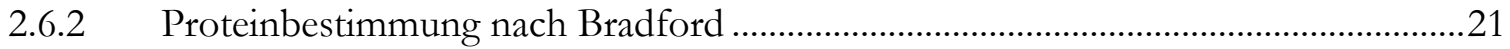

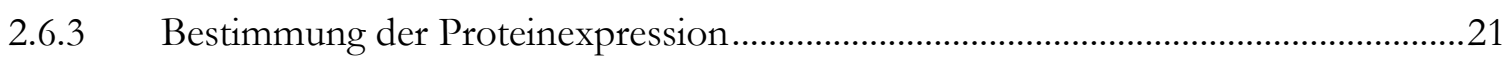

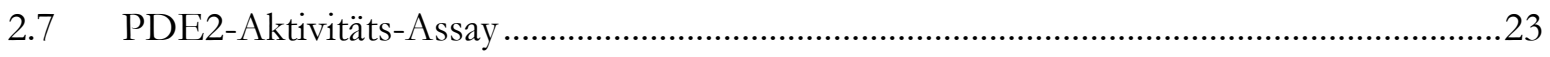

2.8 Bestimmung der zellulären Hypertrophie .............................................................................24

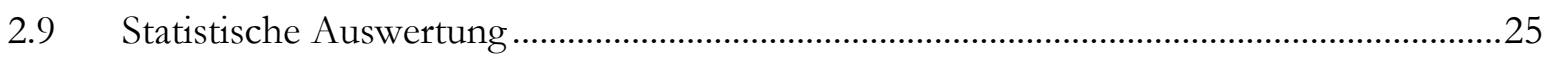

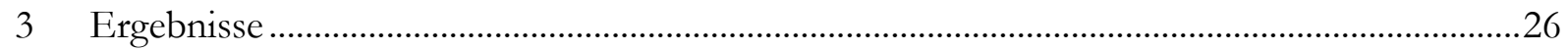

3.1 Herstellung des rekombinanten PDE2-Adenovirus........................................................26

3.1.1 Klonierung des pAdTrack-PDE2-CMV Shuttle-Vektors ............................................26

3.1.2 Homologe Rekombination von pAd-Track-PDE2-CMV und pAdEasy .................27

3.1.3 Viral überexprimierte PDE2 in neonatalen Rattenherzmuskelzellen ........................28

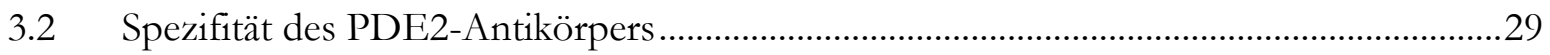

3.3 Endogene PDE2-Expression in kardialen Fibroblasten und Kardiomyozyten ................30

3.4 PDE2-Expression in der menschlichen Herzinsuffizienz ....................................................31 
3.4.1 Klinische Daten der Spenderpatienten ....................................................................... 31

3.4.2 PDE2 ist in der menschlichen Herzinsuffizienz hochreguliert ....................................33

3.4.3 PDE2 ist bei Patienten mit Aortenstenose nicht reguliert ..........................................34

3.4.4 PDE2-Expression ist unabhängig von einer Betablocker-Einnahme ..........................35

3.5 PDE2-Expression in der induzierten Herzinsuffizienz im Großtiermodell ......................36

3.6 PDE2-Expression und -Aktivität im linksventrikulären Myokard von Ratten nach chronischer beta-adrenerger Stimulation durch Isoprenalin..............................................................37

3.6.1 Herz- / Körpergewicht und ANP-Expression im Modell der chronischen

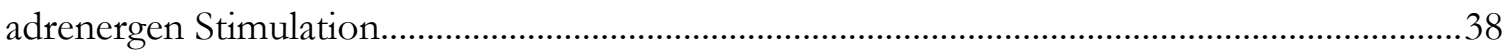

3.6.2 PDE2-Expression im Isoprenalin-Modell ist auf Ebene der Transkription reguliert

3.6.3 PDE2- cAMP- und cGMP-Aktivität im Rattenmodell 40

3.7 PDE2-Überexpression schützt Herzmuskelzellen vor $\alpha / \beta$-adrenerg induzierter Hypertrophie..

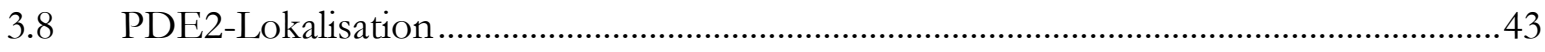

3.8.1 PDE2A3-Lokalisation in adulten Ratten-Herzmuskelzellen ....................................... 43

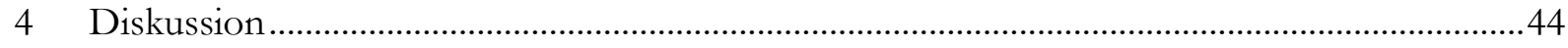

4.1.1 PDE2 ist in der Herzinsuffizienz hochreguliert ...........................................................4

4.1.2 PDE2-Hochregulation als Folge von chronischer $\beta$-adrenerger Stimulation ...........45

4.1.3 PDE2-Überexpression schützt vor $\alpha / \beta$-AR induzierter Hypertrophie ....................46

4.1.4 Viral überexpremierte PDE2A3 stellt sich entlang definierter Linien des Sarkomers

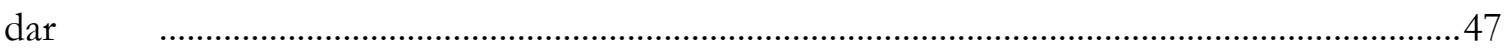

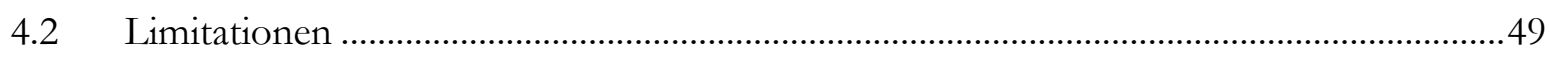

4.3 Klinische Relevanz und Neuheit der Ergebnisse.............................................................

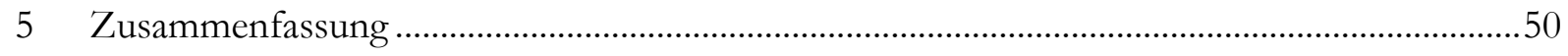

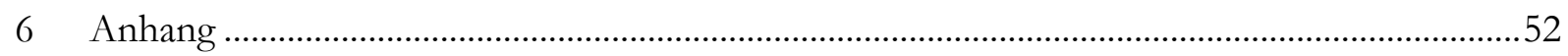

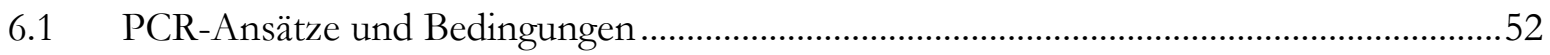

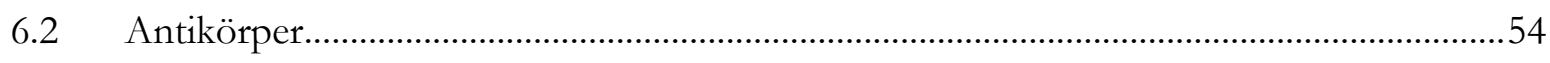

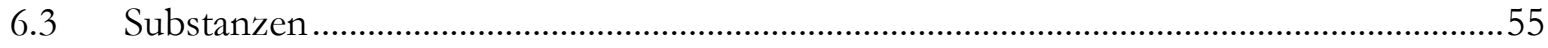




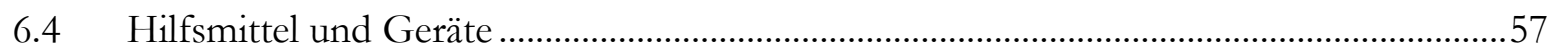

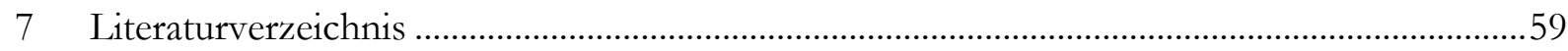

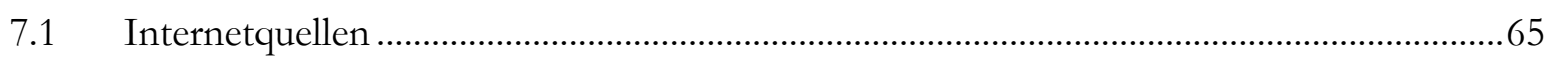




\section{Abbildungsverzeichnis}

Abbildung 1: Schematische Darstellung der PDE2 im cAMP- und cGMP-Signalweg ...................... 8

Abbildung 2: Generierung des PDE2-pAD-Track-CMV .....................................................................26

Abbildung 3: Verdau von pAd-Easy-PDE2A3 nach der homologen Rekombination.....................27

Abbildung 4: Ad-PDE2- infizierte neonatale Rattenkardiomyozyten.............................................28

Abbildung 5: Spezifität des PDE2-Antikörpers ……………..............................................................29

Abbildung 6: Endogene Expression der PDE2 in neonatalen Kardiomyozyten und kardialen

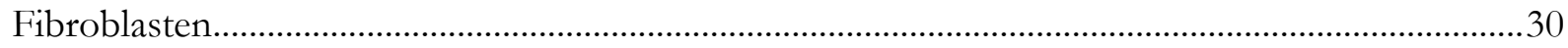

Abbildung 7: PDE2 ist in der menschlichen Herzinsuffizienz hochreguliert .....................................33

Abbildung 8: PDE2 ist bei Patienten mit Aortenstenose nicht reguliert...........................................34

Abbildung 9: PDE2-Expression ist unabhängig von Betablocker-Einnahme....................................35

Abbildung 10: PDE2 ist in der experimentellen Herzinsuffizienz hochreguliert..............................36

Abbildung 11: Auswirkung von chronischer B-adrenerger Stimulation auf Herzgewicht und ANP-

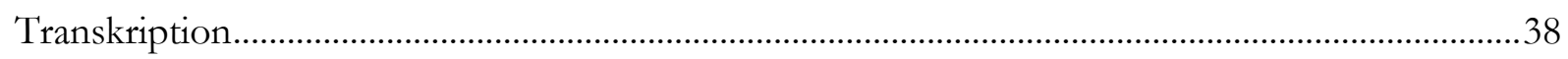

Abbildung 12: PDE2 ist in der durch Isoprenalin induzierten Herzinsuffizienz hochreguliert.....39

Abbildung 13: Höhere PDE2-Protein-Spiegel resultieren in einer erhöhten PDE2-Aktivität.......40

Abbildung 14: PDE2-Überexpression schützt Herzmuskelzellen vor durch $\alpha$ - und $\beta$-adrenerge

Stimulation hervorgerufener Hypertrophie .42

Abbildung 15: Viral überexprimierte PDE2A3 ist entlang definierter Linien lokalisiert. 


\section{Tabellenverzeichnis}

Tabelle 1: Übersicht der PDE-Enzymfamilie ……….........................................................................

Tabelle 2: Patienten-Charakteristika ……………….............................................................................

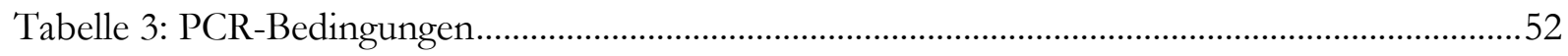

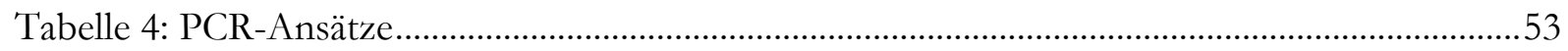

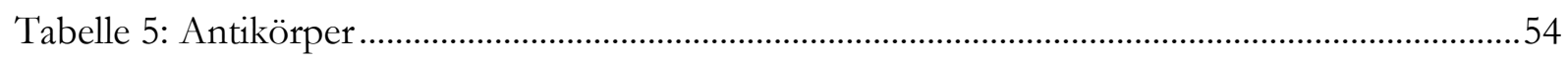

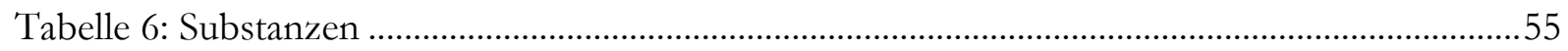

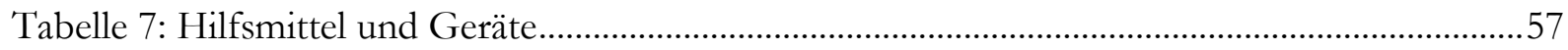




\section{Abkürzungsverzeichnis}

A

AC

ACE

AK

ANP

APS

AS

ATP

$\beta$-AR

$\mathrm{BB}$

BNP

Bpm

BSA

${ }^{\circ} \mathrm{C}$

$\mathrm{Ca}^{2+}$

cAMP/GMP

cDNA

CI

$\mathrm{CF}$

$\mathrm{CM}$

CMV

CNP

$\mathrm{CO}$

$\mathrm{Cpm}$

CSQ

$\mathrm{d}$

DAPI

DCM

doi

DGK

DGP

DNA

dNTP
Ampere

Adenylylzyklase

Angiotensin-converting ensyme, Angiotensin-Konversions-Enzym

Antikörper

Atriales natriuretisches Peptid

Ammoniumpersulfat

Aortenstenose

Adenosintriphosphat

$\beta$-Adrenozeptor

$\beta$-Blocker

B-Typ natriuretisches Peptid

Beats per minute, Schläge pro Minute

Bovines Serumalbumin

Grad Celsius

Calcium-Ion

Zyklisches Adenosinmonophosphat/Guanosinmonophosphat

Komplementäre DNA

Herzindex

Cardiac Fibroblast

Herzmuskelzelle

Zytomegalie-Virus

C-Typ natriuretisches Peptid

Cardiac output, Herzminutenvolumen

Counts per minute, Zäblungen pro Minute

Calsequestrin

Tag

4',6-Diamidin-2-phenylindol

Dilatative Kardiomyopathie

Digitaler Objekte-Identifizierer

Deutsche Gesellschaft für Kardiologie

Deutsche Gesellschaft für Pharmakologie

Desoxyribonukleinsäure

Desoxyribonukleosidtriphosphat 


\begin{tabular}{|c|c|}
\hline DT'T & Dithiothretiol \\
\hline ECL & Enhanced Chemiluminescence \\
\hline E. coli & Escherichia coli \\
\hline $\mathrm{EF}$ & Ejektionsfraktion \\
\hline EDTA & Ethylendiamintetraacetat \\
\hline eGFP & Enhanced green fluorescent protein, Grün fluoreszierendes Protein \\
\hline EHNA & Erythro-9-(2-hydroxy-3-nonyl)adenine \\
\hline FIB & Fibroblast \\
\hline For & Forward 5'-3' Primer, Vorwärts 5'-3' Primer \\
\hline g & Gramm \\
\hline GAF-A/B-Domäne & 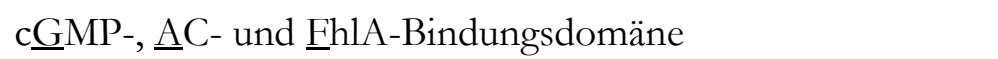 \\
\hline GAPDH & Glycerinaldehyd-3-phosphat-Dehydrogenase \\
\hline GFP & Grün fluoreszierendes Protein \\
\hline GTC & Guanidinthiocyanat \\
\hline GTP & Guanosintriphosphat \\
\hline $\mathrm{h}$ & Stunde \\
\hline HA & Humanes Influenza-Hemagglutinin \\
\hline HG & Herzgewicht \\
\hline HCN-Kanal & $\begin{array}{l}\text { Hyperpolarisationsaktivierte zyklische Nukleotid-verstärkte } \\
\text { Kationenkanäle }\end{array}$ \\
\hline $\mathrm{HF}$ & Herzfrequenz \\
\hline HEK & Human embryonic kidney, menschliche embryonale Nierenzelle \\
\hline HRPO & Horseradish peroxidase, Meerrettich-Peroxidase \\
\hline HW & Herzgewicht \\
\hline IBMX & 3-Isobutyl-1-Methylxanthin \\
\hline $\mathrm{ICM}$ & Ischämische Kardiomyopathie \\
\hline ISO & Isoprenalin \\
\hline $\mathrm{kb}$ & Kilobasenpaare \\
\hline $\mathrm{kDa}$ & Kilodalton \\
\hline $\mathrm{K}_{\mathrm{m}}$ & Michaeliskonstante \\
\hline KG & Körpergewicht \\
\hline Ctr & Positivkontrolle \\
\hline 1 & Liter \\
\hline LTCC & L-Typ-Ca ${ }^{2+}-\mathrm{Kanal}$ \\
\hline LVEDP & Linksventrikulärer enddiastolischer Druck \\
\hline $\mathrm{m}$ & Meter \\
\hline $\mathrm{mg}$ & Milligram \\
\hline
\end{tabular}


M

MHC

$\mathrm{MHz}$

Min

$\mathrm{ml}$

Mol

MOI

mRNA

n

$\mathrm{NaCl}$

$\mathrm{Nm}$

no

$\mathrm{NO}$

NOR

NOS

NF

NYHA

pA

PBS

PCR

PDE

GC-A

$\mathrm{pH}$

PHE

PKA

PKG

PLB

PolyA

PVDF

qPCR

RAAS

Rcf

Rev

RNA

Rpm

RT-PCR

SDS
$\mathrm{Mol} / 1$

Myosin heary chain, schwere Kette des Myosins

Megahertz

Minute

Milliliter

Basiseinheit der Stoffmenge

Multiplizität der Infektion

Boten-Ribonukleinsäure

Anzahl

Natriumchlorid

Nanometer

Nummer

Stickstoffmonoxid

Norepinephrine

Stickstoffmonoxid-Synthase

Non failing, gesunde Spender

New York Heart Association

PolyA

Phosphate-buffered saline, Phosphatgepufferte Salzlösung

Polymerase chain reaction, Polymerase-Kettenreaktion

Phosphodiesterase

Particulate guanylate cyclase, transmembranöse Guanylylzyklase pH-Wert

Phenylephrin

Proteinkinase A

Proteinkinase G

Phospholamban

Polyadenylierungs-Region

Polyvinylidenfluorid

Quantitative Echtzeit-PCR

Renin-Angiotensin-Aldosteron-System

Relative centrifugal force, relative Zentrifugalbeschleunigung

Reverse 3'-5' Primer, Rückwärts 3'-5' Primer

Ribonukleinsäure

Rounds per minute, Umdrehungen pro Minute

Realtime PCR, Echtzeit-PCR

Sodiumdodecylsulfat, Natriumdodecylsulfat 
Sec

sGC

SR

SV

TBE

TEMED

TnI

$\mathrm{U}$

UV

VASP

$\mathrm{V}$

$\mathrm{V}_{\max }$

vs.
Sekunde

Soluble guanylyl cyclase, lösliche Guanylylzyklase

Sarkoplasmatisches Retikulum

Schlagvolumen

Tris-Borat-EDTA-Puffer

Tetramethylethylendiamin

Troponin-I

Units; Enzymeinheit

Ultraviolett

Vasodilatation-stimulierendes Phosphoprotein

Volt

Maximale Enzymgeschwindigkeit

versus 


\section{$1 \quad$ Einleitung}

\subsection{Herzinsuffizienz}

Die Herzinsuffizienz ist einer der häufigsten Gründe für Morbidität und Mortalität in der westlichen Welt. Die ESC (European Society of Cardiology) erhebt Daten einer Population von 900 Millionen Menschen, von denen bei wenigstens 10 Millionen eine Herzinsuffizienz angenommen wird (Swedberg et al. 2005). In Deutschland wurde im Jahr 2012 in 40,2 \% aller Sterbefälle (absolut 350.000 Fälle) eine Erkrankung des Herzkreislaufsystems als Ursache angegeben. Damit ist sie die zweithäufigste Todesursache nach Erkrankungen durch bösartige Neubildungen. Die Geschlechterverteilung betrug 55,6 \% Männer und 44,3 \% Frauen. $92 \%$ der Betroffenen waren älter als 65 Jahre (Statistisches Bundesamt 2012). Die Prognose der Herzinsuffizienz ist nach wie vor ernst, 50 \% der Erkrankten versterben innerhalb von 5 Jahren (McMurray und Stewart 2000). Die nach wie vor schlechte Prognose und das häufige Auftreten verlangen nach der Suche und Entwicklungen neuer Therapiemaßnahmen.

\subsubsection{Klinik der Herzinsuffizienz}

Eine Herzinsuffizienz liegt vor, wenn das Herz, unabhängig von der Ursache, nicht in der Lage ist, das vom Körper benötigte Herzzeitvolumen zu fördern. Klinisch äußert sich die Herzinsuffizienz in Abhängigkeit von ihrer Ätiologie in einer verminderten Belastbarkeit, Dyspnoe und Ödem-Neigung. Die Herzinsuffizienz kann je nach Auswirkung und zugrundeliegender Pathologie in eine systolische oder diastolische Herzinsuffizienz sowie in Vorund Rückwärtsversagen eingeteilt werden. Das Rückwärtsversagen beschreibt einen Zustand, in dem das Herzminutenvolumen ausreichend ist, um die Peripherie mit Sauerstoff zu versorgen, aber durch eine insuffiziente Pumpleistung es nicht zu einem vollständigen Abtransport der Vorlast und damit zu einem Rückstau im kleinen Blutkreislauf kommt. Im Gegensatz dazu beschreibt das Vorwärtsversagen einen Zustand, in dem das Herzminutenvolumen nicht ausreichend ist, um die Peripherie mit Sauerstoff zu versorgen. Eine Kombination aus Vor- und Rückwärtsversagen ist als Globalherzinsuffizienz definiert (Böhm et al. 2009). Die Entstehung der Herzinsuffizienz wird durch koronare Herzerkrankungen, Hypertonie, Kardiomyopathien und Klappenvitien begünstigt (McMurray und Stewart 2000). Die verschiedenen Ursachen führen $\mathrm{zu}$ einer Veränderung der Herzphysiologie und enden mit dem Versuch, durch Adaptationsmechanismen, besonders durch neurohumorale Aktivierung, die Versorgung des Organismus zu gewährleisten. Bei dem Versuch der chronischen Kompensation kommt es durch 
die neurohumorale Aktivierung zu einer Zunahme der Belastung des Myokards mit Hypertrophie und Fibrose und einer Abnahme der $\beta$-Adrenozeptordichte, was wiederum das Herzzeitvolumen verringert und einen circulus vitiosus entstehen lässt (Bristow et al. 1982, El-Armouche und Eschenhagen 2009). Die aktuellen Therapien der Herzinsuffizienz zielen auf die Prävention der Entstehung des circulus vitiosus, indem Medikamente zum Einsatz kommen, die zum einen nachlastsenkend wirken wie Calciumantagonisten und Betablocker oder zum anderen eine kombinierte Senkung der Vor- und Nachlast bewirken wie Diuretika und ACE-Hemmer.

\subsubsection{Die $\beta$-adrenerge Signalkaskade und ihr Einfluss auf die Herzaktivität}

Unter Belastung muss für eine suffiziente Versorgung des Organismus die Pumpleistung des Herzens kurzfristig und kalkuliert um bis auf das 5-Fache der Ausgangssituation gesteigert werden können. Die Anpassung erfolgt über das sympathische Nervensystem. Die sympathische Aktivierung erfolgt über die Bindung von Adrenalin und Noradrenalin an die in den Herzmuskelzellen exprimierten $\beta$-Adrenozeptoren. Dies führt $\mathrm{zu}$ einer Zunahme der Kontraktion und des Herzzeitvolumens mit einer gesteigerten Auswurfleistung (Brodde 1993). Die Stimulation der $\beta 1$ - und $\beta 2$-Adrenozeptoren wirkt positiv chronotrop (Zunahme der Schlagfrequenz des Herzens), dromotrop (Zunahme der Erregungsleitung des Erregungsleitungssystems des Herzen), inotrop (Zunahme der Kontraktionskraft des Myokards) und lusitrop (Zunahme der Relaxation des Myokards). Die Effekte werden über die an die $\beta$ Adrenozeptoren gekoppelten G-Proteine weitergeleitet. Die Stimulation des $\beta 1$-Adrenozeptors führt zu einer Disseminierung der stimulierenden $G \alpha$-Untereinheit. Die stimulierenden Einflüsse der $G \alpha$-Untereinheit $(G s)$ führen zu einer vermehrten Aktivität der membranständigen Adenylylcyclase (AC), welches zu einer Zunahme der intrazellulären cAMP-Spiegel führt. Die durch cAMP aktivierte Proteinkinase A (PKA) verändert die intrazelluläre $\mathrm{Ca}^{2+}$-Konzentration, die Aufnahme des $\mathrm{Ca}^{2+}$ in das SR (sarkoplasmatisches Retikulum) sowie die $\mathrm{Ca}^{2+}$ Sensitivität der Myofilamentproteine in der Herzmuskelzelle (Brodde 1993, El-Armouche und Eschenhagen 2009, Lohse et al. 2003). Die Regulation der $\beta$-adrenergen Signalkaskade findet auf zwei Ebenen statt. Zum einen durch eine Kontrolle der für die Regulation der Herzaktion wichtigen cAMPSpiegel durch Phosphodiesterasen, zum anderen durch Phosphatasen, die Effektor-Proteine der PKA dephosphorilieren. Die Feinregulation der cAMP-Spiegel durch Phosphodiesterasen erfolgt durch eine Spaltung der zyklischen 3',5'-Phosphatgruppen des cAMP und/oder cGMP, wodurch das inaktive lineare $5^{6}$-Nukleotid entsteht. 


\subsubsection{Störung der $\beta$-adrenergen Signalkaskade}

Im Verlauf einer Herzinsuffizienz kommt es, unabhängig von der Ätiologie, durch eine Aktivierung des Sympathikus zu einer vermehrten Ausschüttung von Adrenalin und Noradrenalin. Die Bindung dieser Katecholamine an $\beta$-Adrenozeptoren hat eine Zunahme der Herzfrequenz mit einer gesteigerten Relaxation- und Kontraktionsfähigkeit zur Folge (Böhm et al. 2009). Die Bindung von Noradrenalin an $\beta 1$ - oder $\beta 2$-AR führt zu einer G-Proteinvermittelten Aktivierung der Adenylatzyklase (AC), dieses führt zu einer vermehrten Bildung von cAMP aus Adenosintriphosphat (ATP). Der intrazelluläre Anstieg des cAMPs führt zu einer gesteigerten Aktivität der Proteinkinase A (PKA), die durch Phosphorylierung verschiedener Regulator-Proteine zu einer Zunahme der Herzleistung führt. Die Regulation der $\beta$-adrenergen Signalkaskade findet auf zwei Ebenen statt. Zum einen durch eine Kontrolle der cAMP-Spiegel durch Phosphodiesterasen, zum anderen durch Phosphatasen, die die Effektor-Proteine der PKA dephosphorylieren. Patienten mit Herzinsuffizienz haben unabhängig vom Grund der Erkrankung erhöhte Plasma-Katecholaminspiegel und daraus resultierend eine Daueraktivierung der $\beta$-adrenergen Signalkaskade. Die dauerhafte Stimulation durch Katecholamine im Rahmen der Herzinsuffizienz führt zu einer kompensatorischen Desensitivierung, vermittelt durch eine verminderte Expression von $\beta 1$ - Adrenozeptoren (El-Armouche und Eschenhagen 2009). Die verminderte Expression von $\beta 1$ - Adrenozeptoren und die damit verbundene kompensatorische Desensitivierung gegen katecholaminerge Stimulation schützt das Myokard kurzfristig gegen Hypertrophie und Fibrosierung, verursacht durch veränderte Genexpression und eine daraus resultierende Zunahme der Proteinsynthese. Auf lange Sicht hin entwickelt sich durch die Veränderung der Rezeptorexpression und der geänderten Hämodynamik eine Herzinsuffizienz.

\subsection{4 cAMP- und cGMP-Signalweg}

Die Anpassung des menschlichen Organismus an Stresssituationen und die Regulation der mehr als 100.000 Kontraktionen und Relaxationen des Myokards in 24 Stunden wird durch die zyklischen 3',5'-Monophosphate cAMP und cGMP und ihre Effektorproteine der Proteinkinase A (PKA) und der Proteinkinase B (PKB) vermittelt (Zhang und Kass 2011). Der sekundäre Botenstoff cAMP wird durch die membrangebundene Adenylylcyclase aus Adenosintriphosphat (ATP) nach Stimulierung des $\beta 1$ - oder $\beta 2$-AR gebildet. Die sich anschließende Aktivierung der PKA und die Phosphorylierung der Regulationsproteine gehen mit einer Zunahme der Kontraktion und der Herzfrequenz einher. Die Synthese von cGMP aus GTP wird durch zwei Enzyme katalysiert, durch die direkt durch NO aktivierbare, zytoplasmatische Form der Guanylylcyclase (sGC) und durch die membrangebundene Form der Guanylylcyclase (GC-A). Die GC-A wird durch die Bindung von atrialem natriuretischem Peptid (ANP) und dem B-Typ natriuretischem Peptid (BNP) aktiviert (Kojda et al. 1996, Zhang et al. 2005). Die cGMP- 
abhängige Aktivierung der PKG, führt zu einer Aktivierung verschiedener Effektorproteine, wie Phospholamban (PLB), Vasodilatation-stimulierendes Phosphoprotein (VASP), L-Typ $\mathrm{Ca}^{2+}$ Kanal und weiteren (Tsai und Kass 2009). Die beiden Signalwege beeinflussen die Herzaktivität gegensätzlich (Shah und MacCarthy 2000). Es konnte wiederholt gezeigt werden, dass höhere Spiegel an cGMP im Myokard die durch cAMP vermittelten negativen Einflüsse der $\beta$-ARÜberstimulation positiv beeinflussen können (Mika et al. 2012, Pokreisz et al. 2009, Stangherlin et al. 2011, Mehel et al. 2013). Die verschiedenen Affinitäten sowie die aktivierenden und inhibitorischen Einflüsse von cAMP und cGMP auf die unterschiedlichen PDE-Isoenzyme sind in Tabelle 1 dargestellt.

\subsubsection{Phosphodiesterasen-Superfamilie}

Der Einfluss des Botenstoffes cAMP und seine essentielle Rolle in der Zunahme der Isotropie nach Stimulation durch Katecholamine wurde bereits 1965 beschrieben (Robinson et al. 1965). Dennoch bleibt die Feinmodulation bis heute Bestandteil intensiver Forschung (Levy 2013). Phosphodiesterasen sind Enzyme, die durch Degradation die Spiegel der sekundären Botenstoffe cAMP und cGMP regulieren. Bis heute sind 21 verschiedene Gene bekannt, die für 12 PDEIsoenzyme kodieren (PDE1-12).Von den 12 PDE-Isoenzymen sind weitere 48 Splicevarianten bekannt (Bender und Beavo 2006). Die in dieser Arbeit verwendete Nomenklatur der verschiedenen PDEs erfolgt auf Grundlage von Beavo (Beavo et al. 1994) und soll am Beispiel von PDE2A3 dargestellt werden. PDE steht für eine 3',5'-Zyklonukleotid-Phosphodiesterase. Durch die arabische Ziffer 2 wird die Zugehörigkeit zu der Isoenzym-Familie beschrieben, der Buchstabe A beschreibt das Gen in der Reihenfolge, in der es in der GenBank hinterlegt wurde. Abschließend wird mit der Ziffer 3 die Splicevariante beschrieben (Bender und Beavo 2006). Die verschiedenen Mitglieder der PDE-Superfamilie unterscheiden sich in ihrer Struktur, den kinetischen Eigenschaften, der zellulären Expression, der intrazellulären Lokalisation und der Substrataffinität sowie ihren katalytischen Eigenschaften (Bender und Beavo 2006). 
Tabelle 1: Übersicht der PDE-Enzymfamilie

\begin{tabular}{|c|c|c|c|c|c|}
\hline $\begin{array}{l}\text { PDE } \\
\text { Isoenzym }\end{array}$ & $\begin{array}{l}\text { GAF- } \\
\text { Domäne }\end{array}$ & Substrate & $\begin{array}{l}\mathrm{Km} \\
(\mu \mathrm{M}) \\
\mathrm{cAMP}\end{array}$ & $\begin{array}{l}\mathrm{Km} \\
(\mu \mathrm{M}), \\
\mathrm{cGMP}\end{array}$ & Gewebe \\
\hline 1 & Nein & $\begin{array}{l}\mathrm{Ca}^{2+} / \text { Calmodulin } \\
\text { stimuliert }\end{array}$ & $1-30$ & 3 & Herz, Hirn, Lunge, glatte Muskulatur \\
\hline 2 & $\mathrm{Ja}$ & cGMP-stimuliert & 50 & 50 & Herz, Lunge, Leber \\
\hline 3 & Nein & $\begin{array}{l}\text { cGMP-inhibiert, } \\
\text { cAMP-selektive }\end{array}$ & 0,2 & 0.3 & Herz, Lunge, Leber, Fettzellen \\
\hline 4 & Nein & cAMP-spezifisch & 4 & - & $\begin{array}{l}\text { Sertolizellen, Niere, Hirn, Leber, } \\
\text { Lunge }\end{array}$ \\
\hline 5 & $\mathrm{Ja}$ & cGMP-spezifisch & 150 & 1 & $\begin{array}{l}\text { Lunge, glatte Muskulatur der Gefäße, } \\
\text { Herz }\end{array}$ \\
\hline 6 & $\mathrm{Ja}$ & cGMP-spezifisch & - & 60 & Fotorezeptoren \\
\hline 7 & Nein & cAMP-spezifisch, & 0,2 & - & $\begin{array}{l}\text { quergestreifte Muskulatur, Herz, } \\
\text { Niere, Hirn, Pankreas }\end{array}$ \\
\hline 8 & Nein & cAMP-selektive & 0,06 & - & $\begin{array}{l}\text { Hoden, Auge, Leber, quergestreifte } \\
\text { Muskulatur, Herz, Nieren, Ovarien, } \\
\text { Hirn }\end{array}$ \\
\hline 9 & Nein & cGMP-spezifisch & - & 0,17 & $\begin{array}{l}\text { Nieren, Leber, Lungen, Hirn, fraglich } \\
\text { im Herzen }\end{array}$ \\
\hline 10 & $\mathrm{Ja}$ & $\begin{array}{l}\text { cGMP-sensitive, } \\
\text { cAMP-selektive }\end{array}$ & 0,05 & 3,0 & Hoden, Gehirn \\
\hline 11 & $\mathrm{Ja}$ & $\begin{array}{l}\text { cGMP-sensitive, } \\
\text { dualspezifisch }\end{array}$ & 0,7 & 0,6 & $\begin{array}{l}\text { quergestreifte Muskulatur, Hoden, } \\
\text { Leber, Nieren }\end{array}$ \\
\hline
\end{tabular}

Tabellarische Darstellung der PDE-Isoenzymfamilien mit Informationen über GAF-Domänen, Substratspezifität und Hydrolyseaktivität sowie ihre Expression in den verschiedenen Geweben. (Kass et al. 2007). 


\subsubsection{Phosphodiesterasen in Herzmuskelzellen}

Es konnte eine Expression in Herzmuskelzellen von 7 PDE-Familien nachgewiesen werden: PDE1, PDE2, PDE3, PDE4, PDE5, PDE8 und PDE9 (Loughney et al. 1996, Meacci et al. 1992, Kostic et al. 1997, Soderling et al. 1998, Onody et al. 2003, Senzaki et al. 2001). Sowohl cAMP als auch cGMP werden von den drei Dual-spezifischen PDEs, PDE1, PDE2 und PDE3 hydrolysiert, ausschließlich cAMP wird von PDE4 und PDE8 sowie ausschließlich cGMP durch PDE5 und PDE9 hydrolysiert (Zaccolo und Movsesian 2007).

\subsubsection{Phosphodiesterase 2 (PDE2)}

Die cGMP-stimulierbare Phosphodiesterase 2 ist ein Homodimer aus zwei jeweils speziesabhängig 103-105 kDa großen Untereinheiten und wurde erstmals aus Rattenleber extrahiert und als cGMP-stimulierbare Phosphodiesterase durch Beavo et al. 1970 beschrieben. Das PDE2-Protein wurde in kardialem Gewebe mehrerer Spezies, unter anderem in der Ratte, der Maus und in dem Menschen nachgewiesen (Sadhu et al. 1999). Die PDE2 hydrolysiert sowohl cGMP als auch cAMP mit ähnlichen maximalen Raten und relativ hohen $K_{\mathrm{m}}$ Werten. Die $K_{\mathrm{m}-}$ Werte für cAMP betragen basal $30 \mu \mathrm{M}$ und für cGMP $10 \mu \mathrm{M}$ (Zaccolo und Movsesian 2007). Die Bindung von cGMP führt zu einer Steigerung der Hydrolyseaktivität, besonders für cAMP (Martinez et al. 2002).

Das PDE2-Protein wurde in einer Vielzahl von Geweben nachgewiesen: im Herzen, der Leber, der Nebenniere, im Gehirn, in den Endothelzellen und Makrophagen (Martins et al. 1982, Bender und Beavo 2006). Aus dem PDE2-kodierenden Gen sind drei verschiedene Spleißvarianten der PDE2 bekannt: PDE2A1 (Sonnenburg und Beavo 1991), PED2A2 (Yang et al. 1994), PDE2A3 (Sadhu et al. 1999). Sie unterscheiden sich in ihrer Struktur nur in den Nterminalen Aminosäuren. Es wird davon ausgegangen, dass das N-terminale Ende für die intrazelluläre Lokalisation verantwortlich ist (Rosman et al. 1997). Es sind keine Unterschiede in der Kinetik der einzelnen PDE2-Varianten bekannt. PDE2A1 ist im Zytoplasma lokalisiert, PDE2A2 und PDE2A3 sind membrangebunden (Bender und Beavo 2006, Sadhu et al. 1999).

Von den 11 bekannten Phosphodiesterasen besitzen fünf GAF-Domänen, von denen wiederum drei cGMP binden können (Aravind und Ponting 1997). Das 941 Aminosäure große menschliche PDE2-Monomer ist in vier Domänen organisiert: Der N-Terminus (1-214), GAF-A (215-372), GAF-B (393-541) und die katalytische Domäne (579-941) (Martins et al. 1982). Die Anordnung der Domänen ist linear, die Verbindungen der Domänen sind über $\alpha$-Helices organisiert. In der Homodimer-Form stehen sich die GAF-A-Domänen der beiden Monomere sowie die GAF-BDomänen gegenüber (Pandit et al. 2009). Über die GAF-A-Domäne findet die Bindung zum Homodimer statt, die GAF-B-Domäne dient cGMP als Bindungsstelle (Martinez et al. 2002). Bindet cGMP an die GAF-A-Domäne, erfolgt eine Konformationsänderung an der katalytischen 
Domäne und es kommt zu einer Zunahme der Hydrolyse für cAMP um das 5- bis 30-Fache. Diese Änderung der Affinität tritt auch unter physiologischen Konzentrationen von cAMP und cGMP auf ( Manganiello et al. 1990).

Die Phosphodiesterase 2 spielt eine zentrale Rolle im cAMP- und cGMP-Signalweg. Ihre einmalige Funktion, durch die allosterische Bindung von cGMP eine Erhöhung der katalytischen Aktivität um das 5- bis 30-Fache für cAMP zu haben, ermöglicht der PDE2 einen negativen Crosstalk zwischen den beiden Signalwegen (vergl. Abbildung 1) (Francis et al. 2011). Des Weiteren konnte gezeigt werden, dass durch eine Stimulation der PDE2 mit cGMP die lokalen cAMP-Spiegel des L-Typs $\mathrm{Ca}^{2+}$-Kanals gesenkt werden und somit den auf Grund von $\beta$-AR und /oder cAMP-Stimulus erhöhten $\mathrm{Ca}^{2+}$ Fluss $\left(\mathrm{I}_{\mathrm{Ca}, \mathrm{I}}\right)$ des L-Typs $\mathrm{Ca}^{2+}$-Kanals stark antagonisieren können (Hartzell und Fischmeister 1986, Mery et al. 1995). Im menschlichen Myokard wurden mit Hilfe des selektiven PDE2-Inhibitors EHNA (erythro-9-(2-Hydroxy-3-nonyl)-adenin) die regulatorischen Einflüsse der PDE2 auf den basalen Ca2+-Einstrom untersucht (Rivet-Bastide et al. 1997). In neonatalen Kardiomyozyten konnte der abschwächende Effekt auf die beta-adrenerg hervorgerufene Inotropie des Herzens der PDE2 auf die cAMP-abhängige PKA und damit ein antagonistischer Effekt über den $\beta 3$-AR/NO/cGMP- Signalweg gezeigt werden (Stangherlin et al. 2011, Mongillo et al. 2006). Diese Funktionen macht die PDE2 zu einem wichtigen und potentiell pharmakologisch modulierbaren Stellglied in der $\beta$-adrenergen Signalkaskade. 


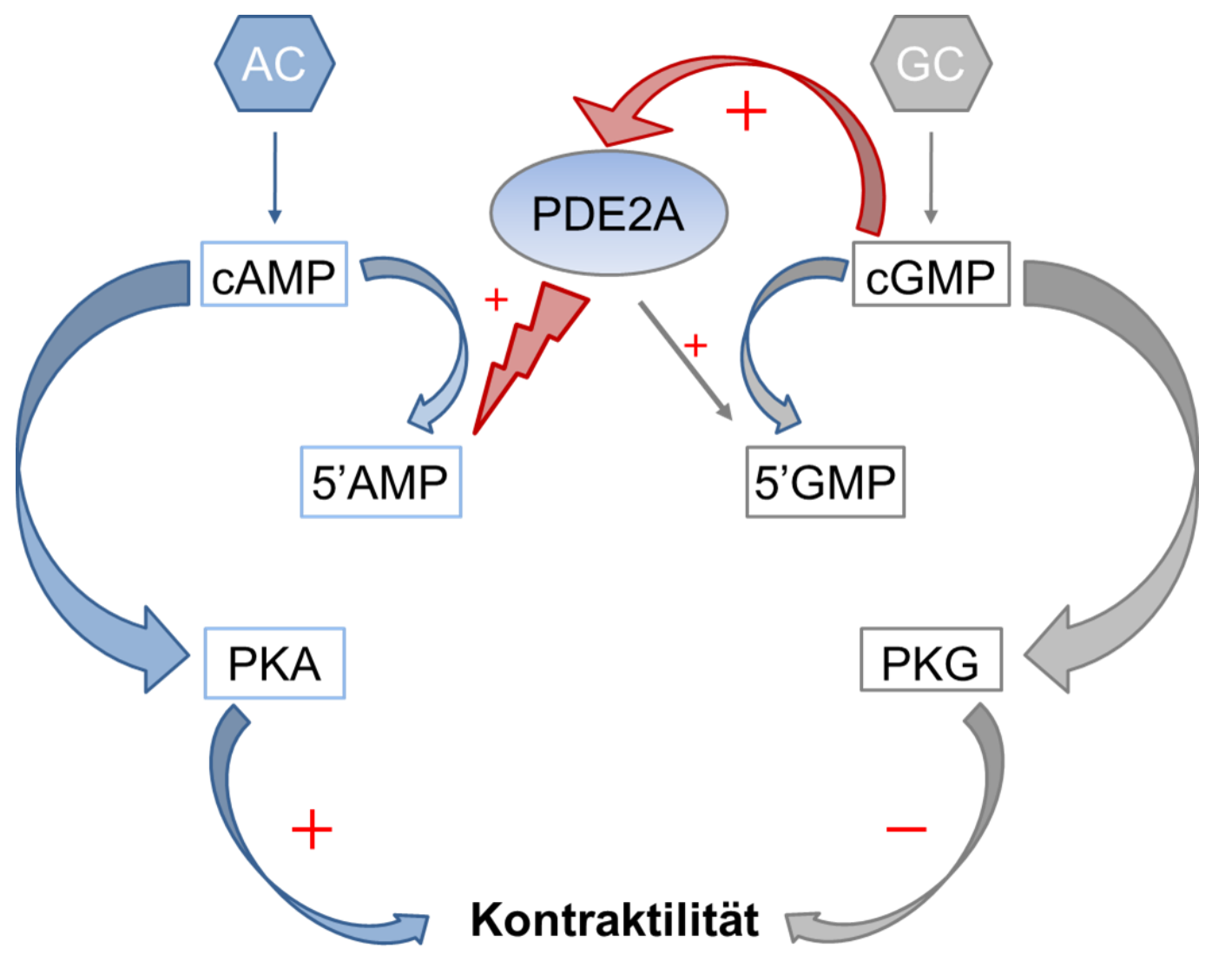

Abbildung 1: Schematische Darstellung der PDE2 im cAMP- und cGMP-Signalweg

In der schematischen Darstellung ist die zentrale Rolle der PDE2 zwischen dem cAMP- und cGMPSignalweg dargestellt. Eine Zunahme von cGMP führt zu einer Aktivierung der PDE2 und somit zu einer vermehrten Hydrolyse von cAMP, was wiederum mit einer relaxierenden Wirkung auf das Myokard einhergeht. 


\subsection{Zielsetzung}

Die zentrale Rolle der PDE2, in dem an der Entstehung und Aufrechterhaltung der Herzinsuffizienz beteiligtem cAMP- und cGMP-Signalweg, sowie die Möglichkeit einer Steigerung der Aktivität der PDE2 durch eine Erhöhung der cGMP-Spiegel, machen die PDE2 zu einem potentiell pharmakologisch beeinflussbaren intrazellulären Target. Ziel dieser Arbeit war die Etablierung von molekularbiologischen Untersuchungsmethoden sowie die Generierung eines PDE2-Adenovieruses, um in der menschlichen und experimentellen Herzinsuffizienz die Expression der PDE2 im erkrankten und gesunden Myokard auf Protein- und RNA-Ebene zu untersuchen, mögliche Ursachen für eine Regulation zu detektieren und so ein besseres Verständnis über die veränderte Aktivität und Expression der PDE2 in der Herzinsuffizienz zu erhalten.

Der überwiegende Anteil der im Rahmen dieser Arbeit entstandenen Ergebnisse und Abbildungen wurde von dem Ersteller der Arbeit als gleichberechtigter Erstautor unter dem Titel Phosphodiesterase-2 Is Up-Regulated in Human Failing Hearts and Blunts $\beta$-Adrenergic Responses in Cardiomyocytes im Journal of the American College of Cardiology veröffentlicht. Abbildung 6 wurde als Koautor in PDE2-mediated cAMP bydrolysis accelerates cardiac fibroblast to myofibroblast conversion and is antagonized by exogenous activation of cGMP signaling pathways . im Am J Physiol Heart Circ Physiol veröffentlicht. 


\section{Material und Methoden}

\section{$2.1 \quad$ Klonierung}

\subsubsection{Restriktionsverdau}

Restriktionsverdaue wurden mit folgenden Restriktionsenzymen (Fermentas) durchgeführt: NotI, SalI, PmeI, PacI und BamHI. Der Standardreaktionsansatz umfasste 2 IU Restriktionsenzym pro $\mu \mathrm{g}$ DNA, $1 \mu \mathrm{l} 10 \mathrm{X}$ Reaktionspuffer und wurde mit Aqua ad iniectabilia auf $10 \mu \mathrm{l}$ aufgefüllt. Der Ansatz wurde für 1,5 Stunden bei $37^{\circ} \mathrm{C}$ inkubiert. Nach abgelaufener Reaktion wurde der Ansatz für 2 Minuten auf $65^{\circ} \mathrm{C}$ erhitzt, um den Verdau zu stoppen.

\subsubsection{DNA-Gelaufreinigung}

Für die Gelaufreinigung wurden die Reaktionsprodukte aus dem Restriktionsverdau auf ein 0,8\%- Agarose-Gel in $2 \mathrm{~cm}$ große Geltaschen geladen. Die Fragmente wurden für 90 Minuten bei $80 \mathrm{~V}$ im elektrischen Feld aufgetrennt. Die enthaltende Dann wurde mittels Ethidiumbromid und UV-Strahlung dargestellt. Die Isolation der DNA aus dem Gel erfolgte mit dem QIAquick Gel Extraction Kit (Qiagen). Zur Elution der DNA wurden die Gelstücke mit QG-Puffer aufgelöst, die DNA an eine Silica-Säule gebunden und anschließend in TE-Puffer $(10 \mathrm{mM}$ Tris $\cdot \mathrm{Cl}, 1 \mathrm{mM}$ EDTA, $\mathrm{pH}$ 8.0) eluiert.

\subsubsection{Ligation}

Die Ligationsreaktionen wurden mit T4-Ligase (New England Biolabs, NEB) unter Verwendung von ATP-haltigem Puffer bei Raumtemperatur durchgeführt. Für die Ligation wurde ein Insert/Backbone-Verhältnis von 3:1 gewählt. Der Ligationsansatz bestand aus $1 \mu \mathrm{l}$ T4-Ligase, $1 \mu \mathrm{l} 10 \mathrm{x}$ Ligasepuffer, $6 \mu \mathrm{l}$ Insert und $2 \mu \mathrm{l}$ Backbone-Vektor. Die Ligationszeit war über Nacht

\subsubsection{Ansatz von LB-Medium}

\section{LB-Medium}

$\begin{array}{ll}\text { Trypton } & 1 \% \\ \text { Hefeextrakt } & 0,5 \% \\ \mathrm{NaCl} & 170 \mathrm{mM}\end{array}$


Der Ansatz wurde mit Bidestwasser aufgefüllt und ein $\mathrm{pH}$-Wert von 7,4 mit 0,1 $\mathrm{N} \mathrm{NaOH}$ eingestellt.

\subsubsection{Transformation von PDE2A3-Plasmid-DNA in hitzekompetente Bakterien}

Für die Transformation von Plasmid-DNA wurden thermokompetente Bakterien vom DH $10 \mathrm{~B}$ (Invitrogen) verwendet. Die Transformation erfolgte durch die Hitze-Schock-Methode. Es wurden $100 \mu \mathrm{l}$ Bakterien auf Eis aufgetaut. In die Lösung wurden vorsichtig $5 \mu$ l Ligationsansatz an den Boden des Transformationsgefäßes gegeben, Nach 30-minütiger Inkubation auf Eis, wurde der Ansatz für 45-60 sec bei $42{ }^{\circ} \mathrm{C}$ inkubiert, dann kurz auf Eis gekühlt und mit $250 \mu \mathrm{l} 37$ ${ }^{\circ} \mathrm{C}$ warmen SOC-Medium vermengt. Der Ansatz wurde im Anschluss für 60 Minuten bei $37^{\circ} \mathrm{C}$ inkubiert und dann je $150 \mu \mathrm{l}$ auf kanamycinhaltige $(60 \mu \mathrm{g} / \mathrm{ml})$ Agarplatten ausplattiert. Die Platten wurden bei $37{ }^{\circ} \mathrm{C}$ über Nacht inkubiert, um ein optimales Bakterienwachstum zu erreichen.

\subsubsection{Transformation von PDE2- Plasmid-DNA in elektrokompetente Zellen}

Für die Herstellung des adenoviralen PDE2-Konstruktes (Ad-PDE2/EGFP) wurden $50 \mu \mathrm{l}$ elektrokompetente E. coli vom Typ BJ5183 (Addgene) mit 100 ng Plasmid-DNA auf Eis vermischt. Der Ansatz wurde in eine gekühlte Elektroporationsküvette (Gene Pulser-Küvette, Biorad) pipettiert. Die Elektroporation erfolgte bei 2.500 V, $200 \Omega$ (Gene Pulser, Biorad). Nach erfolgter Elektroporation wurde dem Ansatz sofort $250 \mu \mathrm{l} 37{ }^{\circ} \mathrm{C}$ warmes SOC-Medium (Invitrogen $2 \%$ Tryptone, $0.5 \%$ Hefe-Extract, $10 \mathrm{mM} \mathrm{NaCl}, 2.5 \mathrm{mM} \mathrm{KCl}, 10 \mathrm{mM} \mathrm{MgCl} 2,10$ $\mathrm{mM} \mathrm{MgSO}_{4}$ und $20 \mathrm{mM}$ Glucose) zugeführt. Nachdem der Ansatz für weiter 30 Minuten bei 37 ${ }^{\circ} \mathrm{C}$ geschüttelt worden war, wurden jeweils $150 \mu \mathrm{l}$ Gemisch auf LB-Agarplatten mit dem jeweiligen zum Resistenzgen passenden Antibiotikum ausgestrichen.

\subsubsection{Animpfen einer Schüttelkultur}

Ausgewählte Bakterienkolonien wurden von den Agarplatten mit sterilen Pipettenspitzen aufgenommen und in $12 \mathrm{ml}$ LB-Medium überführt. Dem Medium wurden je nach im Vektor enthaltendem Resistenzgen $100 \mu \mathrm{g} / \mathrm{ml}$ Kanamycin oder Ampicilin zugesetzt. Der fertige Ansatz wurde über Nacht bei $37^{\circ} \mathrm{C}$ und einer Frequenz von $200 \mathrm{rpm}$ inkubiert.

\subsubsection{Mini-Plasmidpräperation aus einer Schüttelkultur}

Zur weiteren DNA-Analyse wurde die Plasmid-DNA aus den transformierten Bakterien isoliert. Es wurden $4 \mathrm{ml}$ aus dem Medium-Bakteriengemisch der Tageskultur in ein $2 \mathrm{ml}$ Eppendorfgefäß überführt und bei 12.000 rpm für 10 Minuten bei Raumtemperatur zentrifugiert. Der vom Pellet 
separierte Überstand wurde verworfen und das Bakterienpellet in $200 \mu \mathrm{l}$ P1-Puffer (50 mM Tris$\mathrm{HCl}, 10 \mathrm{mM}$ EDTA, $100 \mu \mathrm{g} / \mathrm{ml}$ RNase A, pH 8,0, Qiagen) resuspendiert. Im Anschluss wurden die Bakterien durch Zugabe von Puffer P2 (200 mM NaOH, 3,5 mM SDS, Qiagen) und Invertieren für 5 min lysiert. Die Lysereaktion wurde durch die Zugabe von Puffer P3 (3 M Kaliumacetat, Qiagen) durch Neutralisation beendet. Die überflüssigen Reagenzien und Bakterienreste wurden durch 10-minütige Zentrifugation bei $4{ }^{\circ} \mathrm{C}$ und $14,500 \mathrm{rpm}$ von der DNA-haltigen Lösung getrennt. Der entstandene Überstand wurde in ein 1,5 ml Eppendorfgefäß überführt und die DNA mit $500 \mu \mathrm{l}$ Isopropanol gefällt. Nach einem anschließenden Waschschritt mit $70 \%$ Ethanol wurde die DNA getrocknet und in $50 \mu \mathrm{H}_{2} \mathrm{O}$ resuspendiert. Der DNA-Gehalt wurde photometrisch bei einer Wellenlänge von $280 \mathrm{~nm}$ (NanoDrop ND1000, Thermo Scientific) bestimmt. Es wurde darauf geachtet, dass das Absorbtionsverhältnis von 260/280 nm bei ca. 1,8 lag. Wobei eine optische Dichte von 1 bei einer Wellenlänge von $260 \mathrm{~nm}$ einer DNA Konzentration von $50 \mu \mathrm{g} / \mathrm{ml}$ entsprach. Im Anschluss erfolgte eine Restriktionsanalyse zur Identifikation positiver Klone.

\subsubsection{Transfektion von Plasmid-DNA in HEK293-Zellen}

Für die Transfektion von Plasmid-DNA in HEK293-Zellen wurden $6 \mathrm{~cm}$ Zellkulturschalen verwendet, die zum Zeitpunkt der Transfektion eine Konfluenz von ca. 60 - 80 \% aufwiesen. Die Zellen wurden mit DMEM gespült und mit $100 \mathrm{ml}$ Medium bedeckt. Die zu transfizierende DNA wurde in $150 \mu \mathrm{l}$ Medium aufgenommen. $10 \mu \mathrm{l}$ Lipofectamin 3000 (Invitrogen) wurden ebenfalls in $150 \mu \mathrm{l}$ Medium aufgenommen. Die beiden Ansätze wurden vereint und es folgte ein 20-minütiger Reaktionsschritt, in dem sich das Lipofectamin an die negativ geladene DNA anlagert. Zu dem Kulturmedium wurden tröpfchenweise $300 \mu \mathrm{l}$ Transfektionsansatz gegeben. Nach ca. 4 - 6 Stunden wurde das Medium gegen FCS-haltiges Kulturmedium ausgetauscht. Die Transfektionseffizienz wurde durch ein positives GFP-Signal ermittelt.

\subsubsection{Isolation großer Plasmid-DNA-Mengen durch Ionenaustauscher-Säule}

Für die Bereitstellung größerer DNA-Mengen wurden 2,5 $\mathrm{ml}$ Bakteriensuspension aus einer zuvor positiv getesteten Tageskultur in einen $500 \mathrm{ml}$ fassenden Kolben mit $250 \mathrm{ml}$ LB-Medium und $100 \mu \mathrm{g} / \mathrm{ml} \mathrm{Kanamycin} \mathrm{oder} \mathrm{Ampicilin} \mathrm{gegeben.} \mathrm{Der} \mathrm{Ansatz} \mathrm{wurde} \mathrm{für} 12 \mathrm{~h}$ bei $37^{\circ} \mathrm{C}$ und 200 rpm bebrütet. Für die Isolation wurde eine Ionenaustauschersäule verwendet (NucleoBondPC 500, Macherey-Nagel). Die Isolation beruht auf einer alkalischen Bakteriolyse, einer Bindung der Plasmid-DNA an eine Anionentauschersäule und einer Trennung von genomischer DNA und bakteriellen Bestandteilen. Die Bindung der geladenen Plasmid-DNA erfolgt bei niedrigem $\mathrm{pH}$ und geringer Salzkonzentration über die negativ geladenen Phosphatreste an der DNA und den positiv geladenen Diethylaminomethanol-Gruppen der 
Säulen. Nach weiteren Waschschritten wurde die gebundene DNA durch Spülen mit einem hoch konzentrierten Salzpuffer von der Säule gelöst und mit Isopropanol gefällt. Die bestehende Salzverunreinigung wurde durch einen weiteren Waschschritt mit $70 \%$ Ethanol verringert. Die Plasmid-DNA wurde durch einstündige Zentrifugation aus der Lösung extrahiert und getrocknet, um etwaige Ethanolrückstände zu beseitigen. Die Reinheit der in Aqua ad iniectabilia gelösten DNA und die Konzentration wurden photometrisch (NanoDrop ND1000, Thermo Scientific) bestimmt. 


\subsection{Adenovirale Expressionssysteme}

$\mathrm{Da}$ in dieser Arbeit hauptsächlich mit primären Zellen gearbeitet wurde und diese sich nur unzureichend mit den üblichen Transfektionsmaßnahmen (z. B. durch Kalziumchlorid oder liposomale Transfektion, Lipofectamin 2000) transfizieren lassen, musste ein alternativer Gentransport in die Zelle gewählt werden. Aus diesem Grund wurde auf die von (He et al. 1998) beschriebene Methode des adenoviral vermittelten Gentransfers zurückgegriffen. Bei diesen nach der Methode von (He et al. 1998) generierten Adenoviren handelt es sich um replikationsdefiziente, rekombinante extrachromosomal verbleibende Adenoviren vom Serotyp 5.

\subsubsection{Klonierung des PDE2-Konstrukts in den pAD-Track CMV-Vektor}

Für die Generierung des Ad-PDE2 wurden jeweils 10 ng pAd-Track CMV und pYX-ASCPDE2A2 (Open Biosystems, BC086800) in einem präparativen Verdau mit den Restriktionsenzymen SalI und NotI für 2 h verdaut. Der Reaktionsansatz setzt sich aus $10 \mathrm{ng}$ Plasmid-DNA, je $6 \mu \mathrm{l}$ SalI und NotI (Fermentas) und $1 \mu \mathrm{l}$ BSA zusammen. Das Volumen wurde mit Aqua ad iniectabilia auf ein Volumen von $100 \mu \mathrm{l}$ aufgefüllt. Nach $2 \mathrm{~h}$ wurden die Enzyme durch Erhitzen auf $65^{\circ} \mathrm{C}$ denaturiert, die verdauten DNA-Fragmente in einem 0,8\%-Agarosegel $(0,8 \%$ Agarose und $0,4 \mathrm{mg} / \mathrm{ml}$ Ethidiumbromid in TBE-Puffer: $45 \mathrm{mM}$ Tris-Base, $45 \mathrm{mM}$ Borsäure, 1 mM EDTA, pH 8) gereinigt und elektrophoretisch aufgetrennt. Daraufhin wurden die DNA-Fragmente mit dem QLAquick Gel Extraction Kit (Qiagen) extrahiert. Die Ligation erfolgte mittels T4-Ligase, wie in 2.1.3 beschrieben. Das Vektor/Plasmid-Verhältnis betrug 1:4. Im Anschluss wurden die Ligationsprodukte mittels der Hitze-Schock-Methode in Hitzekompetente E. coli des Stammes DH10B (Invitrogen) transformiert. Nach einer einstündigen Inkubation wurde der Ansatz auf kanamycinhaltigen Agarplatten ausplattiert und bei $37^{\circ} \mathrm{C}$ für 16 $\mathrm{h}$ bebrütet. Nach Ablauf einer 16-stündigen Wachstumsphase wurden ausgewählte Bakterienkolonien von den Agarplatten (1,5\% Agarose, $100 \mu \mathrm{g} / \mathrm{ml}$ Kanamycin in LB-Medium: 1 $\%$ Trypton, 0,5 \% Hefeextrakt, $1 \% \mathrm{NaCl}, \mathrm{pH}$ 7,4) geerntet. Die selektionierten Kolonien wurden in $12 \mathrm{ml}$ Kanamycin-haltigem LB-Medium für weitere $16 \mathrm{~h}$ bei $37{ }^{\circ} \mathrm{C}$ in einem Schüttler inkubiert. Die DNA wurde mit dem Qiagen Plasmid Mini Kit (Qiagen) isoliert. Positive Klone konnten durch Restriktionsanalysen mit BamHI und NotI in einem 0,8 \%-Agarosegel identifiziert werden.

Ein positiv identifizierter E. coli Stamm wurde über Nacht in $250 \mathrm{ml}$ LB-Medium bei $37{ }^{\circ} \mathrm{C}$ vermehrt und die Plasmid-DNA wie in 2.1.5 beschrieben isoliert. Die isolierte DNA wurde, um die korrekte Insertion des GOI zu überprüfen, sequenziert (SEQLAB Sequence Laboratories Göttingen). Der Sequenzierungsprimer wurde so gewählt, dass er in dem Endbereich des pAdTrack-Vektor bindet und in den Anfangsbereich der PDE2-cDNA hereinragt, um zum einen die 
stattgefundene Insertion und zum anderen die richtige Ausrichtung der PDE2-cDNA in dem pAd-Track-CMV Vektor zu überprüfen. Durch die Sequenzierung (SEQLAB Sequence Laboratories Göttingen) konnten 8 positive Klone festgestellt werden.

\subsubsection{Linearisierung und Aufreinigung des pAd-Track-PDE2-CMV}

Zur Vorbereitung der homologen Rekombination wurde der pAd-Track-PDE2-Transfervektor mit dem Restriktionsenzym PmeI geschnitten. Die Schnittstelle von PmeI teilt den Shuttlevektor in einen linken und rechten Arm und ermöglicht so das Anlagern an das AdEasy-Plasmid. Für die Linearisierung wurden $80 \mu \mathrm{g}$ Transfervektor mit $160 \mathrm{U}$ PmeI für $16 \mathrm{~h}$ bei $37^{\circ} \mathrm{C}$ in einem OrbitalSchüttler inkubiert. Die Linearisierung wurde durch elektrophoretische Auftrennung in 0,8\%Agarosegel bestätigt. Die so geschnittene DNA wurde wie bei (He et al. 1998) beschrieben mit Glykogen gefällt und aufgereinigt.

\subsubsection{Homologe Rekombination mit dem Ad-Easy-System}

Für die homologe Rekombination wurde der aufgereinigte und mit PmeI linearisierte pAd-PDE2Track-CMV in elektrokompetente BJ5183 AdEasier-Zellen transfiziert. Dazu wurden der linearisierte pAd-Track-PDE2-Vektor und die AdEasier-Zellen in eine gekühlte $2 \mathrm{~mm}$ Glasküvette gegeben und mit dem Bio-Rad Genpulser bei $2500 \mathrm{~V}$ und $200 \mathrm{Ohm}$ gepulst. Die Selektion positiver Klone erfolgte auf kanamycinhaltigen Agarplatten. Nach 16 h Inkubationszeit bei $37^{\circ} \mathrm{C}$ wurden die kleinsten sichtbaren Kolonien von den Platten gepickt und wiederum in $2 \mathrm{ml}$ kanamycinhaltigem LB-Medium über Nacht in einem Orbitalschüttler inkubiert. Nach der Inkubationszeit wurde aus jeweils $0,25 \mathrm{ml}$ des LB-Mediums Mini-Präparationen durchgeführt. Die Größe der Klone wurde durch elektrophoretische Auftrennung in einem 0,8 \%-Agarosegel überprüft. Positive Klone wurden wie beschrieben in DH10B-Zellen transfiziert. Die korrekte Insertion des GOI in das finale rekombinante adenovirale Plasmid wurde mittels Sequenzierung (SEQLAB Sequence Laboratories Göttingen) überprüft.

\subsubsection{Herstellung Rekombinanter Adenovieren in HEK293-Zellen}

Die Vermehrung der rekombinanten Ad-PDE2/GFP-Adenoviren in HEK293 erfolgte nach der bekannten Methode von He (Luo et al. 2007). Kurz zusammengefasst wurden dazu HEK293Zellen in $25 \mathrm{~cm}^{2}$-Kulturflaschen mit dem mit PmeI linearisiertem Ad-PDE2-Plasmid mit Hilfe von Lipofectamin transfiziert. Die erfolgreiche Transfektion wurde durch ein positives GFPSignal überprüft. Nach 7 Tagen wurde täglich unter dem Mikroskop das GFP-Signal und die Zellintaktheit überprüft. Nach 20 Tagen wurden die Viren durch, wie bei He beschrieben (Luo et 
Material und Methoden

al. 2007) geerntet und durch Zentrifugation aufgereinigt und konzentriert. Im Anschluss wurden durch eine Verdünnungsreihe die erreichten Virustiter bestimmt. 


\subsection{Modelle der menschlichen und experimentellen Herzinsuffizienz}

Aus dem linken Ventrikel von Patienten wurde Gewebe mit fortgeschrittener dilatativen Kardiomyopathie (DCM) oder fortgeschrittener ischämischer Kardiomyopathie zum Zeitpunkt einer Herztransplantation gewonnen. Die Ejektionsfraktion betrug bei den verwendeten Proben weniger als $37 \%$. Als Kontrollen wurde Gewebe aus dem linken Ventrikel von gesunden Spendern ohne Herzerkrankung in der Anamnese genommen (NF), deren Organe auf Grund von nicht passenden Empfängern nicht transplantiert wurden. Von Patienten mit symptomatischer Aortenstenose wurde aus dem Septum des linken Ventrikels im Rahmen einer Aortenklappenersatzoperation und Muskelgewebeabtragung Myokard gewonnen. Diese Patienten hatten zum Zeitpunkt der Operation eine signifikante myokardiale Hypertrophie, aber eine noch kompensierte Ejektionsfraktion. Die Verwendung der Gewebe in dieser Arbeit wurde von dem Ethikkomitee der Universität Göttingen geprüft und genehmigt. Die schriftliche Einwilligung aller Studienteilnehmer liegt vor. Die Gewebeproben wurden von Prof. Sossalla aus der Arbeitsgruppe Prof. Meier Klinik für Kardiologie und Pneumologie bereitgestellt. Ethik-Antrag „Funktionelle, biochemische und molekularbiologische Charakterisierung von Gewebeproben aus explantierten menschlichen Herzen“ (Antragsnummer: 31/9/00) bereitgestellt. Die klinischen Daten der Spenderpatienten sind in Tabelle 2 aufgelistet, und die verwendete Materialien zusammengefasst. 


\subsection{Chronisches beta-adrenerges Stressmodell in der Ratte}

\subsubsection{Implantation von osmotischen Mini-Pumpen}

Für eine kontinuierliche Applikation mit Isoproterenol für einen Zeitraum von 5 Tagen, wurden männliche Wistar Ratten mit einem Gewicht von 240-300 g mit osmotischen Minipumpen (Alzet Modell 2002) ausgestattet. Um eine Abgaberate von $2,4 \mathrm{mg} / \mathrm{kg} / \mathrm{d}$ Isoprenalin $\mathrm{zu}$ erreichen, wurde jede Pumpe für jedes Tier gewichtsadaptiert mit einem Isoprenalin- $0,9 \% \mathrm{NaCl}$ und 0,2 mM-HCl Gemisch gefüllt und in $\mathrm{NaCl}$ für $12 \mathrm{~h}$ inkubiert (El-Armouche et al. 2007a). Die Tiere wurden in einer mit Isofluran vorgefluteten Kammer betäubt und dann mit einem SauerstoffIsofluran-Gemisch $(1,5 \mathrm{l} / \mathrm{h})$ für wenige Sekunden begast. Die Ratten wurden durch Pflaster auf dem Bauch liegend an den Extremitäten fixiert und die Nackenpartie enthaart. Das enthaarte Gebiet wurde mit $70 \%$ Ethanol desinfiziert. Durch eine ca. 0,7 cm lange horizontale Inzision wurde die Haut mit einem Nadelhalter getunnelt und in die entstandene Hauttasche die Pumpe vorgeschoben. Die Hautinzision wurde durch 2-3 Klammern (Manipler Einweg Hautklammergerät BRAUN) adaptiert. Zur Nachsorge erhielten die Tiere bis $4 \mathrm{~d}$ nach Implantation $125 \mathrm{mg}$ Metamizol auf $1000 \mathrm{ml}$ Trinkwasser. Alle Experimente und Untersuchungen wurden nach den Richtlinien des Europäischen Parlaments durchgeführt (2010/63/EU); Tierversuchsantragsaktenzeichen: 33.14-42502-04-11/0579.

\subsubsection{Organentnahmen}

Zur Organentnahme wurden die Tiere mittels Isoflurangas in eine Narkose versetzt. Das Körpergewicht wurde bestimmt. Durch zervikale Dislokation wurden die Tiere getötet. Der Thorax und das Abdomen wurden durch einen Schnitt entlang der Medianlinie eröffnet und die Herzen, Lebern sowie die Lungen entnommen. Nach kurzer Spülung in 0,9 \% Kochsalzlösung wurden die Einzelgewichte der jeweiligen Organe bestimmt. Das Herz wurde in rechten und linken Ventrikel aufgeteilt. Unmittelbar nach der Entnahme wurden die Organe in flüssigem Stickstoff tiefgefroren und für die folgenden Versuche bei $-80{ }^{\circ} \mathrm{C}$ konserviert. Zur Weiterverarbeitung wurden die Proben unter Zugabe von flüssigem Stickstoff gemörsert, wodurch ein homogenes Pulver entstand. Die anschließende Protein-Aufreinigung erfolgte wie unter 2.6.1 beschrieben.

\subsubsection{Großtiermodell der Herzinsuffizienz in Rapid-Paced-Hunden}

Die Proben wurden freundlicherweise von Dr. S. Nattal (Montreal, Quebec, Canada) bereitgestellt. Die Herzinsuffizienz wurde wie von Li (Li et al. 1999) beschrieben induziert. Dazu wurde bei Mischlingshunden (Gewicht 22 bis $30 \mathrm{~kg}$ ) eine Schraubelektrode in den linken 
Ventrikel angebracht und mit einem im Nacken implantierten Schrittmacher verbunden. Die Hunde (HF) wurden mit einer Frequenz von 240 Schlägen pro Minute für eine Dauer von 14 Tagen stimuliert. Kontrolltiere (Sham) wurden operiert, aber nicht über die Sonde stimuliert. Die beobachteten haemodynamischen Veränderungen waren typisch für eine Dilatative Kardiomyopathie. Es zeigte sich ein erhöhter enddiastolischer Druck im linken Ventrikel (LVEDP). Die Tiere zeigten eine Tachypnoe, Ascites, Lungenödeme und Pleuraergüsse. Die Herzen wurden während einer Anästhesie mit Morphin $(2 \mathrm{mg} / \mathrm{kg} \mathrm{SC})$ und $\alpha$-Chloralose (120 $\mathrm{mg} / \mathrm{kg}$, i.v.) entnommen (El-Armouche et al. 2007b). 


\subsection{RNA-Analysen}

\subsubsection{Isolation von RNA}

Zur Isolation der RNA aus Herzgewebe wurden $30 \mathrm{mg}$ gemörsertes und tiefgefrorenes Gewebe nach Herstellerangaben mit dem SV Total RNA Isolation System Kit (Promega) verarbeitet. Die RNA-Konzentration wurde photometrisch ermittelt (NanoDrop ND1000, Thermo Scientific). Die anschließende Lagerung der RNA erfolgte bei $-80{ }^{\circ} \mathrm{C}$.

\subsubsection{Reverse Transkription}

Um die RNA in cDNA umzuschreiben, wurde nach Herstellerangaben 1000 ng RNA mittels Reverser-Transkriptase mit dem High Capacity cDNA Reverse Transcription Kit (Applied Biosystems) umgeschrieben. Die Synthese der cDNA erfolgte gemäß Herstellerangaben unter Verwendung von Oligo(dt)-Primern mit dem High Capacity $c D N A$ Reverse Transkription Kit (Applied Biosystems). Um Verunreinigungen mit genomischer DNA ausschließen zu können, wurde von jeder Probe eine Negativkontrolle ohne Reverse Transkriptase angefertigt. Die cDNA wurde bei $-20{ }^{\circ} \mathrm{C}$ weggefroren.

\subsubsection{Real-Time PCR}

Die quantitativen Messungen der Transkripte von kardialer PDE2, GAPDH und ANP erfolgte aus Homogenaten aus dem linken Ventrikel. Die RNA wurde, wie in Punkt 2.5.1 beschrieben, aus $\sim 30 \mathrm{mg}$ gefrorenem Myokard isoliert. Mittels Real- Time PCR (SYBR Green/ROX qPCR Master Mix, Fermentas) und den folgenden Primer Paaren:

ANP: 5 'GTGCGGTGTCCAACACAG, 5 `GCTTCATCGGTCTGCTCGCTCA; PDE2: 5`AGTGCTGGGAGAAGAGGTCA, 5`TCATCAGTCGAGCCACTGAC; und GAPDH:5`ATGTTCCAGTATGACTCTACCCACG,5`TGTCGTGGAGTCTACTGGCGTCT TC und wurden mit dem ABI PRISM 7900HT System (Applied Biosystems) die relative Menge der PDE2-, GAPDH- und ANP-mRNA-Transkripte bestimmt. 


\subsection{Proteinanalytische Methoden}

\subsubsection{Proteingewinnung aus Gewebe für Immunoblot-Analysen}

Für die Isolation aus Gewebe wurden $30 \mathrm{mg}$ pulverisiertes Herzgewebe gewogen. Die gesamte Extraktion wurde auf Eis durchgeführt. Nach Zugabe des zehnfachen Volumens des Gewichts an Lysispuffers (3\% SDS, $30 \mathrm{mM}$ Tris Base, $\mathrm{pH}$ 8,8 5mM EDTA, $30 \mathrm{mM} \mathrm{NaF}, 10 \%$ Glycerol) wurden die Proben für 3* 30 Sekunden $\left(20 \mathrm{~Hz},-20^{\circ} \mathrm{C}\right)$ im TissueLyzer II (Qiagen) homogenisiert. Anschließend folgte eine 10-minütige Zentrifugation bei 16.000 rcf bei Raumtemperatur (Eppendorf Centrifuge 5417R), um das gewonnene Homogenat von groben Gewebeteilen zu reinigen. Mit dem Überstand wurden eine Proteinbestimmung (2.6.2) und anschließende immunologische Nachweise von Protein (2.6.3) durchgeführt.

\subsubsection{Proteinbestimmung nach Bradford}

Die Methode der Proteinbestimmung nach Bradford basiert auf einem Farbumschlag einer sauren Coomassie Brilliant Blue G-250-Lösung, in Abhängigkeit von der in der Probe enthaltenen Proteinmenge. Es wurde hierzu Nanoquant der Firma Roth verwendet. Die Interaktion von Protein mit dem Farbstoff löst eine Verschiebung des Absorptionsmaximums von 465 nach $595 \mathrm{~nm}$ aus. Um eine absolute Proteinbestimmung aus der gemessenen Absorption durchführen zu können, wurde mittels Bovine Immunoglobulin G (Sigma-Aldrich) eine Standartreihe von $0-1020 \mathrm{ug} / \mathrm{ml}$ in $85 \mu \mathrm{g} / \mathrm{ml}$ Schritten hergestellt. Aus den verschiedenen Konzentrationen wurde eine Standardkurve angefertigt und in das Photometer eingelesen. Anhand der Standartkurve wurden die mit $0,1 \% \mathrm{NaOH}$ verdünnten Proben gemessen. Die Verdünnung diente dem Zweck, dass die zu bestimmenden Proteinkonzentrationen im linearen Bereich der gemessenen Standardkurve lagen. Für jeden Standard und für jede Probe wurden Doppelmessungen durchgeführt und der Mittelwert bestimmt.

\subsubsection{Bestimmung der Proteinexpression}

\subsubsection{SDS-Polyacrylamid-Gelelektrophorese (SDS-PAGE)}

Für die SDS-PAGE wurde den Proben das 6-Fache an Probenpuffer (2\% SDS, $10 \%$ Glycerol, $10 \mathrm{mM}$ Tris-Base, $\mathrm{pH}$ 6,8, $100 \mathrm{mM}$ DTT und 0,01\% Bromphenolblau) zugesetzt. Die Lysate wurden bei $95{ }^{\circ} \mathrm{C}$ für 5 Minuten denaturiert. Für die Gelelektrophorese wurde in Abhängigkeit des Molekulargewichts des zu untersuchenden Proteins 8-15\% Polyacrylamid-Gele (Trenngel: 375 mM Tris-Base, pH 8,8, 10-15 \% Acrylamid/Bis-Acrylamid-Lösung: 29:1, 0,1 \% SDS, 0,1 \% APS, 0,03\% TEMED; Sammelgel: 125 mM Tris-Base, pH 6,8, $5 \%$ Acrylamid/Bis-Acrylamid- 
Lösung: 29:1, 0,1\% SDS, 0,1\% APS, 0,08\% TEMED) verwendet. Die anschließende Gelelektrophorese wurde in einem Elektrophoresepuffer (25 mM Tris-Base, $192 \mathrm{mM}$ Glycin, 0,1\% SDS) in dem Mini Protean 3 Elektrophoresesystem (Bio-Rad) bei $80 \mathrm{~V}$ für 15 Minuten und anschließend bei $120 \mathrm{~V}$ für weitere 60 bis 120 Minuten durchgeführt. Als Standard wurde der Molekulargewichtsmarker Precision Plus Protein Standard (Bio-Rad) mitgeführt.

\subsubsection{Western Blot}

Der Transfer der gelelektrophoretisch aufgetrennten Proteine auf eine Nitrozellulose (Protan ${ }^{\circledR}$ BA 85, Schleicher und Schuell) oder PVDF-Membran 0,45 $\mu \mathrm{m}$ (Hybond-P PVDF, AmershamPharmacia), erfolgte in dem Mini Trans-Blot Cell System (Bio-Rad). Über einen Zeitraum von 90 Minuten wurden bei konstant $400 \mathrm{~mA}$ in Transferpuffer I $(50 \mathrm{mM}$ Tris-Base, $380 \mathrm{mM}$ Glycin, 0,1\% SDS, $20 \%$ Methanol) die Proteine auf die Membran geblotted. Im Anschluss wurden die Proteine durch Ponceau-S-Lösung (0,1 m/v Ponceau-S, 1 \% v/v Eisessig) sichtbar gemacht, um so den korrekten Transfer und eine gleichmäßige Beladung feststellen zu können. Nach Entfärbung mit TBST Puffer (100 mM Tris-Base, pH 7,5, $150 \mathrm{mM} \mathrm{NaCl}, 0,1 \%$ Tween 20) wurden die Membranen in 5\% Milchpulver-Lösung geblockt, um unspezifische Antikörperbindungen zu vermeiden.

Die anschließende Inkubationszeit mit dem primären Antikörper variierte zwischen einer und 12 Stunden bei $4{ }^{\circ} \mathrm{C}$. Nach Bindung des primären Antikörpers wurden die Membranen über 25 Minuten mit 4-maligen Wechseln der TBST-Puffer gewaschen und anschließend mit dem vom 1. AK abhängigen HRPO-konjugierten sekundären Antikörper für 1 Stunde inkubiert. Im Anschluss wurden die Membranen wie beschrieben für 10 Minuten gewaschen, um nichtgebundenen sekundären Antikörper zu entfernen. Die Detektion des Chemilumineszenzsignals erfolgte mit ECL-Substrat (Enhanced Chemiluminescence, Pierce) und mit Hilfe des VersaDoc Imaging System 4000 MP (Bio-Rad). Die anschließende Quantifizierung erfolgte mit der Quantity One Software (Bio-Rad). 


\subsection{PDE2-Aktivitäts-Assay}

Die Messungen der Aktivität der PDE2 wurden durch Frau Dr. Mehel am French institute of Health and Medical Research in Paris durchgeführt. Mit Hilfe der Methode von Thompsen und Appleman (Thompson und Appleman 1971) wurde die Degradierung von cyclischem AMP und cyclischem GMP bestimmt. Die cAMP-hydrolytische Aktivität wurde mit $1 \mu \mathrm{M}$ cAMP and $10^{5} \mathrm{cpm}{ }^{3} \mathrm{H}$ cAMP und die cGMP-hydrolytische Aktivität mittels $5 \mu \mathrm{M}$ cGMP und $10^{5} \mathrm{cpm}{ }^{3} \mathrm{H}$-cGMP bestimmt. Die Aktivität der PDE2 wurde als diejenige Fraktion der cAMP/cGMP Aktivität definiert, die durch den hoch spezifischen PDE2-Inhibitor BAY 60-7550 (100 nM) inhibiert wurde. 


\subsection{Bestimmung der zellulären Hypertrophie}

Neonatale Ratten-Kardiomyozyten wurden 24 Stunden nach der Infektion mit Ad-GFP oder AdGFP-PDE2 mit einer MOI von 100 mit $10 \mu \mathrm{M}$ Norepinephrin (NOR) oder $10 \mu \mathrm{M}$ Phenylephrin für weitere 24 Stunden in Serum-freiem MEM inkubiert. Mit Hilfe einer Kamera (Sensicam PE; PCO, Kelheim, Germany) in Verbindung mit einem 20x Objektiv eines Nikon TE 300 Mikroskops bei einer Wellenlänge von $488 \mathrm{~nm}$ wurden GFP-positive Zellen beider Modalitäten abgelichtet. Die Messung der Zelloberfläche der einzelnen Zellen wurde mit der Image J Software (Wayne Rasband, National Institutes of Health, USA) durchgeführt. Die Experimente zur Messung der Zelloberflächen wurden mit den Kollaborationspartnern am French institute of Health and Medical Research, Paris durchgeführt. 


\subsection{Statistische Auswertung}

Die Daten in dieser Arbeit werden als arithmetischer Mittelwert \pm Standardfehler des Mittelwerts (SEM) dargestellt. Die Anzahl der verwendeten Proben ist mit n angegeben. Signifikanzen wurden mit Hilfe des Student-t-Test errechnet. Die Berechnungen der Signifikanzen erfolgte mit der Prism 4 Software (GraphPad). p-Werte $\leq 0,05$ wurden als signifikant gewertet. 


\section{Ergebnisse}

\subsection{Herstellung des rekombinanten PDE2-Adenovirus}

\subsubsection{Klonierung des pAdTrack-PDE2-CMV Shuttle-Vektors}

Zur Untersuchung der Auswirkung einer PDE2-Überexpression sowie der intrazellulären Lokalisation in Primärzellen wurde ein PDE2-Adenovirus nach der Methode von He et al. (He et al 1998, Luo et al. 2007) generiert. Dafür wurde die PDE2-cDNA aus dem pYX-ASC-PDE2A2Vektor (Open Biosystems, BC086800) in den pAdTrack-CMV-Vektor, wie unter 2.2.1.1 beschrieben, kloniert. Die erfolgreiche Insertion wurde durch eine Transfektion in HEK-Zellen im Immunoblot überprüft.

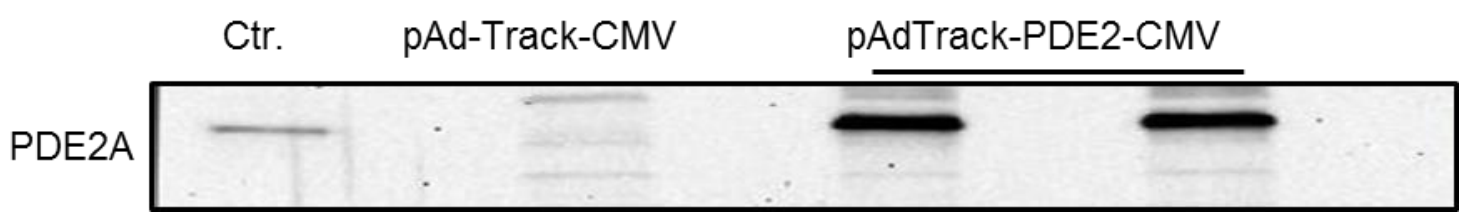

Abbildung 2: Generierung des PDE2-pAD-Track-CMV.

Auf der Membran ist der Proteinnachweis mittels anti-PDE2 Antikörper in Lysaten von mit pAdTrackCMV und pAdTrack-PDE2-CMV transfizierten HEK293 - Zellen dargestellt. Die mit dem PDE2-pAdTrack-CMV transfizierten Zellen generieren eine Bande bei ca. $100 \mathrm{kDa}$. Die Transfektion mit dem leeren Backbone-Vektor pAd-Track-CMV liefert kein Signal. Als Kontrolle wurde murines Hirnlysat mitgeführt. 


\subsubsection{Homologe Rekombination von pAd-Track-PDE2-CMV und pAdEasy}

Zur Vorbereitung der homologen Rekombination wurde der pAd-Track-PDE2-CMV Transfervektor mit dem Restriktionsenzym PmeI geschnitten. Die Schnittstelle von PmeI teilt den pAd-Track-PDE2-CMV Shuttlevektor in einen linken und rechten Arm. Die positiven Klone wurden durch Restriktion mit PacI identifiziert. Die erfolgreiche Rekombination zeigt sich durch ein ca 33,4 kb DNA- Fragment sowie einem dazugehörigen 4,5 kb großen Fragment.

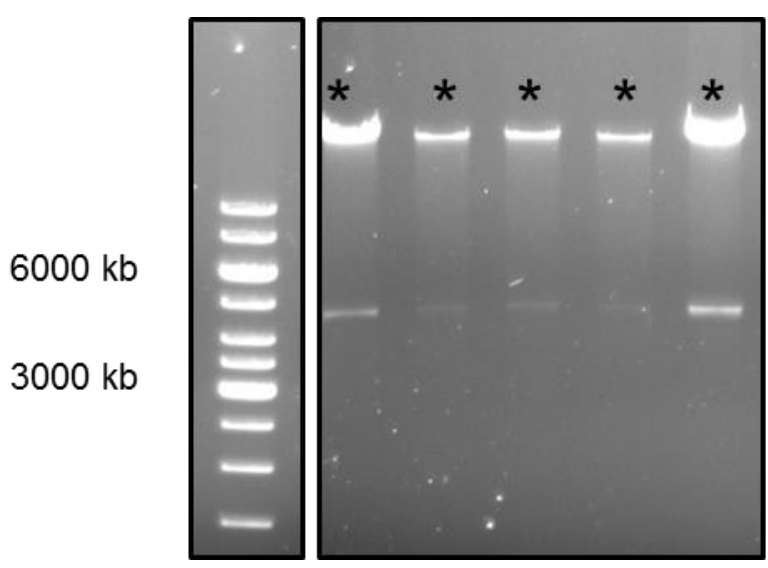

Abbildung 3: Verdau von pAd-Easy-PDE2A3 nach der homologen Rekombination

Bei einer erfolgreichen homologen Rekombination zeigen sich DNA-Fragmente in einer Größe von 4,5 kb sowie $33 \mathrm{~kb}$ (GeneRuler $1 \mathrm{~kb}$ DNA Ladder). Die mit * gekennzeichneten Spuren zeigen positive Klone

Die korrekte Insertion des GOI in das finale rekombinante adenovirale Plasmid wurde mittels Sequenzierung überprüft. Die Replikation der Viren fand wie in den Methoden beschrieben in HEK293-Zellen statt. 


\subsubsection{Viral überexprimierte PDE2 in neonatalen Rattenherzmuskelzellen}

Die erfolgreiche Transfektion von Zellen mit dem pAd-PDE2/GFP-Virus und die daraus resultierende PDE2-Expression, wurden in neonatalen Rattenherzmuskelzellen getestet. Dafür wurden kultivierte neonatale Rattenherzmuskelzellen mit aufsteigenden Viruskonzentrationen infiziert. Die Multiplicity of infection (MOI) betrug 0, 100, 300. Die Immunofluoreszenzfärbung der Rattenherzmuskelzellen zeigt die Zellkerne mit DAPI blau angefärbt, der anti-PDE2-AK mit rot und ein grünes Signal für GFP. Hierbei zeigt sich eine deutliche Intensitätszunahme der AntiPDE2-Immunofluoreszenzfärbung in den mit aufsteigenden MOI transfizierten Zellfraktionen.
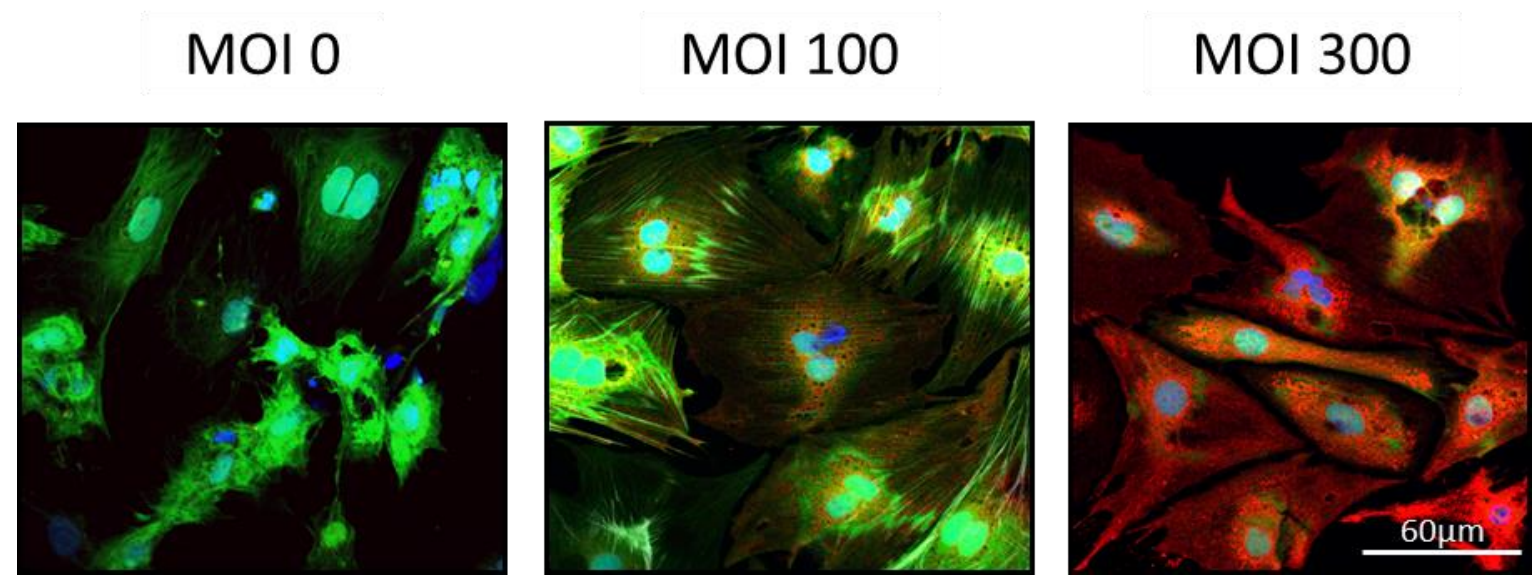

Abbildung 4: Ad-PDE2- infizierte neonatale Rattenkardiomyozyten

Die Abbildung zeigt neonatale Rattenkardiomyozyten transfiziert mit aufsteigenden Viruskonzentrationen. Blau = DAPI, grün = GFP, rot = PDE2. Eine steigende MOI geht mit einer vermehrten PDE2-

Expression einher. 


\subsection{Spezifität des PDE2-Antikörpers}

Da im Rahmen von Vorversuchen eine wechselnde und schlechte Spezifität der verschiedenen kommerziell erhältlichen Antikörper festgestellt wurde, wurde zur Prüfung der Spezifität des für diese Arbeit verwendeten PDE2-Antikörpers (Santa Cruz Biotechnology Klon: PDE2 sc20) HEK293-Zellen mit den Adenoviren pAd-Track-EGFP, pAd-PDE2-HA und pAd-PDE2 transfiziert. Als Kontrolle wurde murines Hirnlysat, mit aus der Literatur bekanntem hohen Level (Repaske et al. 1993) an PDE2, im Western Blot mitgeführt. Die geblottete Nitrocellulosemembran (Protran ${ }^{\circledR}$ BA 85, Schleicher und Schuell) wurde im ersten Schritt mit einem anti-PDE2-Antikörper inkubiert, danach gestrippt und mit einem anti-HA-Antikörper reinkubiert. Das Verteilungsmuster der detektierten Banden zeigt die Spezifität des verwendeten Antikörpers.

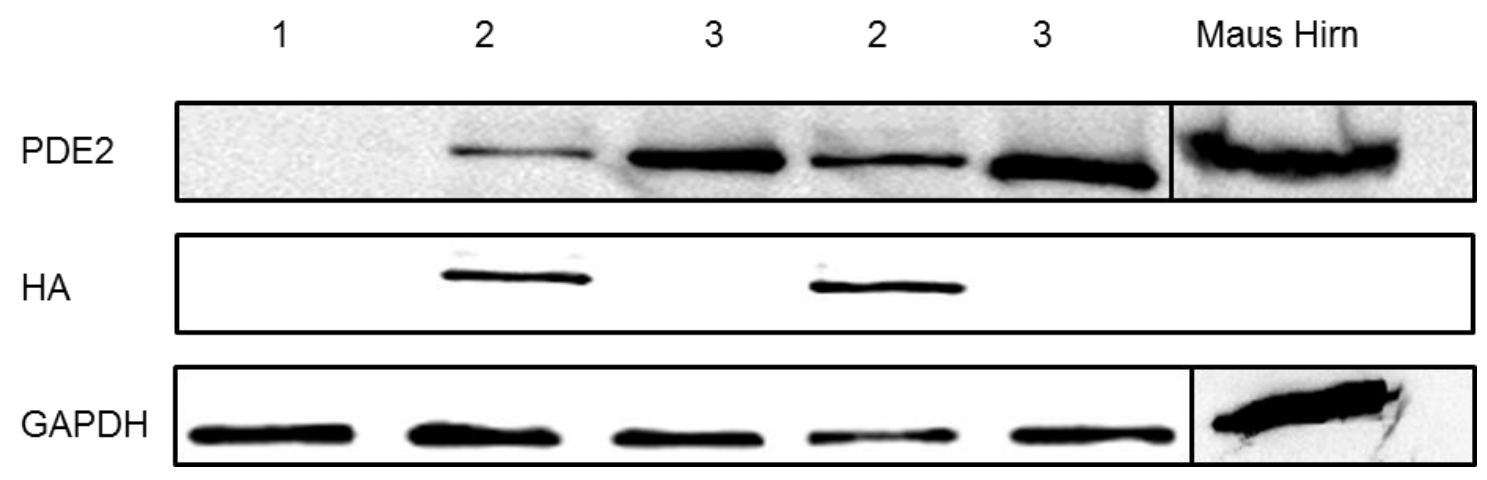

Abbildung 5: Spezifität des PDE2-Antikörpers

Die Spezifität des kommerziell erhältlichen PDE2- Antikörpers wurde mittels Zelllysaten aus HEK293Zellen überprüft. Dafür wurden die Zellen mit pAd-Track-EGFP =1, pAd-Track-PDE2-HA =2 und pAd-Track-PDE2 $=3$ transfiziert. Als weitere Kontrolle wurde auf derselben Blotmembran murines Hirnlysat mit bekanntem hohem PDE2-Gehalt mitgeführt. Der Nachweis wurde mittels anti-PDE2, antiHA und zur Ladungskontrolle anti-GAPDH durchgeführt. 


\subsection{Endogene PDE2-Expression in kardialen Fibroblasten und Kardiomyozyten}

PDE2 wurde in einer Vielzahl von Geweben nachgewiesen: Unter anderem im Herzen, der Leber, der Nebenniere, im Gehirn, in Endothelzellen und Makrophagen (Martins et al. 1982, Bender und Beavo 2006). Auf zellulärer Ebene, besonders im Myokard, ist über die PDE2Expression und mögliche Unterschiede zwischen den Zelltypen wenig bekannt. Aus diesem Grund wurden kultivierte neonatale Maus-Kardiofibroblasten (CF) und Kardiomyozyten (CM) auf ihre endogene PDE2-Expression untersucht. Um die Reinheit der Fraktionierung der beiden Zellpopulationen nach mehrmaligem gefrieren und auftauen überprüfen zu können, wurden zusätzlich Pro-Kollagen als Fibroblasten-spezifischer und Calsequestrin als Kardiomyozytenspezifischer Marker bestimmt. Die Proteinanalysen zeigten eine ca. 2,5-Fach höhere PDE2Expression in den kardialen Fibroblasten im Vergleich zu den Kardiomyozyten.

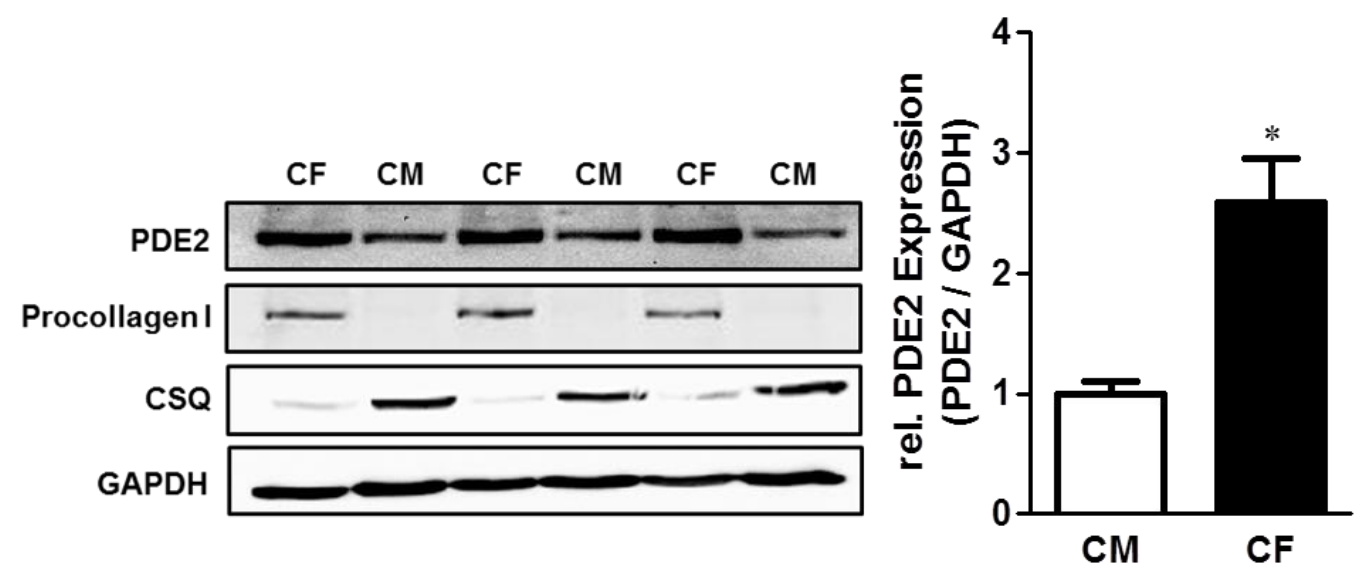

Abbildung 6: Endogene Expression der PDE2 in neonatalen Kardiomyozyten und kardialen Fibroblasten

Gezeigt sind repräsentative Immunoblots von neonatalen Ratten-Kardiofibroblasten (CF) und Kardiomyozyten (CM). Als Markerprotein für Kardiomyozyten wurde Calsequestin (CSQ, $52 \mathrm{kDa}$ ), für Fibroblasten Pro-Kollagen $1(230 \mathrm{kDa})$ verwendet. Der Graph zeigt die Quantifizierung der relativen Expression von PDE2 normalisiert auf GAPDH $(37 \mathrm{kDa}) . \mathrm{n}=5,{ }^{*} \mathrm{p} \leq 0,05$ vs. CM. (Vettel et al 2014) 


\subsection{PDE2-Expression in der menschlichen Herzinsuffizienz}

Im Rahmen dieser Arbeit wurde zum ersten Mal der Nachweis erbracht, dass die Proteinexpression der PDE2 im Rahmen der Herzinsuffizienz beim Menschen reguliert ist. Die PDE2-Expression im Myokard ist bei Patienten mit schwerer Herzinsuffizienz erhöht. Zur Analyse der PDE2-Spiegel im Myokard des linken Ventrikels von Patienten mit schwerer Herzinsuffizienz (Ejektionsfraktion $\leq 37 \%$ ) wurden Herz-Homogenate von erkrankten Patienten mit gesunden Spenderherzen verglichen $(n=6)$. Jede Probe wurde auf Calsequestrin (CSQ) normalisiert. Es zeigte sich eine Erhöhung der PDE2-Expression um das $\sim 2$-Fache in den von einer dilatativen Kardiomyopathie $(n=5)$ oder ischämischen Kardiomyopathie $(n=5)$ betroffenen Patienten. Die klinischen Patientencharakteristiken sind in Tabelle 2 dargestellt. (Mehel et al. 2013)

\subsubsection{Klinische Daten der Spenderpatienten}

Tabelle 2: Patienten-Charakteristika

\begin{tabular}{cccccccc}
\hline Patient & Alter & Geschlecht & Diagnose & Medikation & NYHA & CI & LVEF \\
\hline 1 & 28 & M & NF & n.d. & & n.d. \\
2 & 34 & M & NF & n.d. & & n.d. \\
3 & 20 & M & NF & n.d. & & n.d. \\
4 & 23 & F & NF & n.d. & & n.d. \\
5 & n.d. & F & NF & n.d. & & n.d. \\
6 & 58 & M & ICM & ACDOX & $3-4$ & 1,9 & $19 \%$ \\
7 & 57 & F & ICM & ACDX & n.d. & n.d. & $23 \%$ \\
8 & 40 & M & ICM & ACDX & n.d. & 2,5 & $20 \%$ \\
9 & 48 & F & ICM & ACDGX & 3 & 2,0 & $25 \%$ \\
10 & 66 & M & ICM & AGDX & $3-4$ & 2,4 & $25 \%$ \\
11 & 43 & M & ICM & n.d. & n.d & n.d & $23 \%$ \\
12 & 57 & M & ICM & ADG & 4 & - & $15 \%$ \\
13 & 64 & M & ICM & ADNO & 4 & 3,9 & $15 \%$
\end{tabular}




\begin{tabular}{|c|c|c|c|c|c|c|c|}
\hline Patient & Alter & Geschlecht & Diagnose & Medikation & NYHA & $\mathrm{CI}$ & LVEF \\
\hline 14 & 49 & M & $\mathrm{ICM}$ & ADROS & 4 & 2,1 & $15 \%$ \\
\hline 15 & 46 & M & $\mathrm{ICM}$ & $\mathrm{DO}$ & 3 & 2,2 & $20 \%$ \\
\hline 16 & 55 & M & ICM & $\mathrm{RD}$ & - & 1,7 & $20 \%$ \\
\hline 17 & 52 & $\mathrm{~F}$ & ICM & ADRC & $3-4$ & 1,7 & $25 \%$ \\
\hline 18 & 53 & M & DCM & DRX & 3 & 5,7 & $37 \%$ \\
\hline 19 & 31 & $\mathrm{~F}$ & DCM & ACDX & 3 & n.d & $34 \%$ \\
\hline 20 & 47 & M & DCM & n.d. & $3-4$ & 2,1 & $28 \%$ \\
\hline 21 & 55 & M & DCM & ADGO & 3 & 3,5 & $20 \%$ \\
\hline 22 & 50 & M & DCM & DRGX & $3-4$ & 3,0 & $25 \%$ \\
\hline 23 & 58 & M & DCM & ADX & $3-4$ & 1,9 & $25 \%$ \\
\hline 24 & 24 & M & DCM & ADXO & $3-4$ & 2,6 & $19 \%$ \\
\hline 25 & 43 & M & DCM & ADGXO & 4 & 1,3 & $20 \%$ \\
\hline 26 & 80 & $\mathrm{~F}$ & AS & $A X$ & & & $50 \%$ \\
\hline 27 & 76 & $\mathrm{~F}$ & AS & $\mathrm{D}$ & & & $60 \%$ \\
\hline 28 & 81 & $\mathrm{~F}$ & AS & $A X$ & & & $60 \%$ \\
\hline 29 & 60 & M & AS & AX & & & $65 \%$ \\
\hline 30 & 57 & M & AS & ACX & & & $65 \%$ \\
\hline 31 & 81 & $\mathrm{~F}$ & AS & $\mathrm{AC}$ & & & $60 \%$ \\
\hline
\end{tabular}

Diagnose: NF: Gesunde Spender, ICM: Ischämische Kardiomyopathie, DCM: Dilatative

Kardiomyopathie, AS: Aorten Stenose. Medikamente: A: ACE-Hemmer, C: Calciumkanal-Blocker, D: Diuretika, G: Herzglykoside N: Nitrate, R: Antiarrhythmetika (ausgenommen Betablocker), O:

Dopamin/Dobutamin, S: Steroide, L: Clonidin, V: Vasopressin, X: Betablocker, n.d.: Nicht erhoben.

(Mehel et al. 2013) 


\subsubsection{PDE2 ist in der menschlichen Herzinsuffizienz hochreguliert}

Herz-Homogenate von erkrankten Patienten verglichen mit gesunden Spenderherzen $(n=6)$. Jede Probe wurde auf Calsequestrin (CSQ) normalisiert. Es zeigte sich eine Erhöhung der PDE2Expression um das $\sim 2$-Fache in den von einer dilatativen Kardiomyopathie ( $n=5$ ) oder ischämischen Kardiomyopathie $(\mathrm{n}=5)$ betroffenen Patienten.

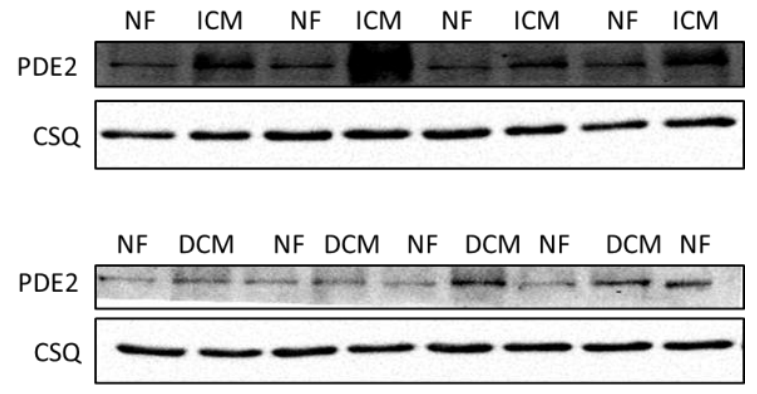

A

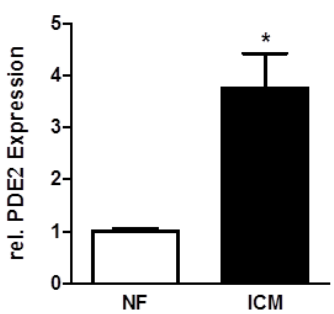

B

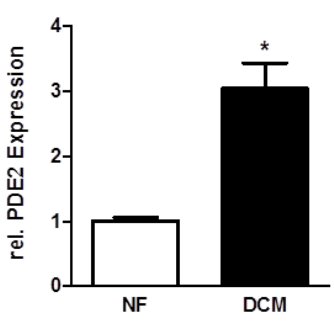

C

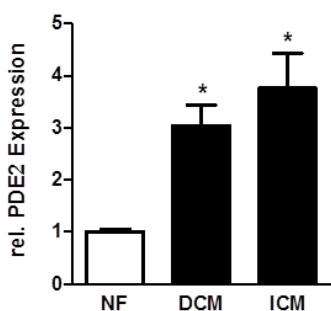

$\mathrm{D}$

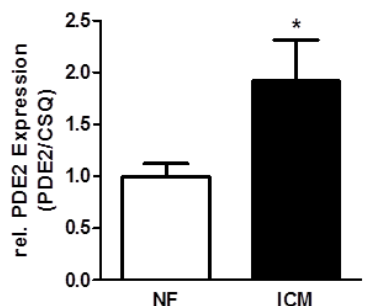

$\mathrm{E}$

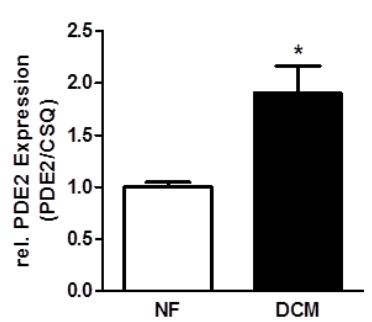

$\mathrm{F}$

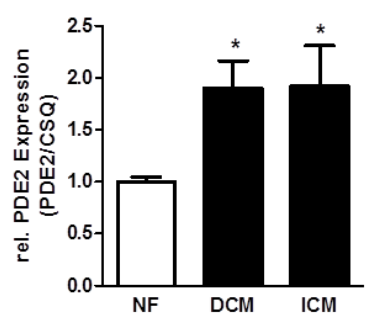

Abbildung 7: PDE2 ist in der menschlichen Herzinsuffizienz hochreguliert

Immunoblots der Phosphodiesterase-2 (PDE2)-Expression aus dem linken Ventrikel von Patienten mit End-Stage dilatativer Kardiomyopathie (DCM) oder ischämischer Kardiomyopathie (ICM) im Vergleich zu gesunden Spenderherzen. Graphen A-C PDE2-Expression unnormalisiert. D-F rel. PDE2-Expression normalisiert auf CSQ (NF) $n=5$ bis $6 .{ }^{*} \mathrm{p} \leq 0,05$ vs. NF. (Mehel et al. 2013) 


\subsubsection{PDE2 ist bei Patienten mit Aortenstenose nicht reguliert}

Interessanterweise zeigte sich kein Unterschied in der Expression der PDE2 in Herzmuskelgewebe von gesunden Spendern (NF) und in hypertrophiertem Myokardium von Patienten, die auf Grund einer Aortenstenose (AS) sich einer Aortenklappenersatzoperation unterziehen mussten. Die Ejektionsfraktion der Patienten war präoperativ $\geq 50 \%$.

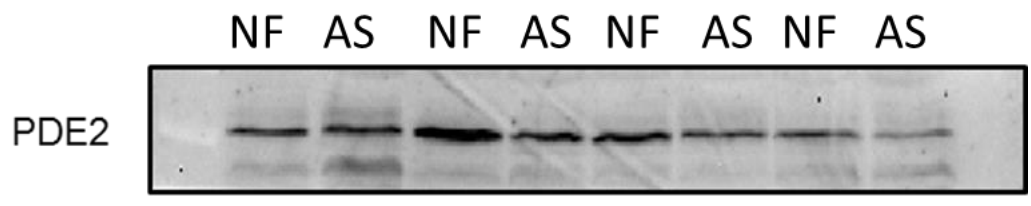

$\mathrm{CSQ}$
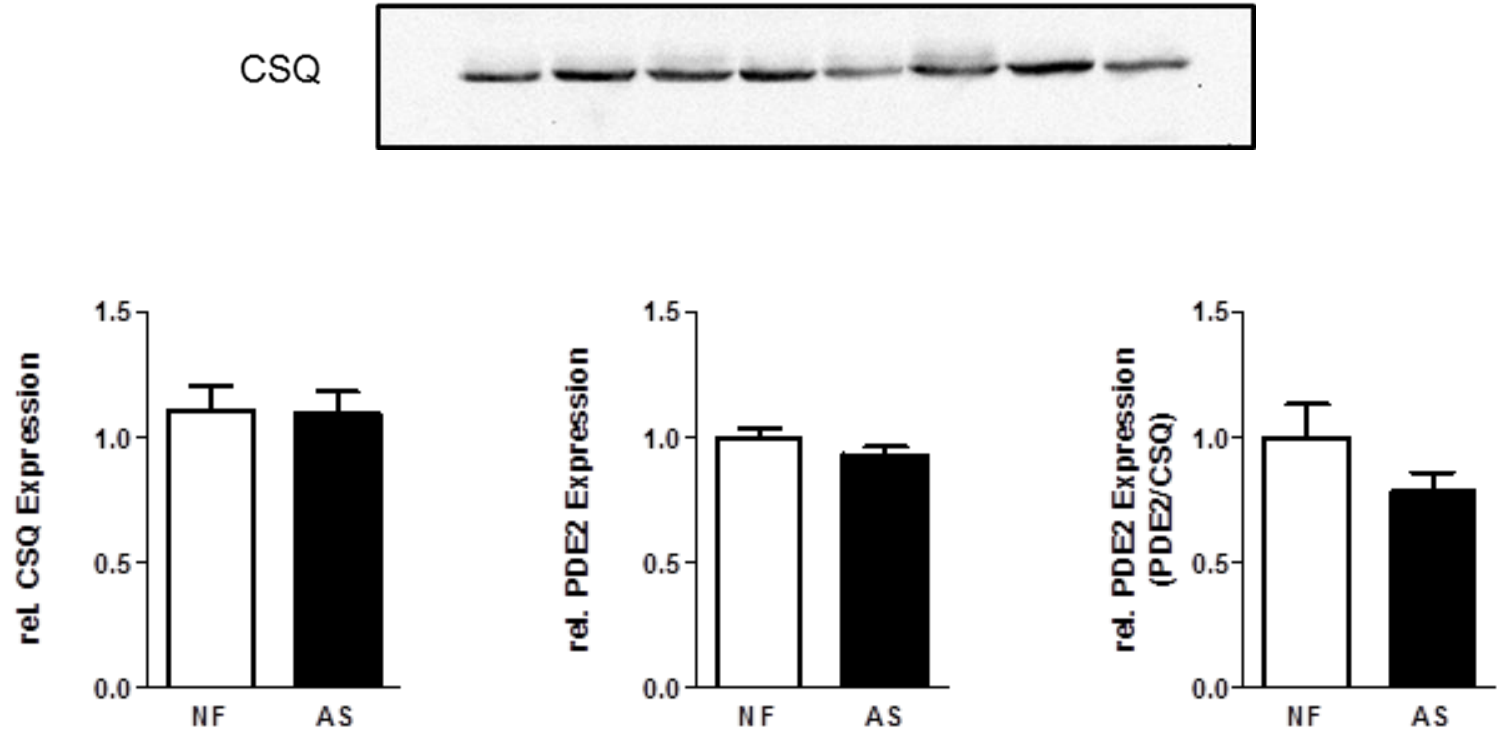

Abbildung 8: PDE2 ist bei Patienten mit Aortenstenose nicht reguliert

PDE2-Expression aus dem linken Ventrikel von Patienten mit Aortenstenose (AS) und erhaltener Ejektionsfraktion $\geq 50 \%$ verglichen mit gesunden Spenderherzen. Es zeigen sich keine signifikanten Unterschiede. PDE2-Expression normalisiert auf CSQ (NF) n=5 bis $6 .{ }^{*} \mathrm{p} \leq 0,05$ vs. NF. (Mehel et al. 2013) 


\subsubsection{PDE2-Expression ist unabhängig von einer Betablocker-Einnahme}

Um einen möglichen Einfluss einer Therapie mit Betablockern zu untersuchen, wurden in Proben von Patienten mit Kardiomyopathie und Betablocker-Einnahme in der Anamnese und Proben von Patienten ohne Betablocker-Vortherapie die PDE2-Expression mittels Western Blot bestimmt. Es zeigten sich keine signifikanten Unterschiede in den untersuchten Gruppen.
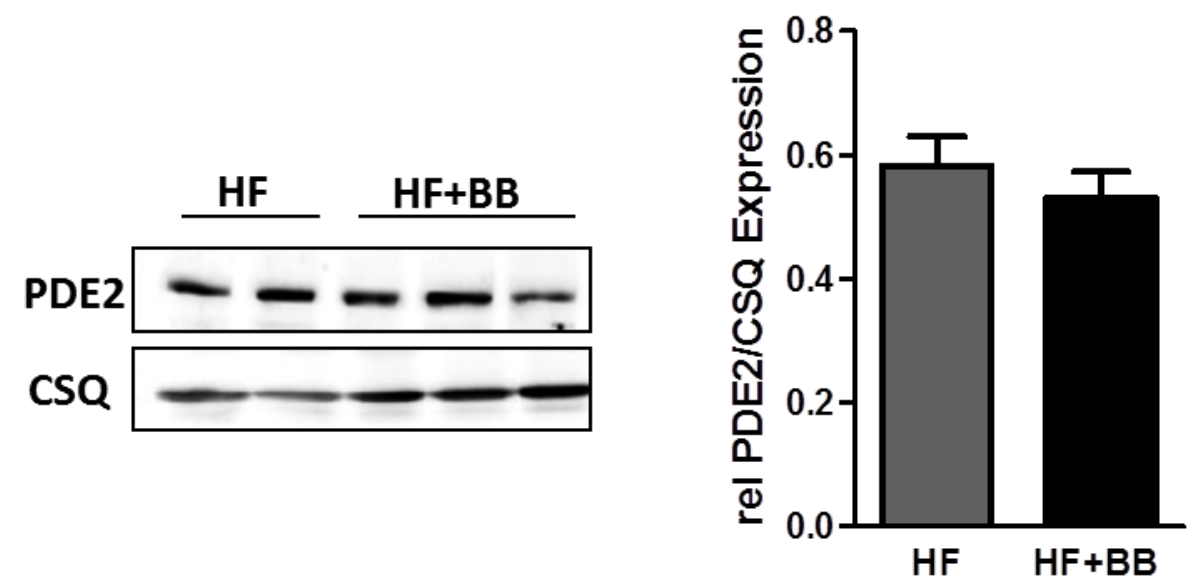

Abbildung 9: PDE2-Expression ist unabhängig von Betablocker-Einnahme

Links: Repräsentativer Auszug aus der Western Blot-Analyse mit anti-PDE2 (PDE2) und anti-CSQ (CSQ) Antikörpern. Rechts: Quantifizierung der PDE2-Expression normalisiert auf Calsequestrin (CSQ). Proben aus dem linken Ventrikel von Patienten mit Kardiomyopathie (HF) ohne und mit Betablocker-Therapie $(\mathrm{HF}+\mathrm{BB})$. Es zeigen sich keine signifikanten Unterschiede in den jeweiligen Untersuchungsgruppen; $\mathrm{n}=6$. (Mehel et al. 2013) 


\subsection{PDE2-Expression in der induzierten Herzinsuffizienz im Großtiermodell}

Auf Grund der bekannten Limitationen von menschlichen Herzgewebe-Proben, wie den teilweise nicht kontrollierbaren klinischen Bedingungen, wurden die Ergebnisse der PDE2-Blots der menschlichen Herzproben in einem gut etablierten Großtiermodell reevaluiert. In dem Modell wurden Mischlingshunde über eine im linken Ventrikel angebrachte, mit einem Schrittmacher verbundene Sonde mit einer Frequenz von 240 Schlägen pro Minute für eine Dauer von 14 Tagen stimuliert und so eine Herzinsuffizienz induziert (HF). Kontrolltiere (Sham) wurden operiert, aber nicht stimuliert. Die hämodynamischen Veränderungen waren typisch für eine Dilatative Kardiomyopathie (Li et al. 1999). Im Myokard der stimulierten Tiere (HF) fand sich in der proteinanalytischen Messung etwa die 2-Fache Konzentration von PDE2 im Vergleich $\mathrm{zu}$ den Kontrolltieren (Sham) und damit bestätigen sich die in den menschlichen Proben erhobenen Ergebnisse.
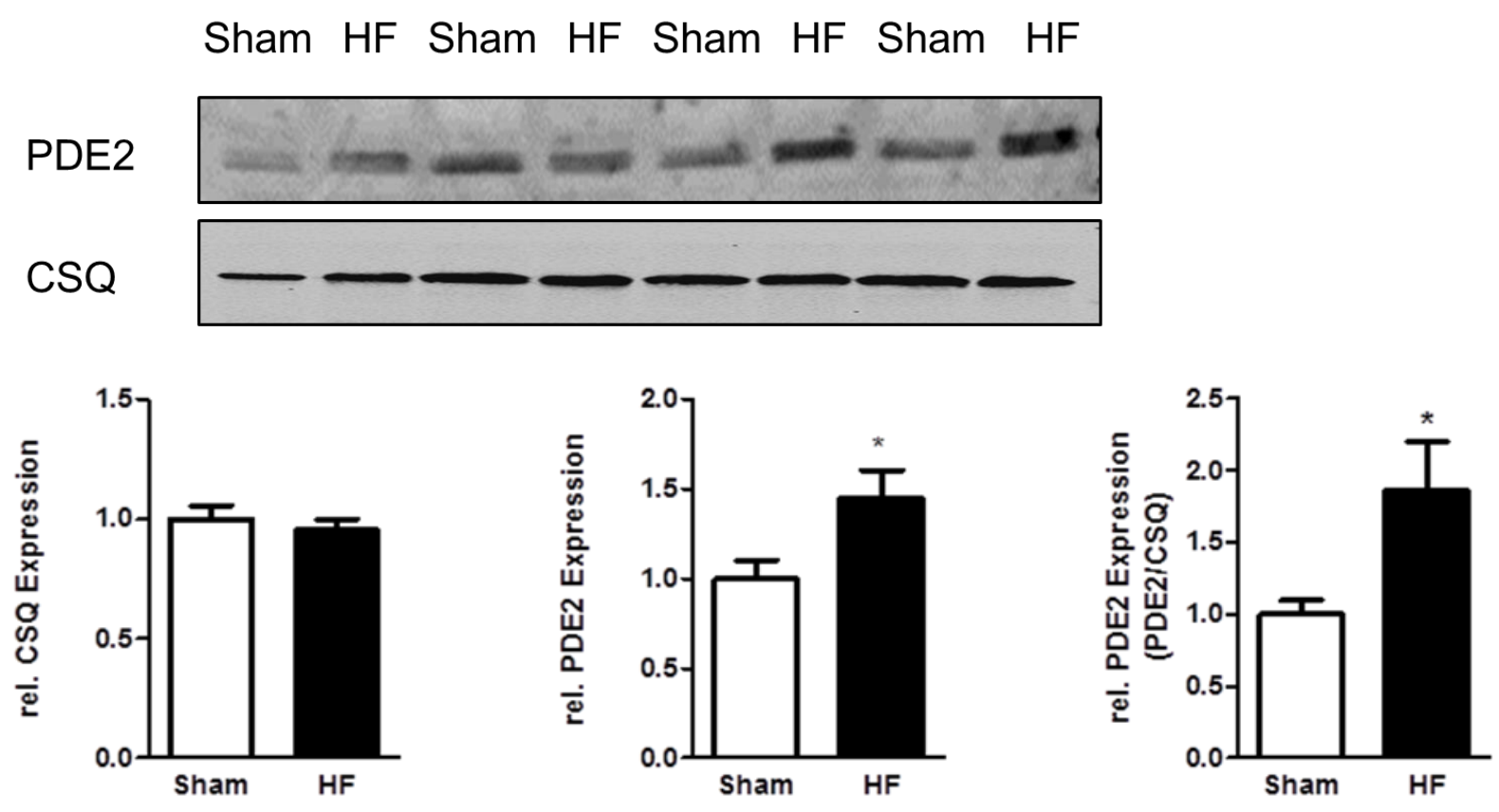

Abbildung 10: PDE2 ist in der experimentellen Herzinsuffizienz hochreguliert

Die Membran zeigt einen repräsentativen Ausschnitt des Proteinnachweises mittels anti-PDE2- und antiCSQ-Antikörpern. Der linke Graph zeigt die CSQ-Expression, der mittlere die unnormalisierte PDE2Expression, der rechte die auf CSQ-normalisierte PDE2 Expression von Hunden, bei denen durch Rapid Pacing eine Herzmuskelhypertrophie induziert wurde (HF), im Vergleich zu operierten, aber nicht stimulierten Tieren (Sham). $n=7$ bis $9 *_{p} \leq 0,05$ vs. Sham. (Mehel et al. 2013) 


\subsection{PDE2-Expression und -Aktivität im linksventrikulären Myokard von Ratten nach chronischer beta-adrenerger Stimulation durch Isoprenalin}

Um zu testen, ob die gemessene PDE2-Hochregulation im Gewebe der menschlichen Spender mit terminaler Herzinsuffizienz und die durch Rapid-Pacing induzierte künstliche Myokardhypertrophie im Modell der Hunde, ähnlich der bekannten pathologischen Runterregulation der $\beta_{1}$-Adrenorezeptoren, eine Folge chronischer pathologischer $\beta$-adrenerger Überstimulation ist, verwendeten wir ein Modell der chronischen Isoprenalinzufuhr. Wie unter 2.4 ausführlich beschrieben, wurden männliche Wistar-Ratten mit einem Gewicht von 240-300 g operativ mit subkutan implantierten osmotischen Minipumpen (Alzet Modell 2002) ausgestattet. Um die kontinuierliche Isoprenalin-Applikation von $2,4 \mathrm{mg} / \mathrm{kg} / \mathrm{d}$ Körpergewicht über einen Zeitraum von 5 Tagen zu erreichen, wurde jede Pumpe gewichtsadaptiert befüllt. Die Tiere erhielten zur Analgesie bis $4 \mathrm{~d}$ nach der Implantation $125 \mathrm{mg}$ Metamizol auf $1000 \mathrm{ml}$ Trinkwasser. Kontrolltieren wurden Minipumpen mit 0,9\% $\mathrm{NaCl}$ implantiert. 


\subsubsection{Herz- / Körpergewicht und ANP-Expression im Modell der chronischen adrenergen Stimulation}

Für die Bestimmung des Ausmaßes der Herzinsuffizienz wurde das Herzgewicht der Tiere bestimmt und auf das Körpergewicht normalisiert (HW/BW-Ratio). Bei den mit Isoprenalin behandelten Tieren (ISO) $(2,4 \mu \mathrm{g} / \mathrm{g} / \mathrm{Tag})$ entwickelte sich eine Herzmuskelhypertrophie, die sich in höheren Quotienten von Herz- zu Körpergewicht abbildete. Des Weiteren konnte über die Bestimmung der relativen Transkription des atrialen natriuretischen Peptids (ANP) die Induktion einer pathologischen Hypertrophie festgestellt werden. In den mit Isoprenalin behandelten Tieren fand sich eine 8-Fach höhere Konzentration von ANP-mRNA.
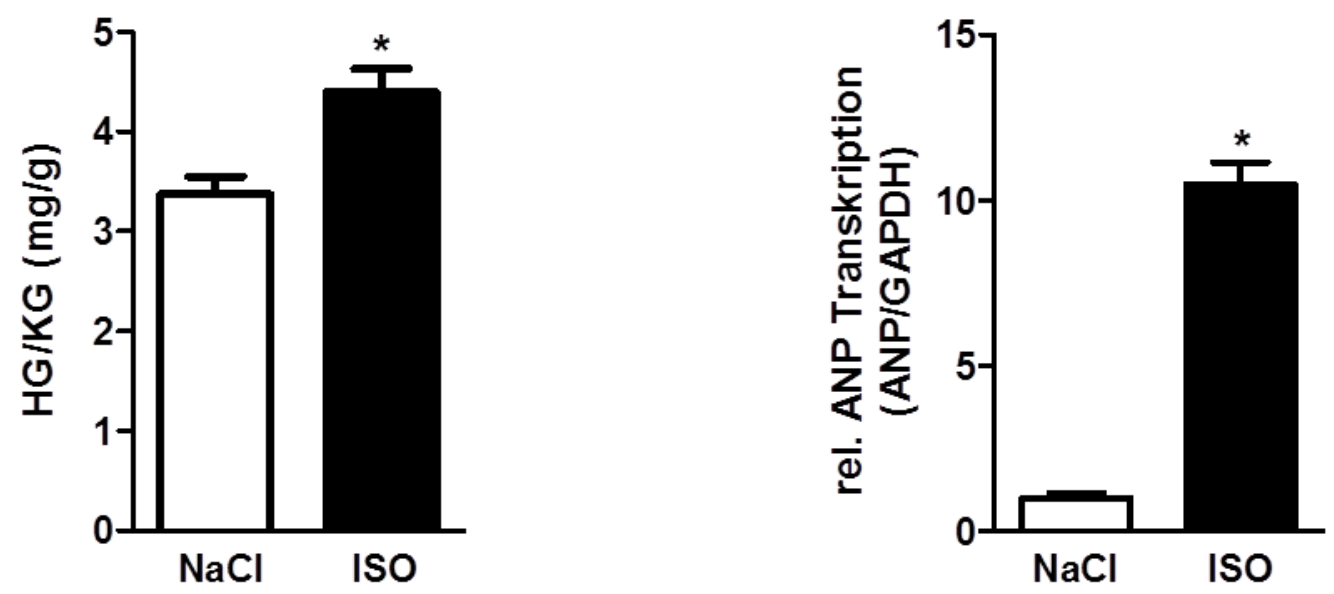

Abbildung 11: Auswirkung von chronischer B-adrenerger Stimulation auf Herzgewicht und ANP-

Transkription

Links sind die Herzgewichte männlicher Wistar-Ratten behandelt mit Isoprenalin (ISO) $(2,4 \mu \mathrm{g} / \mathrm{g} / \mathrm{Tag})$ oder die mit Natriumchlorid $(\mathrm{NaCl})(0,9 \% \mathrm{NaCl})$ behandelten Tiere, normalisiert auf das Körpergewicht (HG/KG) dargestellt. Die mit Isoprenalin stimulierten Tiere zeigen ein signifikant erhöhtes Herzgewicht, $\mathrm{n}=14,{ }^{*} \mathrm{p} \leq 0,05$ vs. ISO. Rechts sind die mRNA-Spiegel des atrialen Naturetischen Peptids (ANP) normalisiert auf Glycerinaldehyd -3-phosphat-Dehydrogenase (GAPDH); $\mathrm{n}=4$ bis $6,{ }^{*} \mathrm{p} \leq 0,05$ vs. ISO. (Mehel et al. 2013) 


\subsubsection{PDE2-Expression im Isoprenalin-Modell ist auf Ebene der Transkription reguliert}

Die Tiere, die der chronischen beta-adrenergen Stimulation ausgesetzt waren, zeigten eine etwa 2Fach erhöhte PDE2-Expression und bestätigten somit die Ergebnisse aus der menschlichen Herzinsuffizienz und aus dem Großtiermodell. Um zu untersuchen, ob die erhöhte PDE2Expression Folge einer vermehrten Transkription ist, wurden mittels Real-Time-PCR die PDE2mRNA-Spiegel bestimmt. In den mit Isoprenalin stimulierten Herzen fanden sich ca. 4-Fach höhere PDE2-mRNA-Spiegel. Dies liefert Hinweise darauf, dass die Regulation der PDE2 im Rahmen der Herzinsuffizienz durch Transkription beeinflusst wird.

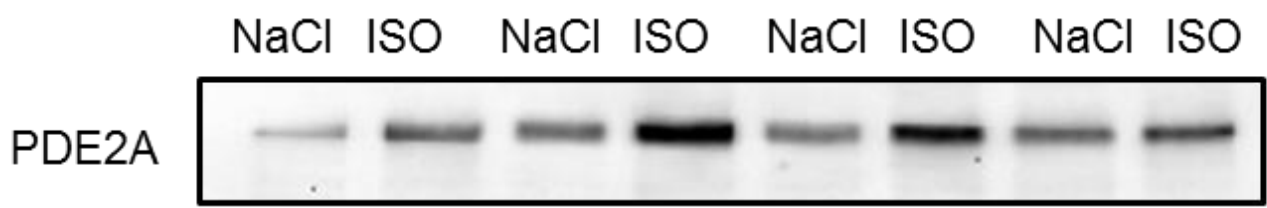

CSQ
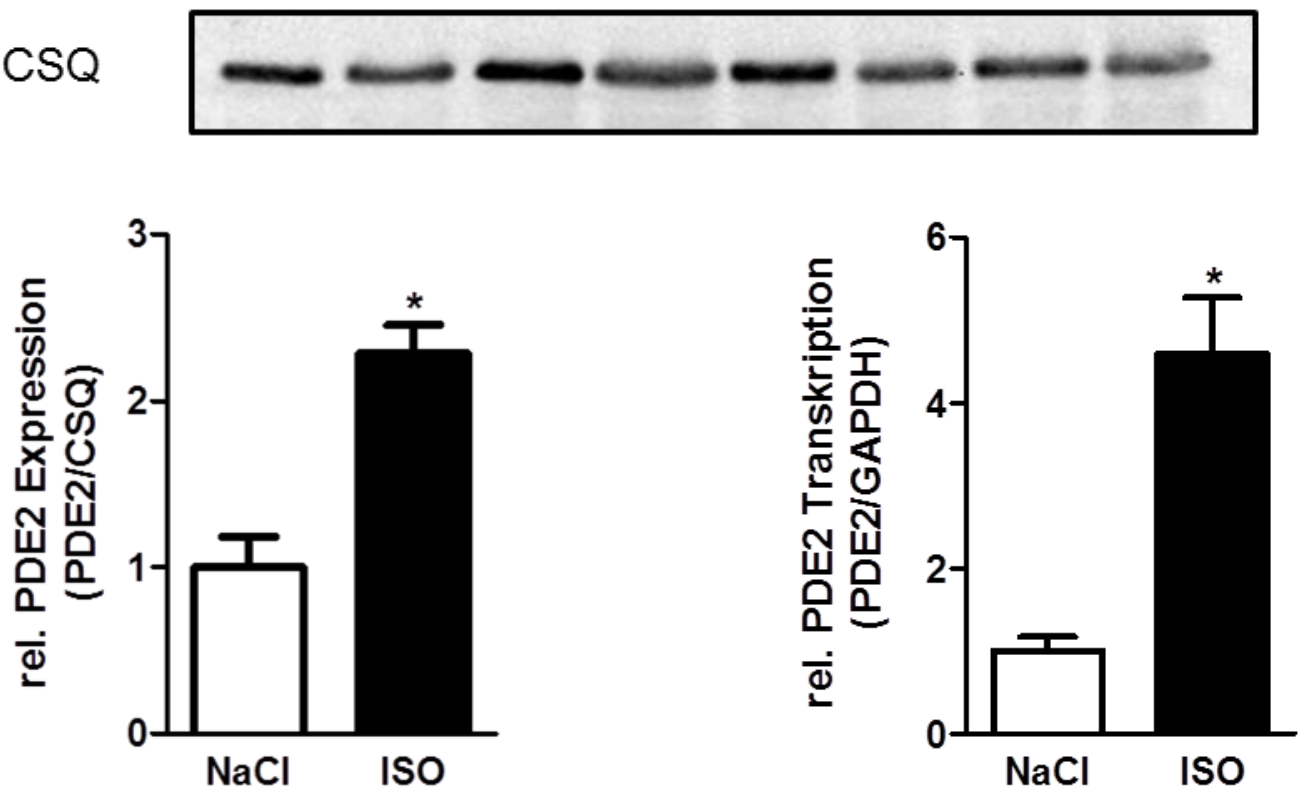

Abbildung 12: PDE2 ist in der durch Isoprenalin induzierten Herzinsuffizienz hochreguliert

Links: Der Graph repräsentiert die auf CSQ normalisierte PDE2-Expression in mit Isoprenalin (2,4 $\mu \mathrm{g} / \mathrm{g} / \mathrm{Tag}$ ) stimulierten Tieren (ISO) im Vergleich zu den mit Natriumchlorid behandelten $(0,9 \% \mathrm{NaCl})$ Kontrolltieren $(\mathrm{NaCl})$. Es zeigte sich eine signifikante, um das ca. 2-Fach höhere PDE2-Expression in den durch Isoprenalin hypertrophierten Herzen, verglichen mit den Kontrollen. Die Membran zeigt die Proteinanalyse mittels anti-PDE2 und anti-CSQ-Antikörper. $n=8 * \mathrm{p} \leq 0,05$ vs. ISO. Rechts:

Linksventrikuläre PDE2-mRNA-Konzentrationen normalisiert auf GAPDH. $n=5$ bis $6,{ }^{*} \mathrm{p} \leq 0,05$ vs. ISO. (Mehel et al. 2013) 


\subsubsection{PDE2- cAMP- und cGMP-Aktivität im Rattenmodell}

Um zu untersuchen, ob die auf Proteinebene erhöhte Expression der PDE2 im linken Ventrikel ebenfalls mit einer gesteigerten Enzymaktivität einhergeht, wurde die PDE2-abhängige cAMPund cGMP-Hydrolyse mit Hilfe von $10^{5} \mathrm{cpm}{ }^{3} \mathrm{H}$ - gekoppeltem cAMP und cGMP bestimmt. Die Aktivität der PDE2 wurde als die Fraktion cAMP-PDE- bzw. cGMP-PDE-Aktivität definiert, die durch die Zugabe von 100 nM BAY 60-7550 inhibiert wurde, wie durch Thompsen und Applemann beschrieben (Thompson und Appleman 1971). BAY 60-7550 ist ein hoch spezifischer PDE2-Inhibitor. Die Messungen ergaben eine ca. 4-Fache Steigerung der relativen cAMP-PDE2-Aktivität und ca. eine Verdopplung der cGMP-PDE2-Aktivität in den mit Isoprenalin behandelten Herzen im Vergleich zu den Kontrollen. Höhere PDE2-Protein-Spiegel resultieren in einer erhöhten PDE2-Aktivität. Die Messungen der PDE2-Aktivität wurden mit Frau Dr. Mehel am French institute of Health and Medical Research, Paris durchgeführt.
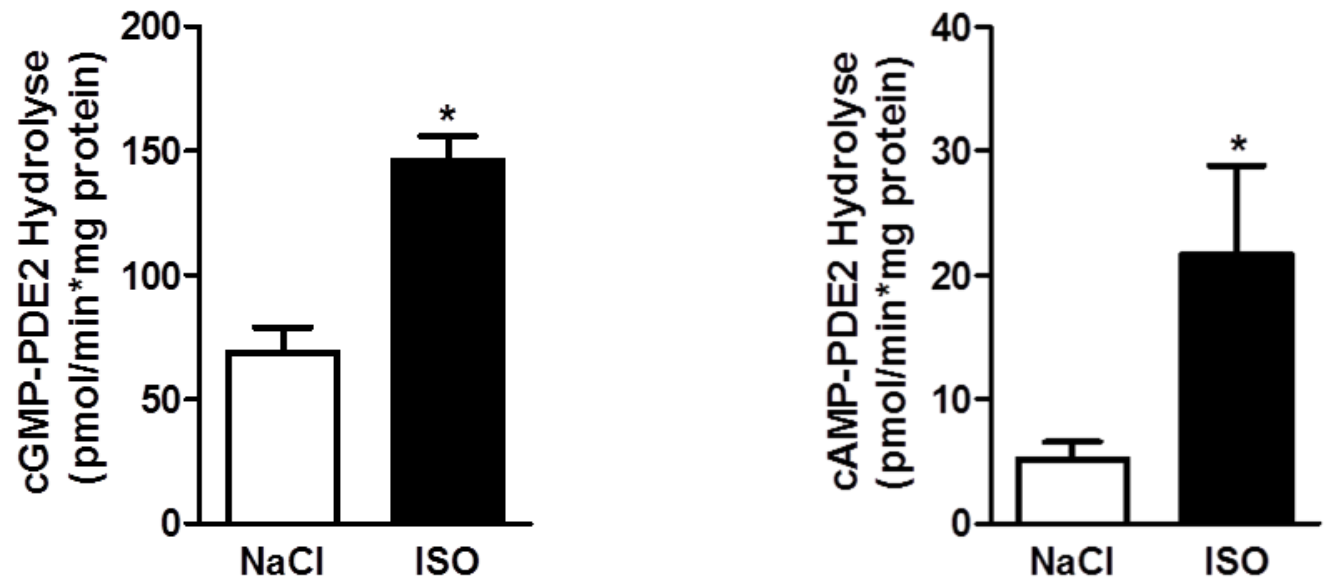

Abbildung 13: Höhere PDE2-Protein-Spiegel resultieren in einer erhöhten PDE2-Aktivität

Die PDE2-Aktivität in Gewebe aus dem linken Ventrikel wurde durch ein Radio-Immunoassay mit Tritium-gekoppelten cAMP und cGMP bestimmt. Die Graphen zeigen die PDE2-Aktivität, definiert als die durch $100 \mathrm{nmol}$ inhibierte cAMP/cGMP-PDE2-Aktivität. Es zeigt sich eine signifikante um das ca. 4Fach erhöhte cAMP-PDE2-Aktivität und eine Verdopplung der cGMP-PDE2-Aktivität in den Isoprenalin behandelten Herzen im Vergleich zu den Kontrollen. $\mathrm{n}=6,{ }^{*} \mathrm{p} \leq 0,05$ vs. ISO. (Mehel et al. 2013) 


\subsection{PDE2-Überexpression schützt Herzmuskelzellen vor $\alpha / \beta$-adrenerg induzierter Hypertrophie}

Kardiale Hypertrophie ist ein frühes Zeichen der Stress-induzierten Herzinsuffizienz. Um zu sehen, ob eine Überexpression von PDE2 einen protektiven Einfluss auf die durch $\alpha$ - und $\beta$ adrenerge Stimulation hervorgerufene Hypertrophie in Herzmuskelzellen hat, wurden neonatale Ratten-Kardiomyozyten für 24 Stunden mit Ad-EGFP und Ad-PDE2/EGFP transfiziert. Um eine Unterscheidung zwischen $\alpha$ - und $\beta$-adrenerg vermittelter Hypertrophie treffen zu können, wurden die selektiv wirkenden Agonisten Phenylephrin ( $\alpha_{1}$-Adrenozeptor-Agonist) und Noradrenalin ( $\alpha$ - und $\beta$-Adrenozeptor-Agonist) gewählt. Ein Drittel der Zellen wurde mit Phenylephrin und ein Drittel mit Noradrenalin behandelt. Das letzte Drittel wurde als Kontrolle unbehandelt gelassen. Nach einer weiteren Inkubationszeit von $24 \mathrm{~h}$ wurde die erfolgreiche Infektion mittels Nachweis eines EGFP-Signals bei $488 \mathrm{~nm}$ Wellenlänge überprüft, die Zellen mikroskopiert und die Zellfläche bestimmt. In der nicht stimulierten Gruppe zeigte sich kein Unterschied in der Zellfläche der mit Ad-EGFP und Ad-PDE2/EGFP transfizierten Zellen. Daraus lässt sich schließen, dass eine Überexpression von PDE2 keinen Einfluss auf die Zellfläche und somit kein hypertrophes Potential hat. Die PDE2-überexprimierenden Zellen waren gegen die durch $\alpha$ - und $\beta$-adrenerge Stimulation verursachte Hypertrophie geschützt und hatten eine signifikant kleinere Zellfläche. Diese Ergebnisse lassen den Schluss zu, dass eine PDE2-Überexpression mit einer einhergehenden Steigerung der cAMP- und cGMP-PDE2Aktivität einen protektiven Einfluss auf die Kardiomyozyten unter pathologischer chronischer $\alpha$ und $\beta$-adrenerger Exposition hat. Die Messungen der Zelloberfläche wurden mit Frau Dr. Mehel am French Institute of Health and Medical Research durchgeführt. (Mehel et al. 2013) 


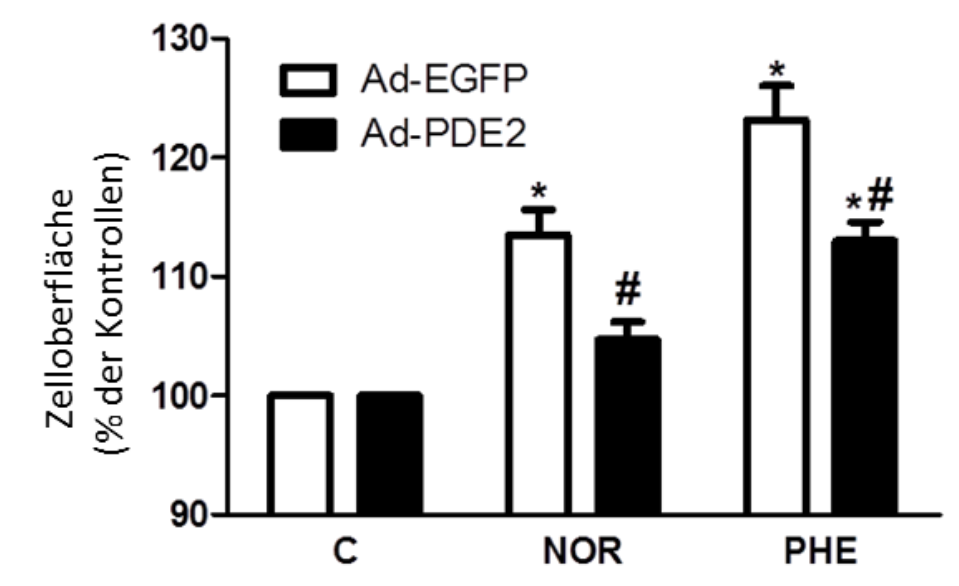

Abbildung 14: PDE2-Überexpression schützt Herzmuskelzellen vor durch $\alpha$ - und $\beta$-adrenerge Stimulation hervorgerufener Hypertrophie

Die Abbildung zeigt neonatale Ratten-Herzmuskelzellen infiziert mit Ad-EGFP (weiß) und Ad-PDE2 (schwarz) und einer Stimulation mit $10 \mu \mathrm{mol} / 1$ Noradrenalin (NOR) und Phenylephrin (PHE), sowie Kontrollen (C) für 24 h. Die Graphen zeigen die ermittelten Zelloberflächen in \%, bezogen auf die jeweilige Kontrolle. $n=5$ bis $6,{ }^{*} \mathrm{p} \leq 0,05$ vs. C; $\# \mathrm{p} \leq 0,05$ vs. Ad-EGFP vs. Ad-PDE2. (Mehel et al. 2013) 


\subsection{PDE2-Lokalisation}

\subsubsection{PDE2A3-Lokalisation in adulten Ratten-Herzmuskelzellen}

Da bislang in der Literatur keine einheitlichen Daten zur intrazellulären Lokalisation der PDE2A3 vorliegen, wurden adulte Ratten-Herzmuskelzellen für 48 Stunden mit AdEGFP/PDE2A3 und Ad-EGFP mit einer MOI von 100 infiziert. Nach Immunfluoreszenz-

färbung mit DAPI (blau), EGFP (grün) und anti-PDE2 (rot), wurden die Zellen fixiert und am konfokalen Mikroskop betrachtet und Bilder gemacht. Wie in der unten stehenden Abbildung gut erkennbar, sind die Zellkerne durch DAPI blau gefärbt und das grüne EGFP-Signal bildet die Actin- und Myosin-Struktur nach. Die immunhistologische Färbung mit anti-PDE2 zeigt in den mit Ad-PDE2A3 infizierten Zellen ein Signal entlang definierter Linien, was auf Lokalisation entlang der Z-Linie hindeuten könnte.
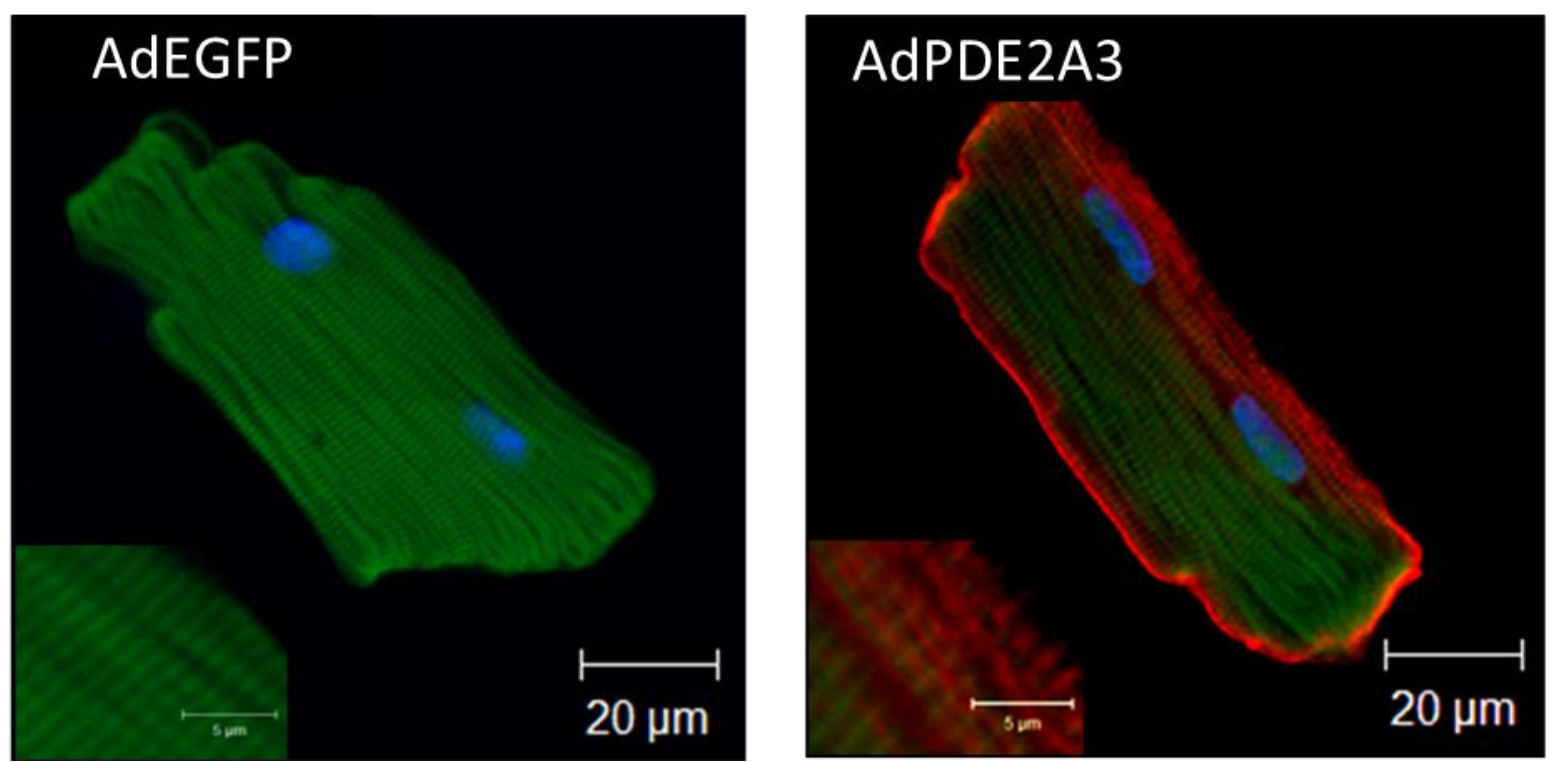

Abbildung 15: Viral überexprimierte PDE2A3 ist entlang definierter Linien lokalisiert

Die linke Graphik zeigt eine mit Ad-EGFP infizierte adulte Ratten-Herzmuskelzelle, die rechte eine mit Ad-PDE2A3/EGFP. Der Maßstab beträgt $20 \mu \mathrm{m}$. Der sich im Bild links unten befindende Ausschnitt hat eine Vergrößerung von $5 \mu \mathrm{m}$. 


\section{Diskussion}

Unter Stresssituationen benötigt der Körper die Möglichkeit, kurzfristig und sehr fein abgestimmt das Herzminutenvolumen um das 5-Fache zu steigern, um eine ausreichende Versorgung der Organe und des Gewebes sicherzustellen. Die Kontrolle der Herzaktivität unterliegt dem Sympathischen und Parasympathischen Nervensystem. Durch die Bindung der Katecholamine an die $\beta$-Adrenozeptoren wird über ein regulatorisches G-Protein der Stimulus auf die Adenylatcyclase übertragen und damit die Bildung von cAMP angeregt. Das intrazelluläre cAMP, der sekundäre Botenstoff, bedingt eine Zunahme der Proteinkinase A und dadurch einen erhöhten $\mathrm{Ca}^{2+}$-Einstrom und eine Zunahme des Herzzeitvolumens.

Im Rahmen dieser Arbeit wurde zum ersten Mal der Nachweis erbracht, dass die Expression der PDE2 im Rahmen der Herzinsuffizienz beim Menschen reguliert ist. Im Myokard von Patienten mit terminaler Herzinsuffizienz zeigte sich eine um den Faktor 2 erhöhte PDE2-Expression. Es konnte nachgewiesen werden, dass die Hochregulation der PDE2-Expression unabhängig von einer Betablocker-Einnahme ist. Auf Grund der bekannten Limitationen von menschlichen Gewebeproben, wurde die erhöhte PDE2-Expression in einem Großtiermodell bestätigt. Im chronischen Isoprenalin-Stressmodell konnte der Zusammenhang von erhöhter PDE2Expression als Konsequenz auf chronische $\beta$-adrenerge Stimulation hergestellt werden. Die vermehrte Produktion von PDE2-Protein ist durch eine vermehrte Transkription von PDE2mRNA bedingt. Die erhöhten PDE2-Spiegel gehen mit einer erhöhten hydrolytischen Aktivität für cAMP einher. Eine virale Überexpression von PDE2 in neonatalen Ratten-Kardiomyozyten schützt die Zellen vor durch $\beta$-adrenerger Stimulation hervorgerufener Hypertrophie. (Mehel et al. 2013)

\subsubsection{PDE2 ist in der Herzinsuffizienz hochreguliert}

Für die PDE3A und PDE4D ist in der menschlichen Herzinsuffizienz eine verminderte Expression beschrieben (Ding et al. 2005, Lehnart et al. 2005). Für die PDE 5 ist bekannt, dass sie im gesunden Myokard nur sehr gering exprimiert wird, in insuffizienten Herzen konnte ein gesteigerter Proteingehalt und ein Einfluss auf die Kontraktilität nachgewiesen werden (Shan et al. 2012). Die absolute Menge an PDE2-Protein in gesundem Myokard ist ebenfalls relativ gering und eine Inhibition der PDE2 hat nur wenig Einfluss auf die cAMP-Hydrolyse in gesunden Kardiomyozyten. Unter normalen Bedingungen wird der Großteil der Hydrolyse von cAMP im Myokard durch die PDE3A verursacht. Die PDE3 besitzt eine hohe Hydrolyserate für cAMP und eine hohe Affinität zu cGMP. Die hohe Affinität und sehr niedrige Hydrolyserate der PDE3 
zu cGMP, machen dieses zu einem kompetitiven Inhibitor für die cAMP-Hydrolyse (Beavo 1995). Der Einfluss der PDE3 in der Herzaktion wird deutlich in ihrer Rolle für die Regulation der kardialen Kontraktion über eine Modulation des $I_{c a}$ durch Veränderung der cAMPabhängigen Phosphorylierung (Fischmeister und Hartzell 1990). Vereinfacht lässt sich sagen, dass cGMP die PDE2 aktiviert und gleichzeitig die PDE3 inhibiert (Degerman et al. 1997). Die Daten in dieser Arbeit zeigen zum ersten Mal, dass PDE2 in der menschlichen Herzinsuffizienz hochreguliert ist. Diese um rund 2-Fach erhöhte Proteinmenge deutet bereits auf eine mögliche pathophysiologische Bedeutung der PDE2 in der kardialen Hypertrophie hin. Es lässt sich somit vermuten, dass die im Rahmen der Herzinsuffizienz stattfindende vermehrte Produktion von cGMP die PDE3 abhängige cAMP-Hydrolyse durch Bindung von cGMP vermindert wird und auf der anderen Seite die PDE2 durch die Bindung von cGMP in ihrer cAMP-Hydrolyseaktivität gesteigert wird. Auf Grund der bekannten Limitationen in der Verwendung von menschlichen Spendergeweben in wissenschaftlichen Fragestellungen, wie nicht einheitlich kontrollierbare klinische Einflüsse, wurden die Ergebnisse in einem Großtiermodell reevaluiert und die sich anschließenden funktionellen Daten in unter Laborbedingungen verfügbaren Kleintiermodell erhoben. (Mehel et al. 2013)

Die von Bristow et al. gezeigte Wiederherstellung der normalen Herzphysiologie mit Runterregulation von $\beta$-Adrenorezeptoren durch Betablocker-Therapie (Bristow et al. 1982), konnte nicht auf die Regulation der PDE2 übertragen werden. Es fanden sich keine Unterschiede in der Expression der PDE2 in Patienten, die mit Betablockern behandelt wurden im Vergleich zu unbehandelten. Dieses kann auf einen anderen Regulationsmechanismus der Expression der PDE2 in der Herzinsuffizienz hinweisen. Ebenfalls zeigten sich keine Unterschiede in der Expression der PDE2 in den Herzen von gesunden Spendern und Patienten mit Aortenstenose. Diese zeichnen sich durch eine beginnende Myokardhypertrophie bei noch erhaltenen Herzfunktion aus. Diese Ergebnisse lassen den Schluss auf eine Zunahme des Einflusses der PDE2 mit zunehmender Dekompensation der Herzinsuffizienz und nicht im Beginn des Remodeling $\mathrm{zu}$ und geben Anlass $\mathrm{zu}$ weiteren Untersuchungen im finalen Stadium der Herzinsuffizienz. (Mehel et al. 2013)

\subsubsection{PDE2-Hochregulation als Folge von chronischer $\beta$-adrenerger Stimulation}

Das in der Arbeit verwendete Modell der Langzeitapplikation mit Isoprenalin zeigt viele Parallelen zur menschlichen Herzinsuffizienz. Es zeigt sich ein erhöhtes Herz-/KörpergewichtVerhältnis als Indikator für eine Herzhypertrophie sowie die Induktion des fetalen Genprogramms im Herzgewebe der stimulierten Tiere (Wittköpper et al. 2010, El-Armouche et al. 2008). In dem Modell konnten ebenfalls höhere Spiegel an PDE2 nachgewiesen werden. So, dass die vermehrte Expression von PDE2 als Folge einer Zunahme von beta-adrenerger 
Stimulation gewertet werden kann. Die mRNA-Transkription und auch die PDE2-spezifische cAMP- und cGMP-Hydrolyse waren erhöht. Diese Ergebnisse lassen den Schluss zu, dass die Regulation der PDE2-Expression in der Herzinsuffizienz auf der Ebene der Transkription abläuft und mit einer vermehrten katalytischen Aktivität einhergeht. (Mehel et al. 2013)

\subsubsection{PDE2-Überexpression schützt vor $\alpha / \beta$-AR induzierter Hypertrophie}

Die Stimulation mit Katecholaminen führt durch eine veränderte Genexpression und einer Zunahme der Proteinsynthese zu Zellhypertrophie. Neonatale Ratten-Kardiomyozyten, die durch adenovirale Transfektion PDE2 überexprimieren, zeigen geringere Hypertrophie bei Stimulation mit Norepinephrin (Noradrenalin) und Adrenalin. Die antihypertrophen Eigenschaften einer PDE2-Überexpression bei erhaltener Kontraktilität (Daten nicht gezeigt) lassen den Schluss zu, dass die Hochregulation ein kompensatorischer Mechanismus sein könnte, der das Myokard, ähnlich der bekannten $\beta_{1}$-AR Runterregulation, schützt. Es muss beachtet werden, dass sich die hier gefundenen Ergebnisse nur über die Oberflächenbestimmung und nicht durch Hypertrophiemarker stattgefunden hat. Des Weiteren handelt es sich um viral überexprimierte PDE2 und eine 2D-Kultur. Die gesehenen Effekte müssen sich nicht zwingend auf das lebende Herz übertragen lassen. In der im August 2015 veröffentlichten Arbeit von Zoccarato (Zoccarato et al. 2015) kommen die Autoren zu dem Schluss, dass sich eine Inhibition der PDE2 protektiv auf die Zellhypertrophie auswirkt und schließen daraus, dass sich eine Inhibition der PDE2 therapeutisch nutzen lassen könnte. Kontroverse Daten sind in diesem frühen Stadium der Forschung nicht überraschend und liegen häufig in unterschiedlichen methodischen Ansätzen bzw. konzeptionellen Ausgangspunkten begründet. Die hieraus entstehenden Diskussionen beschleunigen in der Regel die Entwicklung des Feldes, da sie dazu zwingen, die eigenen Ergebnisse und Hypothesen fortwährend kritisch zu hinterfragen, die Experimente noch genauer zu planen und mit immer detaillierteren Methoden zu arbeiten. In der Literatur gibt es immer mehr Beispiele dafür, dass insbesondere in komplexen pathologischen Modellen ein und dasselbe Molekül kontextbezogen durchaus auch diametral entgegensetzte Funktionen ausüben kann, z.B. abhängig vom genetischen Hintergrund, Erkrankungsstadium, Komorbiditäten und/oder Komedikation. Der scheinbare Konflikt der Daten bzw. Hypothesen zeigt die dringende Notwendigkeit weiterer detaillierter Versuche zur Rolle der PDE2 im Herzen auf. Zum Beispiel könnten Experimente zur zellulären Lokalisation der PDE2 und insbesondere der Modulation von spezifischen cAMP-Pools bei akuter und chronischer PDE2-Überexpression sowie deren Hemmung Daten über die Effekte der PDE2 auf die kardiale Hypertrophie liefern. (Mehel et al. 2013) 


\subsubsection{Viral überexpremierte PDE2A3 stellt sich entlang definierter Linien des Sarkomers dar}

In einer Vielzahl von Geweben wurden Phosphodiesterasen nachgewiesen. Ein Nachweis der PDE2 ist bis dato im Herzen, der Leber, der Nebenniere, im Gehirn, in Endothelzellen und Makrophagen erbracht worden (Martins et al. 1982, Bender und Beavo 2006). Aus dem PDE2kodierenden Gen sind 3 verschiedene Spleißvarianten der PDE2 bekannt: PDE2A1 (Sonnenburg und Beavo 1991), PDE2A2 (Yang et al. 1994), PDE2A3 (Sadhu et al. 1999). Sie unterscheiden sich in ihrer Struktur nur in den N-terminalen Aminosäuren. Es wird davon ausgegangen, dass das N-terminale Ende für die Lokalisation verantwortlich ist (Rosman et al. 1997). Als erstes wurde 1982 die Spleißvariante PDE2A1 als lösliches Protein aus bovinen Herzen isoliert (Martins et al. 1982). Darauf folgend konnten aus Rattenleber sowohl eine membrangebundene, als auch eine cytosolische PDE2-Variante isoliert werden. Es konnten keine Unterschiede in den katalytischen Eigenschaften der cytosolischen und der membrangebundenen Formen festgestellt werden (Pyne et al. 1986).

Die Löslichkeit der PDE2A1 kommt durch eine $\mathrm{N}^{\alpha}$-Acetylierung des $\mathrm{N}$-Terminuses zustande. Der Mechanismus der $\mathrm{N}^{\alpha}$-Acetylierung am $\mathrm{N}$-Terminus wurde bei der Calmodulin-abhängigen PDE1 beschrieben (Novack et al. 1991). Es konnten keine weiteren posttranslationalen Veränderungen der PDE2A1 im Vergleich zu den membrangebundenen Formen festgestellt werden. Für den Verankerungsmechanismus der PDE2A2 ist zum einen ein stark hydrophobes N-terminales Segment beschrieben (Yang et al. 1994), zum anderen wird über Protein-ProteinInteraktionen oder durch Palmitoylierung, einem Prozess bei dem Palmitat an Cysteinreste gebunden wird, (Noyama und Maekawa 2003) diskutiert. Die durch Triton X-100 lösliche Bindung der PDE2A3 wird durch N-Myristoylierung, eine Anhängung von Myristat an einen Glycinrest des Proteins am N-Terminus, bedingt (Russwurm et al. 2009).

Da die PDE2 basal nur sehr gering exprimiert wird, wurde auf eine virale Überexpression zurückgegriffen. Die adenovirale Überexpression von PDE2A3 in adulten RattenKardiomyozyten zeigt die PDE2A3 an der Membran entlang der Sarcomerischen Z-Linie befestigt. Die Lokalisation an der Z-Linie ist mit den durchgeführten Färbungen nicht eindeutig belegbar, da keine Färbungen zur Colokalisation oder spezifische Färbung der Z-Linie z. B. mit Sacromeric $\alpha$-Actinin durchgeführt wurde. Die Daten der Arbeitsgruppe von Zoccarato (Zoccarato et al. 2015) stützen die Hypothese, dass die PDE2A an der Z-Linie colokalisiert ist, sie zeigten, die PDE2A zu ca. 80 \% mit der Z-Bande colokalisiert. Diese mögliche Lokalisierung der PDE2 an der sarcomerischen Z-Linie könnte ein Hinweis auf lokale Effekte und Kompartimentierung der cAMP-Hydrolyse durch Phosphodiesterasen sein. Auch lassen sich dadurch Rückschlüsse auf die protektive Wirkung der PDE2 in den mit Katecholaminen 
Diskussion

gestressten Zellen ziehen. Die relativ geringe cAMP-Hydrolyse der PDE2 von weniger als $5 \%$ an der gesamten PDE-Aktivität in der Kardiomyozyte und die gegenüberstehende potente Modulation katecholaminer Effekte auf intrazelluläre $\mathrm{Ca}^{2+}$ Transienten und Kontraktilität weisen darauf hin, dass die PDE2 eine große Rolle in der lokalen Kontrolle von cAMP nach $\beta$-ARStimulation besitzt (Mongillo et al. 2006). Kritisch zu beachten ist, dass die in dieser Arbeit nachgewiesene Lokalisation durch eine artifizielle Expression nachgewiesen wurde und nicht der endogenen Lokalisation entsprechen muss. 


\subsection{Limitationen}

Die Rolle der PDE2 wurde in verschiedenen Spezies, einschließlich im Menschen untersucht. Es sind verschiedene Isoformen und Expressionsmuster in unterschiedlichen Spezies bekannt (Zaccolo und Movsesian 2007, Fischmeister et al. 2006). Da die meisten hier gezeigten funktionellen Versuche nicht im Menschen, sondern im Tiermodell durchgeführt worden sind, könnten die Regulation und der Einfluss der PDE2 auf den Ventrikel im Menschen auf Grund der Artendiversität der PDE-Isoformen in den unterschiedlichen Spezies anders sein. Die bisher vorhandenen Inhibitoren der PDE2 sind bislang nur in vitro untersucht worden, transgene Tiermodelle für einen tieferen Einblick der Rolle der PDE2 in der Herzinsuffizienz existierten zum Zeitpunkt der Untersuchungen nicht. Deshalb wurden auf adenovirale Überexpression und Inhibition in vitro zurückgegriffen. Diese Ergebnisse müssen sich nicht zwangsläufig auf die komplexe Regulation der Phosphodiesterasen in vivo übertragen lassen. (Mehel et al. 2013)

\subsection{Klinische Relevanz und Neuheit der Ergebnisse}

Da die Herzinsuffizienz eine der weitverbreitetsten Todesursachen in der westlichen Welt ist und die aktuellen Therapien der Herzinsuffizienz trotz ihrer Komplexität leider nur moderate Ergebnisse liefern, bedarf es neuer Therapien. Neue Erkenntnisse über die Pathophysiologie der Herzinsuffizienz liefern neue therapeutisch nutzbare Ansatzpunkte. Vielfach wurden bereits die positiven Effekte von erhöhten cGMP-Spiegeln in der Herzinsuffizienz untersucht, hervorgerufen entweder durch eine Inhibition der cGMP-hydrolysierenden PDE5 oder durch eine Aktivierung der löslichen Guanylylcyclase (Lee und Kass 2012). Die Ergebnisse dieser Arbeit untermauern die anfängliche Hypothese, dass über eine indirekte Verstärkung des cGMPSignalweges die Herzaktion entspannt werden kann und so die negativen Einflüsse der exzessiven katecholaminen Stimulation in der HF abgeschwächt werden können. (Mehel et al. 2013) 


\section{$5 \quad$ Zusammenfassung}

Die Herzinsuffizienz ist einer der häufigsten Gründe für Morbidität und Mortalität in der westlichen Welt. Die Prognose der Herzinsuffizienz ist nach wie vor schlecht, $50 \%$ der Erkrankten versterben innerhalb von fünf Jahren nach Diagnosestellung. Diese Situation erfordert die Erforschung neuer Zielmoleküle und neuer Behandlungsstrategien.

In der Herzmuskelzelle stehen sich auf molekularer Ebene zyklisches Adenosinmonophosphat (cAMP) als Effektor der B-adrenergen Signalkaskade und zyklisches Guanosinmonophosphat (cGMP) als Effektor des Signalwegs natriuretischer Peptide (NP) gegenüber. Ein typisches molekulares Merkmal, das einer terminalen Insuffizienz vorangeht, ist eine Verminderung der Signalübertragung des cAMPs auf der einen Seite und eine Erhöhung der cGMPSignalübertragung auf der anderen Seite. Hohe cAMP-Spiegel im Herzen werden meist als schädlich betrachtet, cGMP-abhängige Signalkaskaden hingegen vorwiegend als protektiv. Die intrazelluläre Kompartimentierung, die Amplitude und Halbwertszeit dieser beiden Signalmoleküle hat dabei entscheidende Wirkung auf deren Effektoren. Den Phosphodiesterasen (PDEs) kommt hierfür eine entscheidende Funktion zu. Unter der PDE-Superfamilie baut das Isoenzym Phosphodiesterase Typ 2 (PDE2) cAMP ab und wird durch cGMP allosterisch reguliert: Die Bindung von cGMP steigert den PDE2-abhängigen Abbau von cAMP um ein Vielfaches und hemmt auf diese Weise die Folgen einer Sympathikus-Aktivierung in der Herzmuskelzelle. PDE2 steht damit im Zentrum eines negativen Crosstalks der cAMP- und cGMP-Signalkaskade.

Die Rolle der kardialen PDE2 und ihre Funktion während der Herzinsuffizienz werden noch nicht ausreichend verstanden. Im Rahmen dieser Arbeit wurde zum ersten Mal der Nachweis erbracht, dass die Expression myokardialer PDE2 im Rahmen der Herzinsuffizienz beim Menschen reguliert ist. Wie in der Literatur beschrieben, fand sich im gesunden Myokard eine geringe basale PDE2-Expression. Dagegen zeigte sich im linksventrikulären Myokard von Patienten mit terminaler Herzinsuffizienz eine um den Faktor 2 erhöhte PDE2-Expression. Interessanterweise zeigten die Daten, dass die Hochregulation der PDE2-Expression bei Patienten mit Herzinsuffizienz unabhängig von einer Betablocker-Behandlung war. Ebenfalls zeigten sich keine Unterschiede in der myokardialen PDE2-Expression zwischen gesunden Spendern und Patienten mit Aortenstenose bei erhaltener Herzfunktion. Diese Ergebnisse lassen den Schluss zu, dass der Einfluss der myokardialen PDE2 mit zunehmender Dekompensation der Herzinsuffizienz wächst. Auf Grund der bekannten Limitationen von menschlichen Gewebeproben wurde die Zunahme der myokardialen PDE2-Expression bei terminaler 
Herzinsuffizienz im Großtiermodell Hund bestätigt. Erwartungsgemäß fand sich in den Tieren, bei denen durch eine Schrittmachersonde eine Herzinsuffizienz induziert wurde, eine um Faktor 2 erhöhte myokardiale PDE2-Expression. Dass diese vermehrte Expression von PDE2 eine Folge von chronischer $\beta$-adrenerger Stimulation ist, wurde schließlich mit einem IsoprenalinStressmodell in der Ratte bestätigt. In diesem Modell fand sich bei chronisch mit Isoprenalin behandelten Tieren eine ebenfalls erhöhte myokardiale PDE2-Expression. Außerdem konnte gezeigt werden, dass diese gesteigerte PDE2-Expression durch eine vermehrte Transkription von PDE2-mRNA im Myozyt bedingt ist. Auf funktioneller Ebene konnte bestätigt werden, dass die in der terminalen Herzinsuffizienz erhöhte PDE2-Expression mit einer ebenfalls erhöhten hydrolytischen Aktivität für cAMP einhergeht. Mechanistisch konnten zudem neonatale RattenKardiomyozyten durch eine adenovirale PDE2-Überexpression vor $\beta$-adrenerg induzierter Hypertrophie geschützt werden.

PDE2 ist in der Herzinsuffizienz hochreguliert und spielt eine wichtige Rolle in der Entstehung und Aufrechterhaltung der für die Herzinsuffizienz zentralen cAMP- und cGMP-Signalwege. Die Einflussnahme auf die Regulation der $\beta$-adrenergen Signalkaskade durch Kontrolle der cAMPSpiegel durch Phosphodiesterasen könnte sich positiv auf die Pathophysiologie der Herzinsuffizienz auswirken. Die Möglichkeit einer Steigerung der cAMP-Hydrolyseaktivität der myokardialen PDE2, könnte folglich eine neue therapeutische Option zur Behandlung der Volkskrankheit Herzinsuffizienz darstellen. Weitere Untersuchungen werden klären müssen, wie sich eine Aktivierung der myokardialen PDE2 unter pathologischen Bedingungen im Sinne der Progression zur terminalen Herzinsuffizienz auswirkt. 
Anhang

\section{Anhang}

\subsection{PCR-Ansätze und Bedingungen}

Alle in dieser Arbeit verwendeten Primer und Sonden wurden mit der Software Primer 3 designt und von der Firma Eurofind MWG Operon hergestellt.

Tabelle 3: PCR-Bedingungen

\begin{tabular}{lllll}
\hline PCR-Bedingungen & PCR-Schritt & Temperatur & Zeit (min:sec) & Zyklen \\
\hline Denaturierung & $94{ }^{\circ} \mathrm{C}$ & $10: 00$ & 1 \\
& Denaturierung & $94^{\circ} \mathrm{C}$ & $00: 15$ & \\
Hybridisierung & $60{ }^{\circ} \mathrm{C}$ & $00: 45$ & 32 \\
Elongation & $72{ }^{\circ} \mathrm{C}$ & $00: 45$ & \\
Elongation & $72{ }^{\circ} \mathrm{C}$ & $07: 00$ & 1
\end{tabular}


Anhang

Tabelle 4: PCR-Ansätze

Substanz

Volumen $(\mu \mathrm{l})$

PCR-Ansatz für GAPDH $(25 \mu \mathrm{l})$

GAPDH for $(10 \mu \mathrm{M}) \quad 1,5$

GAPDH $\operatorname{rev}(10 \mu \mathrm{M}) \quad 1,0$

dNTPs $(10 \mathrm{mM}) \quad 2,0$

$\mathrm{MgCl}_{2}(25 \mathrm{mM}) \quad 3,0$

10-Fach PCR Puffer 2,5

AmpliTaq Gold $\quad 0,75$

cDNA (siehe Kap. 2.8.2) 3

Aqua ad iniectabilia $\quad 11,25$

PCR-Ansatz für die PDE2 (25 $\mu \mathrm{l})$

$\begin{array}{ll}\text { PDE2 for }(10 \mu \mathrm{M}) & 0,5 \\ \text { PDE2 rev }(10 \mu \mathrm{M}) & 0,5 \\ \text { dNTPs }(10 \mathrm{mM}) & 0,25 \\ \mathrm{MgCl}_{2}(25 \mathrm{mM}) & 2,0 \\ \text { 10-Fach PCR Puffer } & 2,5 \\ \text { AmpliTaq Gold } & 0,25 \\ \text { cDNA (siehe Kap. 2.5.3) } & 2,0 \\ \text { Aqua ad iniectabilia } & 17,0\end{array}$

PCR-Ansatz für die ANP $(25 \mu \mathrm{l})$

$\begin{array}{ll}\text { ANP for }(10 \mu \mathrm{M}) & 0,5 \\ \text { ANP rev }(10 \mu \mathrm{M}) & 0,5 \\ \text { dNTPs }(10 \mathrm{mM}) & 0,25 \\ \mathrm{MgCl}_{2}(25 \mathrm{mM}) & 2,0 \\ \text { 10-Fach PCR Puffer } & 2,5 \\ \text { AmpliTaq Gold } & 0,25 \\ \text { cDNA (siehe Kap. 2.5.3) } & 2,0 \\ \text { Aqua ad iniectabilia } & 17,0\end{array}$


Anhang

\subsection{Antikörper}

Tabelle der bei den Proteinanalytischen Verfahren mittels Western Blot verwendeten Antikörper (pk: polyklonal; Anti-m: Anti-Maus; Anti-r: Anti-Kaninchen; Anti-g: Anti-Ziege; IgG: Immunglobulin G; -HRPO: konjugiert an Meerrettich-Peroxidase):

Tabelle 5: Antikörper

\begin{tabular}{lllll}
\hline 1. Antikörper & Verd. & Firma & 2. Antikörper & Verd. \\
\hline CSQ (pk) & $1: 2500$ & Dianova & Anti-r-IgG-HRPO & $1: 5000$ \\
HA-tag (pk) & $1: 1000$ & Invitrogen & Anti-r-IgG-HRPO & $1: 10000$ \\
PDE2 (pk) & $1: 500$ & FabGennix & Anti-r-IgG-HRPO & $1: 10000$ \\
PDE2 (pk) & $1: 200$ & Santa Cruz & Anti-g-IgG-HRPO & $1: 10000$
\end{tabular}

Alle Sekundärantikörper wurden von den Firmen Sigma-Aldrich und Santa Cruz bezogen. 
Anhang

\subsection{Substanzen}

Tabelle 6: Substanzen

\begin{tabular}{|c|c|}
\hline Substanz & Hersteller \\
\hline Acrylamid/Bis-Acrylamid-Lösung (37,5:1) & AppliChem \\
\hline Agarose & Invitrogen \\
\hline Alpha- ${ }^{32} \mathrm{P}-\mathrm{dCTP}$ & Hartmann Analytics \\
\hline Ammoniumpersulfat (APS) & Bio-Rad \\
\hline Aqua ad injectabilia & Braun \\
\hline Bacto $^{\mathrm{TM}}$ Tryptone & Becton Dickinson \\
\hline Bacto $^{\mathrm{TM}}$ Yeast & Becton Dickinson \\
\hline Bovine serum albumin (BSA) & Ambion \\
\hline Bromphenolblau & Merck \\
\hline Dinatriumhydrogenphosphat $\left(\mathrm{Na}_{2} \mathrm{HPO}_{4} \times 2 \mathrm{H}_{2} \mathrm{O}\right)$ & Merck \\
\hline 1,4-Dithiothreitol (DT'T) & Sigma-Aldrich \\
\hline Dobutamin & Fresenius \\
\hline Ethanol absolut & AppliChem \\
\hline Ethidiumbromid & Sigma-Aldrich \\
\hline Ethylendiamintetraessigsäure (EDTA) & AppliChem \\
\hline Fetales Kälberserum & PAA Laboratories \\
\hline Glucose & Sigma-Aldrich \\
\hline Glycerol & Merck \\
\hline Glycin & AppliChem \\
\hline Histidin & Sigma-Aldrich \\
\hline Salzsäure (HCl) & AppliChem \\
\hline Isoprenalin Hydrochloride & Sigma-Aldrich \\
\hline Isopropanol & AppliChem \\
\hline
\end{tabular}


Anhang

\begin{tabular}{|c|c|}
\hline Substanz & Hersteller \\
\hline Kaliumchlorid ( $\mathrm{KCl})$ & Merck \\
\hline Kanamycin & Gibco ${ }^{\circledR}$ Invitrogen \\
\hline Magermilchpulver & AppliChem \\
\hline Magnesiumchloridhexahydrat $\left(\mathrm{MgCl}_{2} \times 6 \mathrm{H}_{2} \mathrm{O}\right)$ & AppliChem \\
\hline Mercaptoethanol & Gibco \\
\hline Metamizol & Ratiopharm \\
\hline Methanol & AppliChem \\
\hline Natriumacetat & Merck \\
\hline Natriumchlorid & AppliChem \\
\hline Natriumchlorid-Lösung $0,9 \%$ & Braun \\
\hline Natrium-Dodecylsulfat (SDS) & AppliChem \\
\hline Natrium-EDTA & AppliChem \\
\hline Natriumfluorid $(\mathrm{NaF})$ & Fluka \\
\hline Natriumhydrogencarbonat $\left(\mathrm{NaHCO}_{3}\right)$ & Merck \\
\hline Natriumhydrogenphosphat $\left(\mathrm{NaH}_{2} \mathrm{PO}_{4}\right)$ & Merck \\
\hline Natriumhydroxid $(\mathrm{NaOH})$ & Merck \\
\hline Ponceau-S & AppliChem \\
\hline Proteinase $\mathrm{K}$ & Roth \\
\hline Saccharose & AppliChem \\
\hline Tetramethylethylendiamin (TEMED) & Bio-Rad \\
\hline Tetranatriumdiphosphat $\left(\mathrm{Na}_{4} \mathrm{P}_{2} \mathrm{O}_{7}\right)$ & Sigma-Aldrich \\
\hline Trishydroxymethylaminomethan (Tris)-Base & Sigma-Aldrich \\
\hline Tris Hydrochlorid (Tris-HCl) & AppliChem \\
\hline Polyoxyethylen(20)sorbitan-monolaurat $\left(\right.$ Tween $\left.^{\circledR} 20\right)$ & AppliChem \\
\hline Ziegenserum & PAA Laboratories \\
\hline
\end{tabular}




\subsection{Hilfsmittel und Geräte}

Tabelle 7: Hilfsmittel und Geräte

Hilfsmittel und Geräte Hersteller

Agarose GEL Electrophoresis System Sub-Cell GT

Bio-Rad

Analysewaage

Sartorius AG

Biosphere ${ }^{\circledR}$ Filter Tips

Sarstedt

Brutschrank (Bakterien)

Heraeus

Elektrophoresespannungsgerät PowerPack P25

Biometra

Elektrophoresespannungsgerät PowerPac Basic

Bio-Rad

Elektrophoresespannungsgerät PowerPac HC

Bio-Rad

Elektrophoresesystem (Mini Protean ${ }^{\circledR}$ electrophoreses cell)

Bio-Rad

Eppendorf Safe Lock Reaktionsgefäße

Eppendorf

Gewebekulturplatten, 6-well

Nunc

Horizontalschüttler Rocking Platform

Biometra

Hybridization bottles HB-OV-BM

Thermo EC

Hybridization mini oven MKli HYBAID

Thermo EC

Kühlzentrifuge Centrifuge 5417R

Eppendorf

Kühlzentrifuge Centrifuge 5804R

Eppendorf

Küvetten (10 x 4 x 45 mm), 67.742

Sarstedt

Magnetrührer Ikamag ${ }^{\circledR}$ Reo

Schütt

PCR-Gerät GeneAmp ${ }^{\circledR}$ PCR System 9700

Applied Biosystems

Photometer, BioPhotometer 6131

Eppendorf

pH-Meter

InoLab

Pipetten $10 \mu \mathrm{l}, 100 \mu \mathrm{l}, 1000 \mu \mathrm{l}$

Eppendorf

Pipetten, serologisch $5 \mathrm{ml}, 10 \mathrm{ml}, 25 \mathrm{ml}$

Sarstedt

Pipettenspitzen

Sarstedt 
Anhang

Hilfsmittel und Geräte

Hersteller

Polytron Stativ-Dispergiergerät

Kinematica

Tischzentrifuge Combi-Spin FVL-2400N

Peqlab

Thermomixer compact

Eppendorf

Ultrazentrifuge L8-70M

Beckman $^{\circledR}$

Wasserbad

Köttermann

Zentrifugenröhrchen $15 \mathrm{ml}, 50 \mathrm{ml}$

Sarstedt 


\section{$7 \quad$ Literaturverzeichnis}

Aravind L, Ponting CP (1997): The GAF domain: an evolutionary link between diverse phototransducing proteins. Trends Biochem Sci $\underline{22}, 458-459$

Beavo JA (1995): Cyclic nucleotide phosphodiesterases: functional implications of multiple isoforms. Physiol Rev $\underline{75}$, 725-748

Beavo JA, Conti M, Heaslip RJ (1994): Multiple cyclic nucleotide phosphodiesterases. Mol Pharmacol 46, 399-405

Bender AT, Beavo JA (2006): Cyclic nucleotide phosphodiesterases: molecular regulation to clinical use. Pharmacol Rev $\underline{58}, 488-520$

Bristow MR, Ginsburg R, Minobe W, Cubicciotti RS, Sageman WS, Lurie K, Billingham ME, Harrison DC, Stinson EB (1982): Decreased catecholamine sensitivity and $\beta$-adrenergic-receptor density in failing human hearts. N Engl J Med $\underline{307}, 205-211$

Böhm M, Hallek M, Schmiegel W (Hrsg.): Innere Medizin. Begründet v. Classen M, Diehl V, Kochsiek k.6., komplett überarb. Auflage; Elsevier, Urban \& Fischer, München 2009

Brodde OE (1993): Beta-adrenoceptors in cardiac disease. Pharmacol Ther $\underline{60}$, 405-430

Degerman E, Belfrage P, Manganiello VC (1997): Structure, localization, and legulation of cGMPinhibited phosphodiesterase (PDE3). J Biol Chem 272, 6823-6826

Ding B, Abe J, Wei H, Huang Q, Walsh RA, Molina CA, Zhao A, Sadoshima J, Blaxall BC, Berk BC, et al. (2005): Functional role of phosphodiesterase 3 in cardiomyocyte cpoptosis: implication in heart failure. Circulation 111, 2469-2476

El-Armouche A, Eschenhagen T (2009): Beta-adrenergic stimulation and myocardial function in the failing heart. Heart Fail Rev 14, 225-241

El-Armouche A, Gocht F, Jaeckel E, Wittkopper K, Peeck M, Eschenhagen T (2007a): Long-term beta-adrenergic stimulation leads to downregulation of protein phosphatase inhibitor- 1 in the heart. Eur J Heart Fail ㅁ, 1077-1080 
El-Armouche A, Pohlmann L, Schlossarek S, Starbatty J, Yeh YH, Nattel S, Dobrev D, Eschenhagen T, Carrier L (2007b): Decreased phosphorylation levels of cardiac myosin-binding protein-C in human and experimental heart failure. J Mol Cell Cardiol 43, 223-229

El-Armouche A, Wittköpper K, Degenhardt F, Weinberger F, Didié M, Melnychenko I, Grimm M, Peeck M, Zimmermann WH, Unsöld B, et al. (2008): Phosphatase inhibitor-1-deficient mice are protected from catecholamine-induced arrhythmias and myocardial hypertrophy. Cardiovasc Res $\underline{80}$, $396-406$

Fischmeister R, Hartzell HC (1990): Regulation of calcium current by low-Km cyclic AMP phosphodiesterases in cardiac cells. Mol Pharmacol $\underline{38}, 426-433$

Fischmeister R, Castro LRV, Abi-Gerges A, Rochais F, Jurevičius J, Leroy J, Vandecasteele G (2006): Compartmentation of cyclic nucleotide signaling in the heart: the role of cyclic nucleotide phosphodiesterases. Circ Res 9ㅗ, 816-828

Francis SH, Blount MA, Corbin JD (2011): Mammalian cyclic nucleotide phosphodiesterases: molecular mechanisms and physiological functions. Physiol Rev $\underline{91}$, 651-690

Hartzell HC, Fischmeister R (1986): Opposite effects of cyclic GMP and cyclic AMP on Ca2+ current in single heart cells. Nature $\underline{323}, 273-275$

He TC, Zhou S, da Costa LT, Yu J, Kinzler KW, Vogelstein B (1998): A simplified system for generating recombinant adenoviruses. Proc Natl Acad Sci U S A $\underline{95}$, 2509-2514

Kass A, Takimoto E, Nagayama T, Champion H (2007): Phosphodiesterase regulation of nitric oxide signaling. Cardiovasc Res $\underline{75}$, 303-304

Kojda G, Kottenberg K, Nix P, Schluter KD, Piper HM, Noack E (1996): Low increase in cGMP induced by organic nitrates and nitrovasodilators improves contractile response of rat ventricular myocytes. Circ Res $\underline{78}, 91-101$

Kostic MM, Erdogan S, Rena G, Borchert G, Hoch B, Bartel S, Scotland G, Huston E, Houslay MD, Krause EG (1997): Altered expression of PDE1 and PDE4 cyclic nucleotide phosphodiesterase isoforms in 7-oxo-prostacyclin-preconditioned rat heart. J Mol Cell Cardiol 29, 3135-3146

Lee DI, Kass DA (2012): Phosphodiesterases and cyclic GMP regulation in heart muscle. Physiology 27, 248-258 
Lehnart SE, Wehrens XH, Reiken S, Warrier S, Belevych AE, Harvey RD, Richter W, Jin SL, Conti M, Marks AR (2005): Phosphodiesterase 4D deficiency in the ryanodine-receptor complex promotes heart failure and arrhythmias. Cell $\underline{123}, 25-35$

Levy F (2013): Cardiac PDEs and crosstalk between cAMP and cGMP signalling pathways in the regulation of contractility. Naunyn-Schmiedeberg's Archives of Pharmacology $\underline{386}$, 665-670

Li D, Fareh S, Leung TK, Nattel S (1999): Promotion of atrial fibrillation by heart failure in dogs: atrial remodeling of a different sort. Circulation $\underline{100}$, 87-95

Lohse MJ, Engelhardt S, Eschenhagen T (2003): What is the role of beta-adrenergic signaling in heart failure? Circ Res $\underline{93}$, 896-906

Loughney K, Martins TJ, Harris EAS, Sadhu K, Hicks JB, Sonnenburg WK, Beavo JA, Ferguson K (1996): Isolation and characterization of cDNAs corresponding to two human calcium, calmodulinregulated, 3',5'-cyclic nucleotide phosphodiesterases. J Biol Chem 271, 796-806

Luo J, Deng ZL, Luo X, Tang N, Song WX, Chen J, Sharff KA, Luu HH, Haydon RC, Kinzler KW, et al. (2007): A protocol for rapid generation of recombinant adenoviruses using the AdEasy system. Nat Protoc $\underline{2}, 1236-1247$

Manganiello Vc, Tanaka T, Murashima S (1990): Cyclic GMP-stimulated cyclic nucleotide phosphodiesterases. In: Beavo J, Houslay M (Hrsg.): Cyclic nucleotide phosphodiesterases: structure, regulation and drug action. John Wiley \& Sons, Chichester 1990, 61-85

Martinez SE, Wu AY, Glavas NA, Tang XB, Turley S, Hol WG, Beavo JA (2002): The two GAF domains in phosphodiesterase $2 \mathrm{~A}$ have distinct roles in dimerization and in cGMP binding. Proc Natl Acad Sci U S A 모, 13260-13265

Martins TJ, Mumby MC, Beavo JA (1982): Purification and characterization of a cyclic GMPstimulated cyclic nucleotide phosphodiesterase from bovine tissues. J Biol Chem 257, 1973-1879

McMurray JJ, Stewart S (2000): Epidemiology, aetiology, and prognosis of heart failure. Heart $\underline{83}$, 596-602

Meacci E, Taira M, Moos M, Smith CJ, Movsesian MA, Degerman E, Belfrage P, Manganiello V (1992): Molecular cloning and expression of human myocardial cGMP-inhibited cAMP phosphodiesterase. Proc Natl Acad Sci U S A 모, 3721-3725 
Mehel H, Emons J, Vettel C, Wittkopper K, Seppelt D, Dewenter M, Lutz S, Sossalla S, Maier LS, Lechene P, et al. (2013): Phosphodiesterase- 2 is up-regulated in human failing hearts and blunts betaadrenergic responses in cardiomyocytes. J Am Coll Cardiol 62, 1596-1606

Mery PF, Pavoine C, Pecker F, Fischmeister R (1995): Erythro-9-(2-hydroxy-3-nonyl)adenine inhibits cyclic GMP-stimulated phosphodiesterase in isolated cardiac myocytes. Mol Pharmacol $\underline{48}, 121-130$

Mika D, Leroy J, Vandecasteele G, Fischmeister R (2012): PDEs create local domains of cAMP signaling. J Mol Cell Cardiol 52, 323-329

Mongillo M, Tocchetti CG, Terrin A, Lissandron V, Cheung YF, Dostmann WR, Pozzan T, Kass DA, Paolocci N, Houslay MD, et al. (2006): Compartmentalized phosphodiesterase-2 activity blunts $\beta$-adrenergic cardiac inotropy via an NO/cGMP-dependent pathway. Circ Res $\underline{98}, 226-234$

Novack JP, Charbonneau H, Bentley JK, Walsh KA, Beavo JA (1991): Sequence comparison of the 63-, 61 -, and 59-kDa calmodulin-dependent cyclic nucleotide phosphodiesterases. Biochemistry $\underline{30}$, 7940-7947

Noyama K, Maekawa S (2003): Localization of cyclic nucleotide phosphodiesterase 2 in the brainderived Triton-insoluble low-density fraction (raft). Neurosci Res $\underline{45}, 141-148$

Onody A, Zvara A, Hackler L, Vigh L, Ferdinandy P, Puskas LG (2003): Effect of classic preconditioning on the gene expression pattern of rat hearts: a DNA microarray study. FEBS Lett $\underline{536}, 35-40$

Pandit J, Forman MD, Fennell KF, Dillman KS, Menniti FS (2009): Mechanism for the allosteric regulation of phosphodiesterase $2 \mathrm{~A}$ deduced from the $\mathrm{X}$-ray structure of a near full-length construct. Proc Natl Acad Sci U S A $\underline{106}, 18225-18230$

Pokreisz P, Vandenwijngaert S, Bito V, Van Den Bergh A, Lenaerts I, Busch C, Marsboom G, Gheysens O, Vermeersch P, Biesmans L, et al. (2009): Ventricular phosphodiesterase-5 expression is increased in patients with advanced heart failure and contributes to adverse ventricular remodeling after myocardial infarction in mice. Circulation $\underline{119}$, 408-416

Pyne NJ, Cooper ME, Houslay MD (1986): Identification and characterization of both the cytosolic and particulate forms of cyclic GMP-stimulated cyclic AMP phosphodiesterase from rat liver.

Biochem J 234, 325-334 
Repaske DR, Corbin JG, Conti M, Goy MF (1993): A cyclic GMP-stimulated cyclic nucleotide phosphodiesterase gene is highly expressed in the limbic system of the rat brain. Neuroscience $\underline{56}$, 673-686

Rivet-Bastide M, Vandecasteele G, Hatem S, Verde I, Bénardeau A, Mercadier JJ, Fischmeister R (1997): cGMP-stimulated cyclic nucleotide phosphodiesterase regulates the basal calcium current in human atrial myocytes. J Clin Invest $\underline{99}$, 2710-2718

Robison GA, Butcher RW, Øye I, Morgan HE, Sutherland EW (1965): The effect of epinephrine on adenosine 3',5'-phosphate levels in the isolated perfused rat heart. Mol Pharmacol $\underline{1}, 168-177$

Rosman GJ, Martins TJ, Sonnenburg WK, Beavo JA, Ferguson K, Loughney K (1997): Isolation and characterization of human cDNAs encoding a cGMP-stimulated 3',5'-cyclic nucleotide phosphodiesterase. Gene 191, 89-95

Russwurm C, Zoidl G, Koesling D, Russwurm M (2009): Dual acylation of PDE2A splice variant 3: targeting to synaptic membranes. J Biol Chem $\underline{284}$, 25782-25790

Sadhu K, Hensley K, Florio VA, Wolda SL (1999): Differential expression of the cyclic GMPstimulated phosphodiesterase PDE2A in human venous and capillary endothelial cells. J Histochem Cytochem 47, 895-905

Senzaki H, Smith CJ, Juang GJ, Isoda T, Mayer SP, Ohler A, Paolocci N, Tomaselli GF, Hare JM, Kass DA (2001): Cardiac phosphodiesterase 5 (cGMP-specific) modulates $\beta$-adrenergic signaling in vivo and is down-regulated in heart failure. The FASEB Journal $\underline{15}$, 1718-1726

Shah AM , MacCarthy PA (2000): Paracrine and autocrine effects of nitric oxide on myocardial function. Pharmacol Ther $\underline{86}, 49-86$

Shan X, Quaile MP, Monk JK, French B, Cappola TP, Margulies KB (2012): Differential expression of PDE5 in failing and nonfailing human myocardium. Circ Heart Fail $\underline{5}, 79-86$

Soderling SH, Bayuga SJ, Beavo JA (1998): Cloning and characterization of a cAMP-specific cyclic nucleotide phosphodiesterase. Proc Natl Acad Sci U S A $\underline{95}$, 8991-8996

Sonnenburg Wk, Beavo JA (1991): Molecular cloning of a cyclic GMP-stimulated cyclic nucleotide phosphodiesterase cDNA. J Biol Chem 266, 17655-17661 
Stangherlin A, Gesellchen F, Zoccarato A, Terrin A, Fields LA, Berrera M, Surdo NC, Craig MA, Smith G, Hamilton G, et al. (2011): cGMP signals modulate cAMP levels in a compartment-specific manner to regulate catecholamine-dependent signaling in cardiac myocytes. Circ Res 108, 929-939

Swedberg K, Cleland J, Dargie H, Drexler H, Follath F, Komajda M, Tavazzi L, Smiseth OA, Gavazzi A, Haverich A, et al. (2005): Guidelines for the diagnosis and treatment of chronic heart failure: executive summary (update 2005): The Task Force for the Diagnosis and Treatment of Chronic Heart Failure of the European Society of Cardiology. Eur Heart J 26, 1115-1140

Thompson WJ, Appleman MM (1971): Multiple cyclic nucleotide phosphodiesterase activities from rat brain. Biochem 10, 311-316

Tsai EJ, Kass DA (2009): Cyclic GMP signaling in cardiovascular pathophysiology and therapeutics. Pharmacol Therapeut 122, 216-238

Vettel C, Lämmle S, Ewens S, Cervirgen C, Emons J, Ongherth A, Dewenter M, Lindner D, Westermann D, Nikolaev V, Lutz S, Zimmermann W H, El-Armouche A (2014): PDE2-mediated cAMP hydrolysis accelerates cardiac fibroblast to myofibroblast conversion and is antagonized by exogenous activation of cGMP signaling pathways . Am J Physiol Heart Circ Physiol 306, 1246-1252

Wittköpper K, Fabritz L, Neef S, Ort KR, Grefe C, Unsöld B, Kirchhof P, Maier LS, Hasenfuss G, Dobrev D, et al. (2010): Constitutively active phosphatase inhibitor-1 improves cardiac contractility in young mice but is deleterious after catecholaminergic stress and with aging. J Clin Invest $120,617-$ 626

Yang Q, Paskind M, Bolger G, Thompson WJ, Repaske DR, Cutler LS, Epstein PM (1994): A novel cyclic GMP stimulated phosphodiesterase from rat brain. Biochem Biophys Res Commun 205, 18501858

Zaccolo M, Movsesian MA (2007): cAMP and cGMP signaling cross-talk: role of phosphodiesterases and implications for cardiac pathophysiology. Circ Res $\underline{100}$, 1569-1578

Zhang M, Kass DA (2011): Phosphodiesterases and cardiac cGMP: evolving roles and controversies. Trends Pharmacol Sci $\underline{32}, 360-365$

Zhang Q, Moalem J, Tse J, Scholz PM, Weiss HR (2005): Effects of natriuretic peptides on ventricular myocyte contraction and role of cyclic GMP signaling. Eur J Pharmacol $\underline{510}$, 209-215 
Zoccarato A, Surdo NC, Aronsen JM, Fields LA, Mancuso L, Dodoni G, Stangherlin A, Livie C, Jiang H, Sin YY, et al. (2015): Cardiac hypertrophy is inhibited by a local pool of cAMP regulated by phosphodiesterase 2. Circ Res 117, 707-719

\subsection{Internetquellen}

Statistisches Bundesamt (2012): Anzahl der Gestorbenen nach ausgewählten Todesursachen 2012, veröffentlicht auf

https://www.destatis.de/DE/ZahlenFakten/GesellschaftStaat/Gesundheit/Todesursachen/Tabelle n/EckdatenTU.html;jsessionid=1635D4B246F3354F2EDCF54439EB8FD4.cae2 (Webseite), Statistisches Bundesamt Wiesbaden (24.02.2015, 20:30) 


\section{Danksagung}

Mein ganz besonderer Dank gilt Herrn Prof. Dr. med. Ali-El Armouche für die Vergabe des interessanten und herausfordernden Dissertationsthemas. Die hervorragende wissenschaftliche, aber auch im Besonderen die freundschaftliche Betreuung hat das Arbeiten in der Arbeitsgruppe immer angenehm gemacht.

Des Weiteren möchte ich mich bei Herrn Prof. Dr. med. Zimmermann für die Bereitstellung ausgezeichneter Arbeitsbedingungen in seinem Institut und für die spannenden Diskussionen bedanken.

Besonders möchte ich mich auch bei Frau Dr. rer. nat. Katrin Wittköpper, Herrn Dr. rer. nat. Simon Lämmle und bei Frau Dr. rer. nat. Christiane Vettel für die große Unterstützung und Hilfsbereitschaft bedanken.

Bei dem gesamten Team der Pharmakologie in Göttingen möchte ich mich für das tolle Arbeitsklima, die stete Hilfsbereitschaft und das Engagement bedanken, besonders bei Roland Blume. 


\section{Lebenslauf}

Als zweites von vier Kindern bin ich, Julius Emons, verheiratet mit Ursula Emons, am 17.05.1985 in Eutin als Sohn der Eheleute Dr. med. Adelgund und Prof. Dr. med Günter Emons geboren. Meine schulische Ausbildung habe ich 1992 in der Grundschule in Schönstadt begonnen. Im Juli 2005 legte ich das Abitur am Max-Planck-Gymnasium in Göttingen ab. Das Studium der Humanmedizin an der Georg-August-Universität Göttingen absolvierte ich von 2006 bis 2013. Im Juni 2010 begann ich mit der Promotion: „Rolle der Phosphodiesterase 2 in der menschlichen und experimentellen Herzinsuffizienz" am Institut für Pharmakologie und Toxikologie, Universitätsmedizin Göttingen, Direktor: Prof. Dr. med. Wolfram-Hubertus Zimmermann, bei meinem Doktorvater Prof. Dr. med. El-Armouche. Seit 2014 arbeite ich als Arzt in Weiterbildung und wissenschaftlicher Mitarbeiter an der Frauenklinik des Universitätsklinikums der Friedrich-Alexander Universität Erlangen-Nürnberg bei Prof. Dr. med. Matthias W. Beckmann. 
El-Armouche A, Schwoerer AP, Neuber C, Emons J, Biermann D, Christalla T, Grundhoff A, Eschenhagen T, Zimmermann WH, Ehmke H (2010): Common microRNA signatures in cardiac hypertrophic and atrophic remodeling induced by changes in hemodynamic load. Plos one $\underline{5}$, e14263

Wittköpper K, Emons J, El-Armouche A (2011): Febuxostat. Deut Med Wochenschr 136, 1270-1274

Unsöld B, Schotola H, Jacobshagen C, Seidler T, Sossalla S, Emons J, Klede S, Knöll R, Guan K, ElArmouche A, Linke WA, Kögker H, Hasenfuss G (2012): Age-dependent changes in contractile function and passive elastic properties of myocardium from mice lacking muscle LIM protein (MLP) Eur J Heart Fail 14, 430-437

Mehel H, Emons J, Vettel C, Wittkopper K, Seppelt D, Dewenter M, Lutz S, Sossalla S, Maier LS, Lechene P, et al. (2013): Phosphodiesterase-2 is up-regulated in human failing hearts and blunts betaadrenergic responses in cardiomyocytes. J Am Coll Cardiol_62, 1596-1606

Vettel C, Lämmle S, Ewens S, Cervirgen C, Emons J, Ongherth A, Dewenter M, Lindner D, Westermann D, Nikolaev V, Lutz S, Zimmermann W H, El-Armouche A (2014): PDE2-mediated cAMP hydrolysis accelerates cardiac fibroblast to myofibroblast conversion and is antagonized by exogenous activation of cGMP signaling pathways . Am J Physiol Heart Circ Physiol 306, 1246-1252

Emons J, Heindl F, Hein A, Beckmann M.W (2016): Management operations- und karzinombedingter Blutungen. Der Gynäkologe 49, 24-28

Schulz-Wendtland R, Harz M, Meier-Meitinger M, Brehm B, Wacker T, Hahn HK, Wagner F, Wittenberg T, Beckmann MW, Uder M, Fasching PA, Emons J (2016): Semi-automated delineation of breast cancer tumors and subsequent materialization using three-dimensional printing (rapid prototyping). J Surg Oncol [Epub ahead of print] 